\title{
Advanced Neutron Source (ANS) Project Progress Report
}

FY 1992

\author{
Princinal Authors \\ D. L. Selby R. M. Harrington \\ Oak Ridge National Laboratory \\ P. B. Thompson \\ Engineering Division \\ Martin Marietta Energy Systems, Inc.
}

\section{Editor}

J. H. Campbell

Oak Ridge National Laboratory

\section{Electronic Publishers}

L. W. Davis

S. C. Lyttle

N. C. Smith

Oak Ridge National Laboratory

Date Published-January 1993

Prepared by the

Oak Ridge National Laboratory

Oak Ridge, Tennessee 37831-6285 managed by

Martin Marietta Energy Systems, Inc. for the

U.S. DEPARTMENT OF ENERGY under Contract No. DE-AC05-84OR21400 


\section{Contributing Authors}

\begin{tabular}{|c|c|c|}
\hline D. J. Alexander & R. A. Lillie & W. E. Ruggles \\
\hline J. L. Anderson & A. W. Longest & W. K. Sartory \\
\hline R. E. Battle & A. T. Lucas & H. B. Shapira \\
\hline R. L. Battiste & C. R. Luttrell & M. Siman Tov \\
\hline N. C. J. Chen & J. A. March-Leuba & H. G. Smith \\
\hline G. L. Copeland & J. T. Mihalczo & W. F. Swinson \\
\hline W. W. Engle & R. M. Moon & R. P. Taleyarkha \\
\hline D. K. Felde & D. G. Morris & C. D. West \\
\hline M. L. Gildner & M. D. Muhlheim & B. A. Worley \\
\hline W. A. Hamilton & R. E. Pawel & G. T. Yahr \\
\hline J. B. Hayter & C. T. Ramsey & G. L. Yoder, Jr. \\
\hline W. R. Hendrich & J. P. Renier & \\
\hline \multicolumn{3}{|c|}{ Oak Ridge National Laboratory } \\
\hline R. A. Allen & K. K. Chipley & C. C. Queen \\
\hline R. S. Booth & P. S. Litherland & B. R. Smith \\
\hline R. A. Brown & T. J. McManamy & D. W. Theisen \\
\hline P. F. Cento & H. R. Payne & \\
\hline J. E. Cleaves & F. J. Peretz & \\
\hline
\end{tabular}

J. L. Snelgrove

T. C. Wiencek

G. L. Hofman

J. Rest

Argonne National Laboratory
C. D. Fletcher
J. M. Ryskamp
S. N. Jahshan
C. A. Wemple

G. A. Rubio

Idaho National Engineering Laboratory
W. E. Meek
P. J. Shipper
H. N. Goldstein
P. T. Talarico
Gilbert/Commonwealth, Inc.

A. Crow

A. Steyerl

University of Rhode Island

G. K. Carlough

DRS/Hundley Kling Gmitter

C. F. Majkrzak

National Institute of Standards and Technology
C. R. Bass

H. G. Wood III

University of Virginia

M. Ibn-Khayat

Oak Ridge Associated Universities

M. Kaminaga

Japan Atomic Energy Research Institute 


\section{CONTENTS}

Page

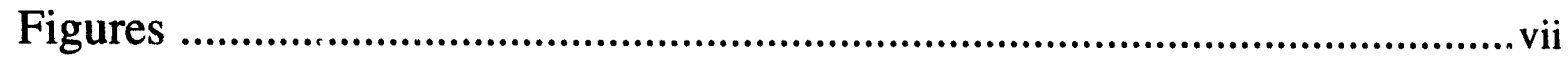

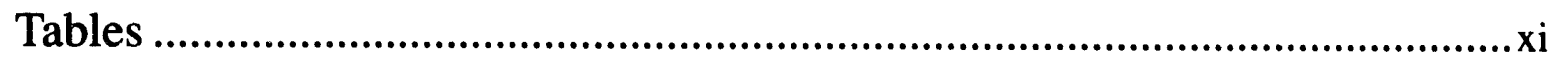

Acronyms ...................................................................................... xiii

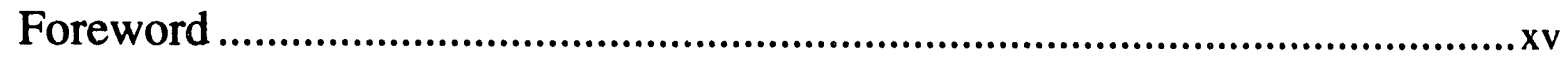

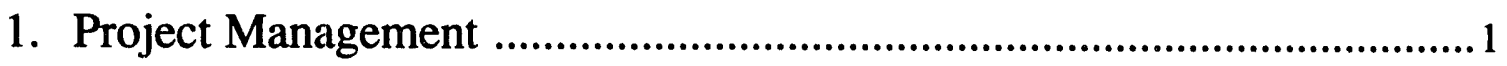

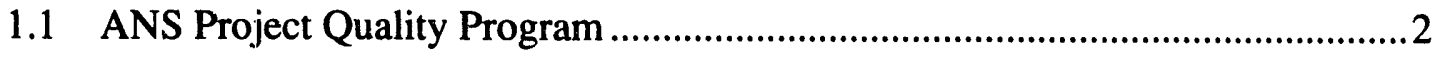

1.1.1 Program Development ..................................................................2

1.1.2 Quality Monitoring Activities .................................................... 2

2. Research and Development ...........................................................5

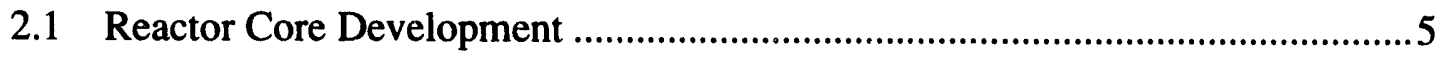

2.1.1 Development of Analysis Techniques..................................................5

2.1.1.1 Modeling of FOEHN Criticals .............................................5

2.1.1.2 Development of MCNP/ORIGEN Coupling Code ..................5

2.1.1.3 Treatment of Uncertainties ...................................................6

2.1.2 Neutronics and Thermal-Hydraulics Support to Design ......................... 7

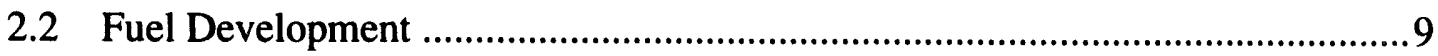

2.2.1 Review of Fuel Development Program ............................................

2.2.2 Irradiation of Fuel Capsules ............................................................. 9

2.2.3 Fuel Performance Studies and Modeling ............................................9

2.2.4 Fabrication Development .............................................................. 11

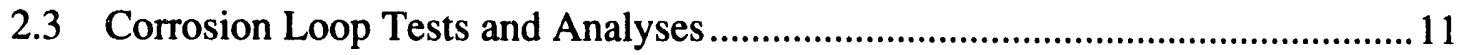

2.3.1 Summary of Results: FY-1992 Update ............................................ 11

2.3.2 Summary of NPR-HWR A-Tests .................................................... 13

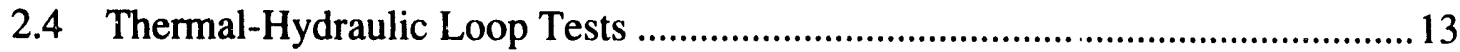

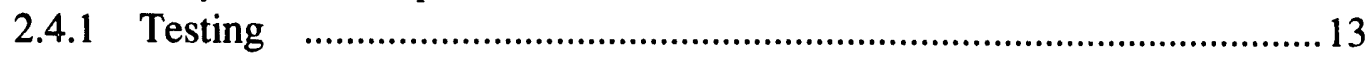

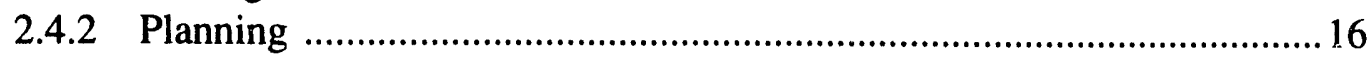


2.5 Reactor Controi and Shutdown Concepts ………..........................................16

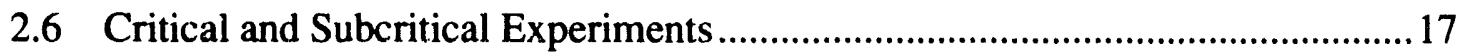

2.7 Material Data, Structural Tests, and Analyses ……….......................................17

2.7.1 Core Pressure Boundary Tube .............................................................

2.7.1.1 Code Case for 6061-T6 Aluminum ........................................18

2.7.1.2 Fracture Toughness of Irradiated 6061-T6 Aluminum .............. 18

2.7.1.3 Flow-Induced Instabilities ................................................... 18

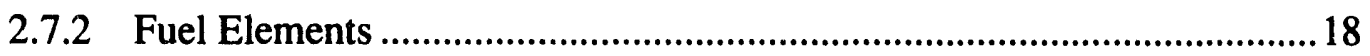

2.7.2.1 Fuel Element Hydraulic Buckling Analysis .............................. 19

2.7.2.2 Experimental Studies of the Structural Response of the Fuel Plates Because of Coolant Flow .............................19

2.7.2.3 Fuel-Plate Thermal Deflection ..................................................20

2.7.3 Inner Control Element .....................................................................20

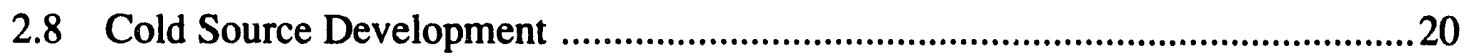

2.8.1 Cold Source Neutronics ...............................................................21

2.8.2 Thermal Modeling .................................................................................21

2.8.3 Cold Source Mechanical Modeling .........................................................21

2.9 Beam Tube, Guide, and Instrument Development .........................................21

2.9.1 Evaluation of Fast Neutron and Gamma Filters for the Straight Neutron Guides ...........................................................................23

2.9.2 Revised Very Cold Neutron/Ultracold Neutron Installations at the Horizontal Cold Source ...........................................25

2.9.3 ALARA Considerations at Instruments ..................................................25

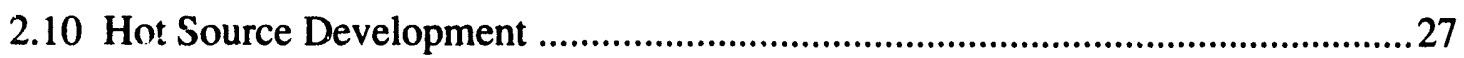

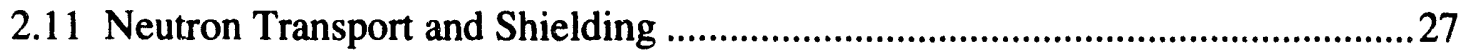

2.11.1 Preliminary Radial Shield Evaluation .................................................22

2.11.2 Preliminary Evaluation of Stack Streaming .........................................27

2.11.3 Guide Tube Tunnel Analysis .................................................................28

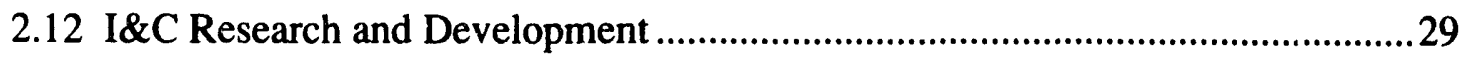

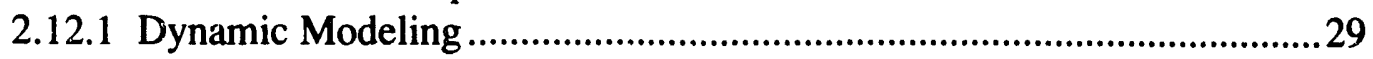

2.12.2 Use of Application-Specific Integrated Circuits for

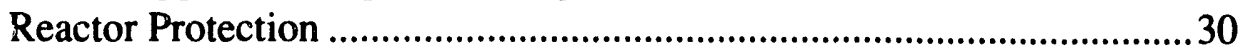

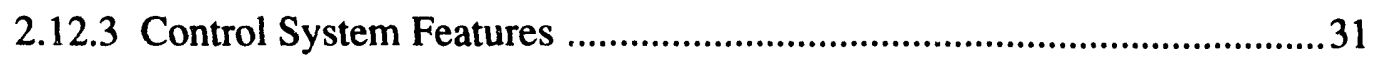

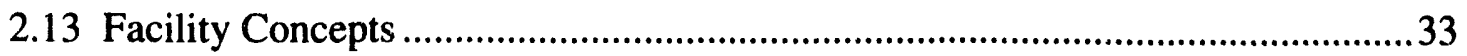

iv Advanced Neutron Source (ANS) Progress Report 


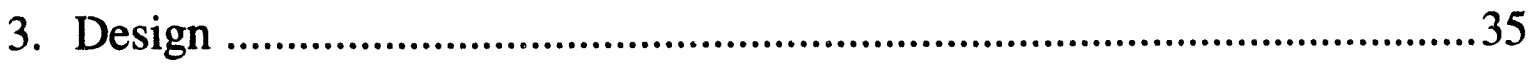

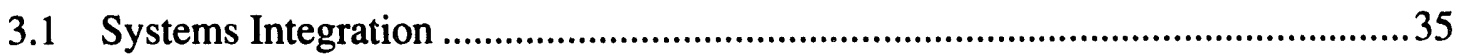

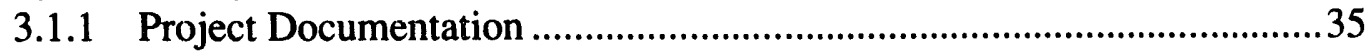

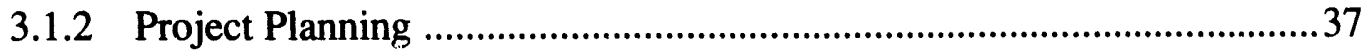

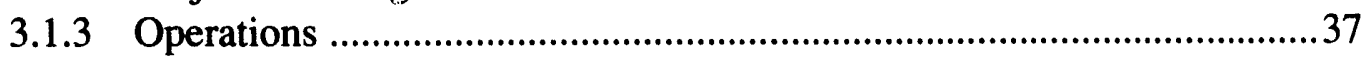

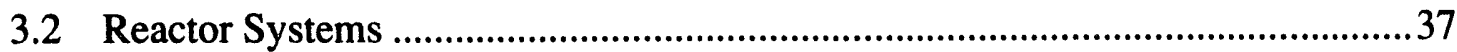

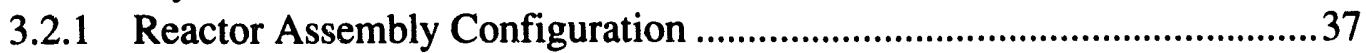

3.2.2 Core Pressure Boundary Tube ............................................................. 37

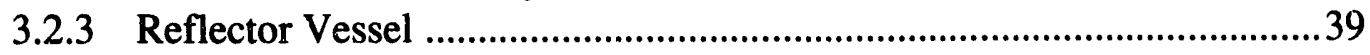

3.2.4 Control and Shutdown Rod Assemblies ...............................................40

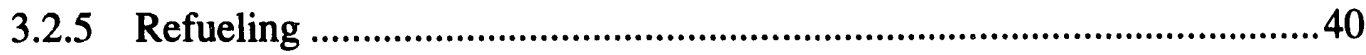

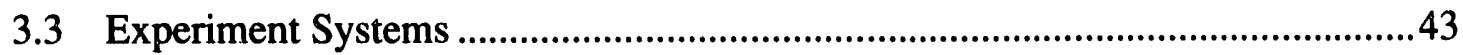

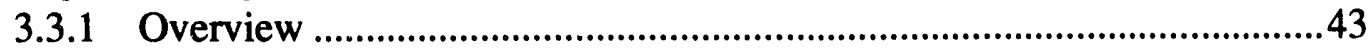

3.3.2 Neutron Beam Transport .................................................................43

3.3.3 Neutron Scattering and Physics Instruments ........................................43

3.3.4 Irradiation and Isotope Production Facilities ........................................45

3.3.5 Activation Analysis Facilities ........................................................47

3.3.6 Cold Source System ........................................................................ 48

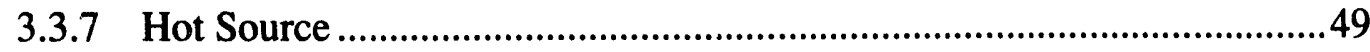

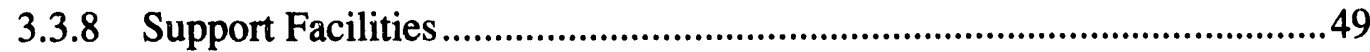

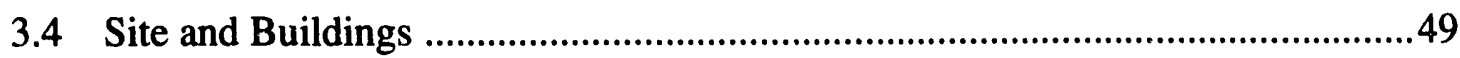

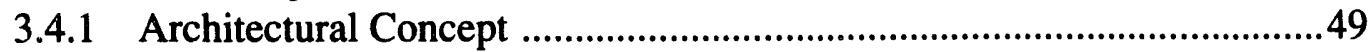

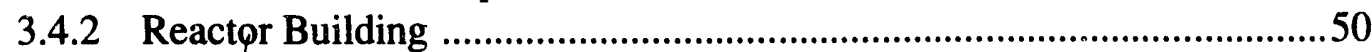

3.4.3 Reactor Support Building/Operations Support Building .......................53

3.4.4 Guide Hall/Research Support Building ................................................54

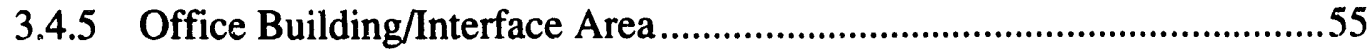

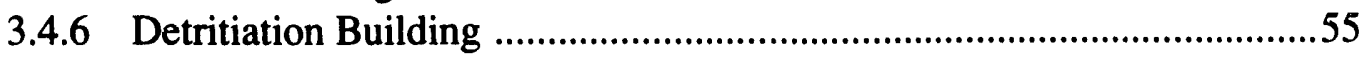

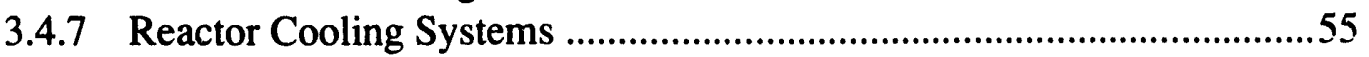

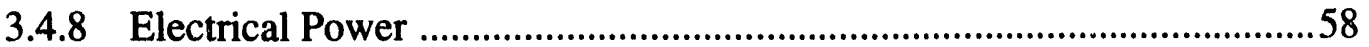

3.4.9 Containment Ventilation and Treatment .............................................58

3.4.10 Heavy Water Detritiation and Upgrade ..............................................59

3.4.11 Plant Instrumentation, Computing, and Telecommunications ................59

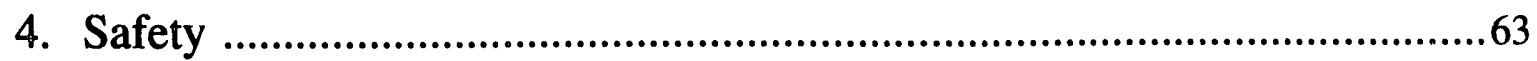

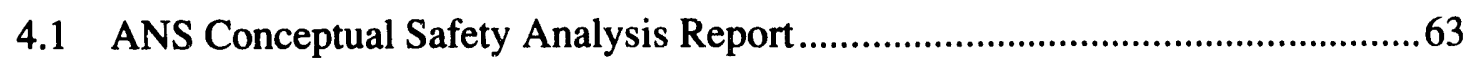




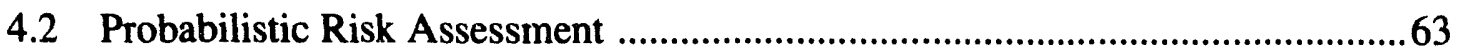

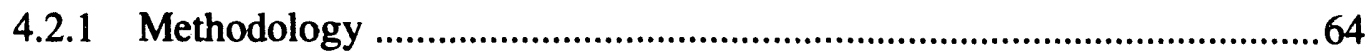

4.2.2 Key Components and Systems ..................................................................64

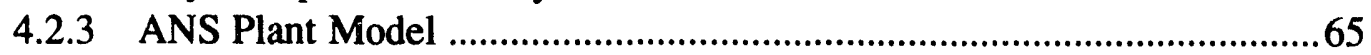

4.2.4 Other PRA-Related Activities ..............................................................65

4.2.4.1 Analysis of Start-up Rod Withdrawal Sequence Failure ……...............................................................65

4.2.4.2 Primary Coolant Loop Reduction -Availability Study ........................................................................66

4.3 Transient Thermal Hydraulics .......................................................................66

4.3.1 Statistical Uncertainty Analysis ..............................................................67

4.3.2 RELAP Model and Accident Analysis Calculations .................................68

4.3.2.1 Station Blackout Analysis ......................................................69

4.3.2.2 Selected Pipe Break Events ....................................................72

4.3.3 RELAP Verification and Validation …………........................................

4.3.3.1 RELAP and ANS Dynamic Model Comparison ........................76

4.3.3.2 Phenomena Identification and Ranking ...................................77

4.3.4 Fuel Assembly Inlet Flow Blockage ……………….............................77

4.4 Severe Accident Analysis................................................................................

4.4.1 Severe Accident Calculations for the Environmental Report and the Conceptual Safety Analysis Report .............................................78

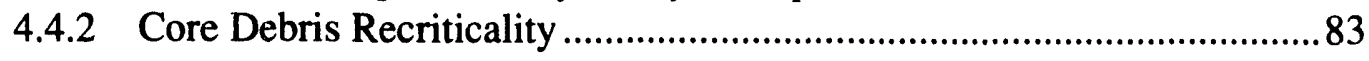

4.4.3 Refueling Accident Modeling and Analysis ...............................................83

4.4.4 Core Melt Progression Considerations for the ANS ...............................85

4.4.5 Severe Accident Experimentation ………………….................................... 85

4.4.6 Severe Accident Mitigation Studies ........................................................ 85

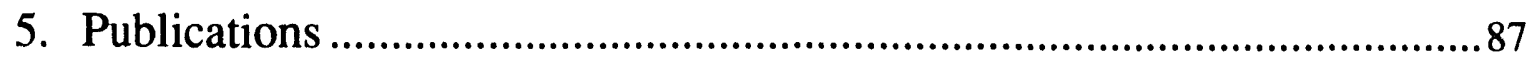

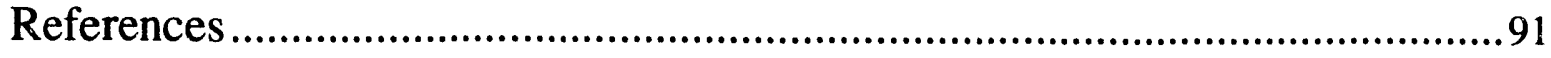

vi Advanced Neutron Source (ANS) Progress Report 


\section{LIST OF FIGURES}

Figure $\quad$ Page

2.1 Comparison of calculated and measured FOEHN reactor reflector thermal fluxes at core midplane .................................................................................. 6

2.2 Thermal flux contours for the L7 reference ANS core at EOC ............................8

2.3 High magnification views showing fission gas bubble morphologies found in $\mathrm{U}_{3} \mathrm{Si}_{2}$ samples irradiated in HFIR HANS-1 capsule, 500× ............................. 10

2.4 ANS corrosion test loop experimental results showing grouping of rate constants for oxide growth on 6061-Al according to ANS Correlation II ............... 12

2.5 Cross sections of the modified and original test channel designs used in the THTL

2.6 Preliminary flow excursion data obtained in the THTL over a range of heat

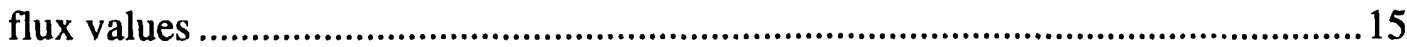

2.7 MCNP and PDQ control rod worths at BOC and EOC ...................................... 16

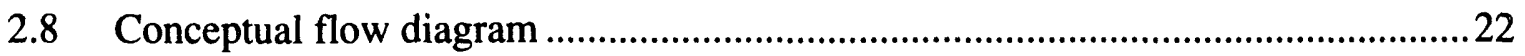

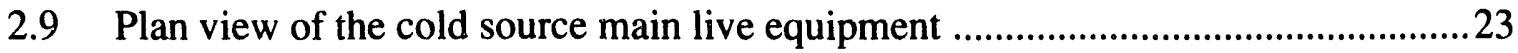

2.10 Elevation showing $\mathrm{D}_{2}$ equipment on second floor and refrigerator cold boxes on third floor.

2.11 Artist's impression of the ground floor beam room..........................................25

2.12 Supermirror filter between straight guide sections ........................................26

2.13 Possible arrangements of the UCN turbine at a horizontal cold source ..................26

2.14 Importance of source particles contributing to neutron and gamma-ray dose .........28

2.15 Simulation of a $\$ 0.8$ reactivity step (largest postulated reactivity event) ...............29 
2.16 Possible ASIC implementation of a reactor protection system 31

2.17 Block diagram of component systems .33

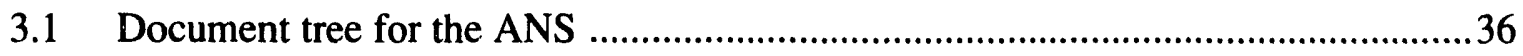

3.2 Reactor assembly showing internal components .............................................38

3.3 Outer shutdown rod with supply lines and relief valves - assembly .....................41

3.4 Refueling concept showing fuel assembly removal .......................................42

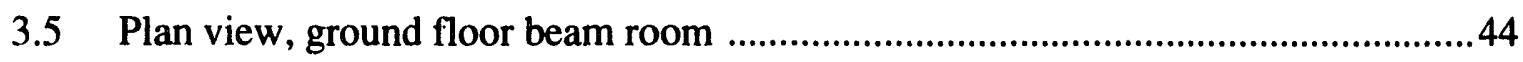

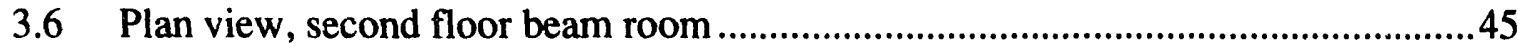

3.7 Elevation view of cold source biological shield penetrations CS1 and CS2 .........46

3.8 Proposed cold source cask with tooling extended to remove source ......................46

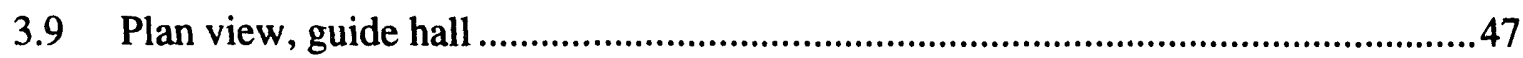

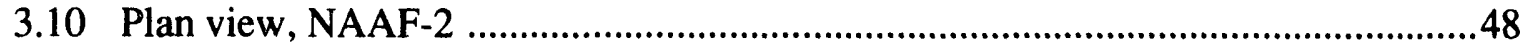

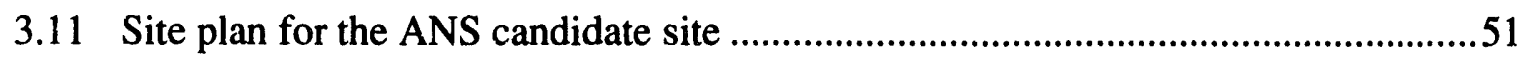

3.12 Lower floors of the main ANS building complex ........................................52

3.13 Intermediate floors of the main ANS building complex ....................................53

3.14 Section through the guide hall, reactor building, reactor support building,

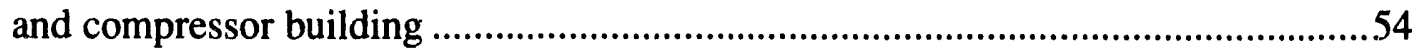

3.15 Flow diagram of the ANS reactor water system ...........................................57

3.16 Instrumentation, controls, and computing architecture .....................................60

3.17 Instrumentation, controls, and computing equipment …................................61

4.1 Nodalization of the conceptual design ANS RELAP5 model ..............................70

4.2 Loop flow rates for the station blackout event ............................................... 71

4.3 Flow excursion and CHF ratios for the station blackout event ..............................72

viii Advanced Neutron Source (ANS) Progress Report 
4.4 Pressure response for a core outlet break with venturi in place ............................74

4.5 Pressure response of the cavitating venturi-hot leg break (short time scale) ........75

4.6 Core inlet and outlet pressure response-increased break opening time

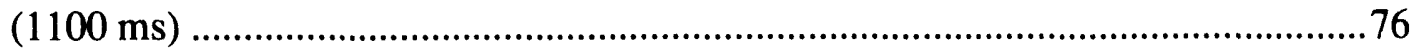

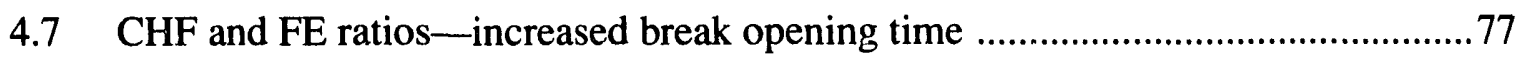

4.8 Partial core melt progression event tree for ANS CSAR studies ............................80

4.9 ANS containment (MELCOR) representation for ANS CSAR ...........................81 


\section{LIST OF TABLES}

$\underline{\text { Table }}$

$\underline{\text { Page }}$

1.1 Advanced Neutron Source Project cost estimates ..............................................2

2.1 Comparison of core multiplication factors $\left(\mathrm{k}_{\mathrm{eff}}\right)$ calculated with MCNP and measured for the FOEHN reactor critical configurations ...............................

2.2 Range of experimental parameters in ANS corrosion loop tests .......................... 12

2.3 Control parameters important for start-up and normal operation ..........................32

3.1 Reactor primary cooling system normal operating parameters ...........................56

4.1 Probability distributions used in simplified statistical uncertainty analysis

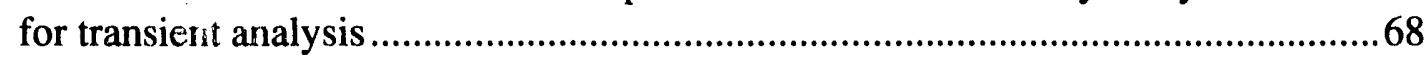

4.2 Hot-spot and channel peaking uncertainty factors at $95 / 95 \%$ and $99.9 / 95 \%$ probability/confidence levels

4.3 Test matrix of recriticality calculations for ANS with dispersed configuration .84 


\section{ACRONYMS}

\begin{tabular}{|c|c|}
\hline ALARA & as low as reasonably achievable \\
\hline ANL & Argonne National Laboratory \\
\hline ANS & Advanced Neutron Source \\
\hline ANSR & Advanced Neutron Source Reactor \\
\hline ASIC & application-specific integrated circuits \\
\hline ASME & American Society of Mechanical Engineers \\
\hline$B \& W$ & Babcock and Wilcox Company \\
\hline BESAC & Basic Energy Sciences Advisory Committee \\
\hline BNL & Brookhaven National Laboratory \\
\hline BOC & beginning-of-cycle \\
\hline $\mathrm{CCI}$ & core-concrete interaction \\
\hline CDR & Conceptual Design Report \\
\hline CETF & Control Element Test Facility \\
\hline CFD & computational fluid dynamics \\
\hline $\mathrm{CHF}$ & critical heat flux \\
\hline CPBT & core pressure boundary tube \\
\hline CSAR & Conceptual Safety Analysis Report \\
\hline DOE & Department of Energy \\
\hline EOC & end-of-cycle \\
\hline ER & environmental report \\
\hline $\mathrm{FCI}$ & fuel-coolant-interaction \\
\hline FE & flow excursion \\
\hline FSAR & final safety analysis report \\
\hline HFIR & High Flux Isotope Reactor \\
\hline IAS & instrument air system \\
\hline IB & incipient boiling \\
\hline ILL & Institut Laue Langevin \\
\hline INEL & Idaho National Engineering Laboratory \\
\hline ISDD & integrating system design description \\
\hline JAERI & Japan Atomic Energy Research Institute \\
\hline JMTR & Japanese Material Testing Reactor \\
\hline LOCA & loss-of-coolant accident \\
\hline MIT & Massachusetts Institute of Technology \\
\hline NAAF & neutron activation analysis facility \\
\hline NECWS & nonessential cooling water system \\
\hline NIST & National Institute of Standards and Technology \\
\hline NPR-HWR & New Production Reactor-Heavy Water Reactor \\
\hline NRC & Nuclear Regulatory Commission \\
\hline NSCANS & National Steering Committee for the Advanced Neutron Source \\
\hline
\end{tabular}




$\begin{array}{ll}\text { NSRR } & \text { Nuclear Safety Research Reactor } \\ \text { ORNL } & \text { Oak Ridge National Laboratory } \\ \text { PCDAS } & \text { plant control and data acquisition system } \\ \text { PDR } & \text { Plant Design Requirements } \\ \text { PIR } & \text { phenomena identification and ranking } \\ \text { PMP } & \text { Project Management Plant } \\ \text { PRA } & \text { probabilistic risk assessment } \\ \text { PSAR } & \text { preliminary safety analysis report } \\ \text { QA } & \text { quality assurance } \\ \text { R\&D } & \text { research and development } \\ \text { RG } & \text { Regulatory Guide } \\ \text { RHX } & \text { reflector heat exchanger } \\ \text { RPS } & \text { reactor protection system } \\ \text { RV } & \text { reflector vessel } \\ \text { RVCS } & \text { reflector vessel cooling system } \\ \text { SAR } & \text { safety analysis report } \\ \text { SDD } & \text { system design description } \\ \text { SEMP } & \text { Systems Engineering Management Plan } \\ \text { SM } & \text { supermirror } \\ \text { THTL } & \text { thermal-hydr: } \\ \text { TVA } & \text { Tennessee Vallest loop } \\ \text { UCN } & \text { ultracold neutron } \\ \text { VCN } & \text { very cold neutron } \\ \text { WBS } & \text { work breakdown structure } \\ & \end{array}$

xiv Advanced Neutron Source (ANS) Progress Report 


\section{FOREWORD}

A conceptual design has been completed for the Advanced Neutron Source (ANS) facility, a new world-class laboratory for neutron research, proposed for construction on the Department of Energy (DOE) reservation in Oak Ridge. The baseline design occupies a 40-acre site and includes a neutron guide hall and research support area; a large reactor containment building housing the neutron source (a 330-MW heavy water reactor) and selected scientific research facilities; operations-support facilities, including reactor secondary cooling systems, cryogenic refrigerators for cold neutron sources, heavy water cleanup and upgrade equipment, and electrical supply systems; and office and accommodation space for the 1000 or more users expected to visit the laboratory each year.

The ANS meets the technical requirements set by the scientific community and is designed to meet or exceed all the regulatory and safety requirements of a comparable Nuclear Regulatory Commission (NRC) licensed :acility.

The estimated line-item design and construction cost is \$1.7B (FY 1992 dollars), and the ANS could be operational in about ten years.

Colin D. West

ANS Project Director 


\section{PROJECT MANAGEMENT}

During this reporting period, a conceptual design of the Advanced Neutron Source (ANS) facility was completed-providing, for the first time, a baseline design with a complete cost estimate and schedule.

The design is based on the scientific requirements, safety goals and regulations, standards and codes, and other guidelines documented in the Plant Design Requirements (PDR). ${ }^{1}$ The baseline facility that arises from these scientific and safety considerations is centered around a 330-MW(f) heavy-water-cooled, -rnoderated, and -reflected reactor housed in a large, double-walled containment dome and surrounded by thermal neutron beam experiments. The reactor cooling systems are designed with many safety features, including large heat sinks sufficient for decay heat removal; passive inventory control by accumulators, pools, and floodable cells; a layout that maximizes natural circulation capabilities; and fast, redundant shutdown systems. There are two large liquid deuterium cold neutron sources, and most of the cold neutron beams are taken, by low-loss guides, to a guide hall that is outside containment and that has low background and the necessary space for neutron scatterixig athd other instruments. The entire facility is designed for easy access to scientific users, combined with rigorous separation of experiments from operational and security areas. It is the first research reactor designed to allow easy visitor access without compromising present nuclear security requirements and regulations.
The conceptual design includes all the scientific facilities and appropriate redundant or safety-related systems that have evolved and been accepted as legitimate design requirements through interactions with all $t,:$ ummunities involved. These features are dumented in the exceptionally complete and detailed concepiual design document package, which is a sound and defensible baseline for the scope documented therein and which can also be used to support evaluation of scope reduction and value engineering trade-off studies that have already begun in order to find the optimum combination of capabilities and cost.

The total estimated construction (line-item) cost of the complete full-scope baseline design is $\$ 1.7 \mathrm{~B}$, in constant 1992 dollars. There is an associated research and development (R\&D) program costed at $\$ 114 \mathrm{M}$ in operating and capital equipment funds. The cost of certain additional instruments that the scientific community proposed not be included in the construction project would be $\$ 34 \mathrm{M}$, and preoperational costs (including training and retraining of operators and maintenance staff) are estimated at $\$ 261 \mathrm{M}$. These figures are shown in Table 1.1. The costs are based on a plan that would begin a line item for preliminary design work (Title 1) in FY 1994, to be followed with a complementary detailed design and construction line item in 1995. Completion of the project is scheduled for FY 2002, including commissioning of the installed experiments systems.

The National Steering Committee for an Advanced Neutron Source (NSCANS), at their 
Table 1.1. Advanced Neutron Source Project cost estimates

\begin{tabular}{lc}
\hline \multicolumn{1}{c}{ Funding category } & FY 1992 \$M \\
\hline Line item & 1699.8 \\
Operating expense & \\
$\quad$ Research and development & 104.3 \\
Preoperational & 261.0 \\
$\quad$ Additional instruments ${ }^{a}$ & 34.5 \\
Capital equipment (R\&D) & 9.8 \\
$\quad$ Total & 2109.4 \\
\hline
\end{tabular}

anstruments beyond the initial complement proposed by NSCANS for installation before project completion. These additional instruments (to a total of 48 ) would be installed later, based on scientific requirements to add instrument technology at that time. Some or all of these would be paid for by participating research teams or industry.

meeting in September 1992, unanimously endorsed the conceptual design as being responsive to their scientific needs and gave their support to the fullscope facility at the cost estimated above.

The Department of Energy (DOE) charged its Basic Energy Sciences Advisory Committee (BESAC) to review the strengths and weaknesses of reactor and spallation sources of neutrons and to discuss the proper timing for a reactor only; a spallation neutron source only; and a combination of the two. The BESAC Panel on Neutron Sources, in a letter presenting their recommendations relating to the FY 1994 budget request, wrote, "The Panel's paramount and unanimous recommendation is that the DOE provide the funding requested by the ANS Project to ensure an early start as well as timely completion of its construction."

\subsection{ANS PROJECT QUALITY PROGRAM}

\subsubsection{Program Development}

A major activity during this period was the revision of the quality assurance (QA) program, and the $Q A$ Plan, ${ }^{2}$ to match the new requirements of DOE Order $5700.6 \mathrm{C}$. The quality program was restructured into the ten elements prescribed in the order, to emphasize the aim of continuous improvement and to embrace the current industry philosophy of Total Quality Management. The revised QA Plan has an accompanying implementation schedule identifying the phases of the project when each element of the program will be activated. The phased approach is designed to provide the necessary controls at the appropriate time, while permitting the greatest possible latitude for creativity where appropriate.

To facilitate the understanding of the revised quality program, a QA specification, formatted in the traditional 18 elements standard to the nuclear industry, has been developed for our subcontractor supporting organizations. This specification will serve as the basis for grading the $\mathrm{QA}$ requirements of supporting organizations for their respective scopes of work.

The QA section of the Conceptual Safety Analysis Report ${ }^{3}$ (CSAR) was developed to address the questions presented in U.S. Nuclear Regulatory Commission (NRC) Regulatory Guide (RG) $1.70^{4}$ and NUREG-0800. 5 It is focused on the function of the project's quality program from the compliance and independent overview perspective of the NRC. The CSAR section differs from the quality program description in the focus on the oversight provisions of the program rather than on the integrated, proactive approach to project completion.

Additional project procedures have been developed and distributed to the project staff. These procedures have addressed some of the administrative and control functions required for project management.

\subsubsection{Quality Monitoring Activities}

The QA monitoring of project activities has increased this year with the performance of several project QA audits or surveillances of ongoing activities. A programmatic audit of the architect/engineer support contractor, Gilbert/ Commonwealth, Inc., was cenducted with the focus on their design control system. Follow-up audits of the supporting neutronics and thermalhydraulics subcontractor, Idaho National 
Engineering Laboratory (INEL), and the fuel development and demonstration subcontractor, Argonne National Laboratory (ANL), were made to verify completion of corrective actions from our initial audits. The project has participated jointly with other Oak Ridge National Laboratory (ORNL) divisions in audits of project work activities [e.g., Babcock and Wilcox's (B\&W's) fuel development; operation of the ANS corrosion test loop].

Surveillances of ongoing project activities have been conducted where deemed to be appropriate (e.g., geoseismic subsurface mapping of the candidate site on the Oak Ridge Reservation). 


\section{RESEARCH AND DEVELOPMENT

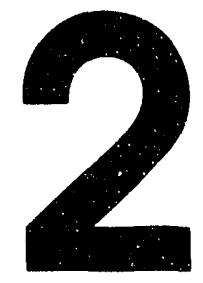

Fourteen R\&D activities have been identified as essential to the ANS Project. These R\&D activities are required to address feasibility issues, to provide some of the data needed for the preparation of the conceptual design report (CDR), to produce the data necessary to make a rational decision when alternative design concepts are identified, and to examine and demonstrate the applicability of technological advances. This chapter summarizes progress on these activities for the reporting period and includes tasks performed by ANL, B\&W, Brookhaven National Laboratory (BNL), INEL, Martin Marietta Engineering, the Massachusetts Institute of Technology (MIT), the McGill University, the National Institute of Standards and Technology (NIST), ORNL, Ovonic Synthetic Materials Company, the Tennessee Techological University, the Texas A\&I Universicy, the University of Rhode Island, the University of Tennessee, and the University of Virginia.

The number of major R\&D activities was increased from 13 to 14 during this report period. The new activity was designated Safety-Related R\&D Tests and includes tasks that were originally part of the safety program but that were moved to the $R \& D$ program to integrate the entire project testing activities under one manager.

\subsection{REACTOR CORE DEVELOPMENT}

The reactor core development task provides the neutronics and thermal-hydraulics activities needed to support the reactor core design.

\subsubsection{Development of Analysis Techniques}

This task includes the development of analysin techniques and involves software and the basic data necessary to perform numerical analyses of the reactor core performance. Three major tasks-modeling of FOEHN criticals, ${ }^{6}$ development of the $\mathrm{MCNP}^{7} / \mathrm{ORIGEN}^{8}$ coupling code, and treatment of uncertainties-are highlighted in the following three subsections.

\subsubsection{Modeling of FOEHN Criticals}

During this report period, it was determined that data from the FOEHN criticals [Institut Laue Langevin (ILL) critical experiments performed in the late 1960s] could be applied to check the ANS neutronics calculation methods in a realistic geometry prior to the performance of more prototypic ANS critical experiments in about 1997. Therefore, a three-dimensional (3-D) MCNP model of the FOEHN critical assembly was developed, and calculations of various FOEHN experiment geometries were performed. To date, the comparisons imply excellent agreement between the MCNP calculations and the measurements performed in the FOEHN criticals. A plot of the calculated and measured thermal flux profiles across the $\mathrm{D}_{2} \mathrm{O}$ reflector region is shown in Fig. 2.1. A comparison of $k_{\text {eff }}$ values is provided in Table 2.1.

\subsubsection{Development of MCNP/ORIGEN Coupling Code}

With the addition of workstations that virtually eliminate computing costs and the seed for treatment of complex geometries, the INEL 3-D MCNP model of the ANS was the workhorse neutronics code for many of the project activities during FY 1992. However, with the MCNP we have generally only been able to examine beginning-of-cycle (BOC) conditions because the 


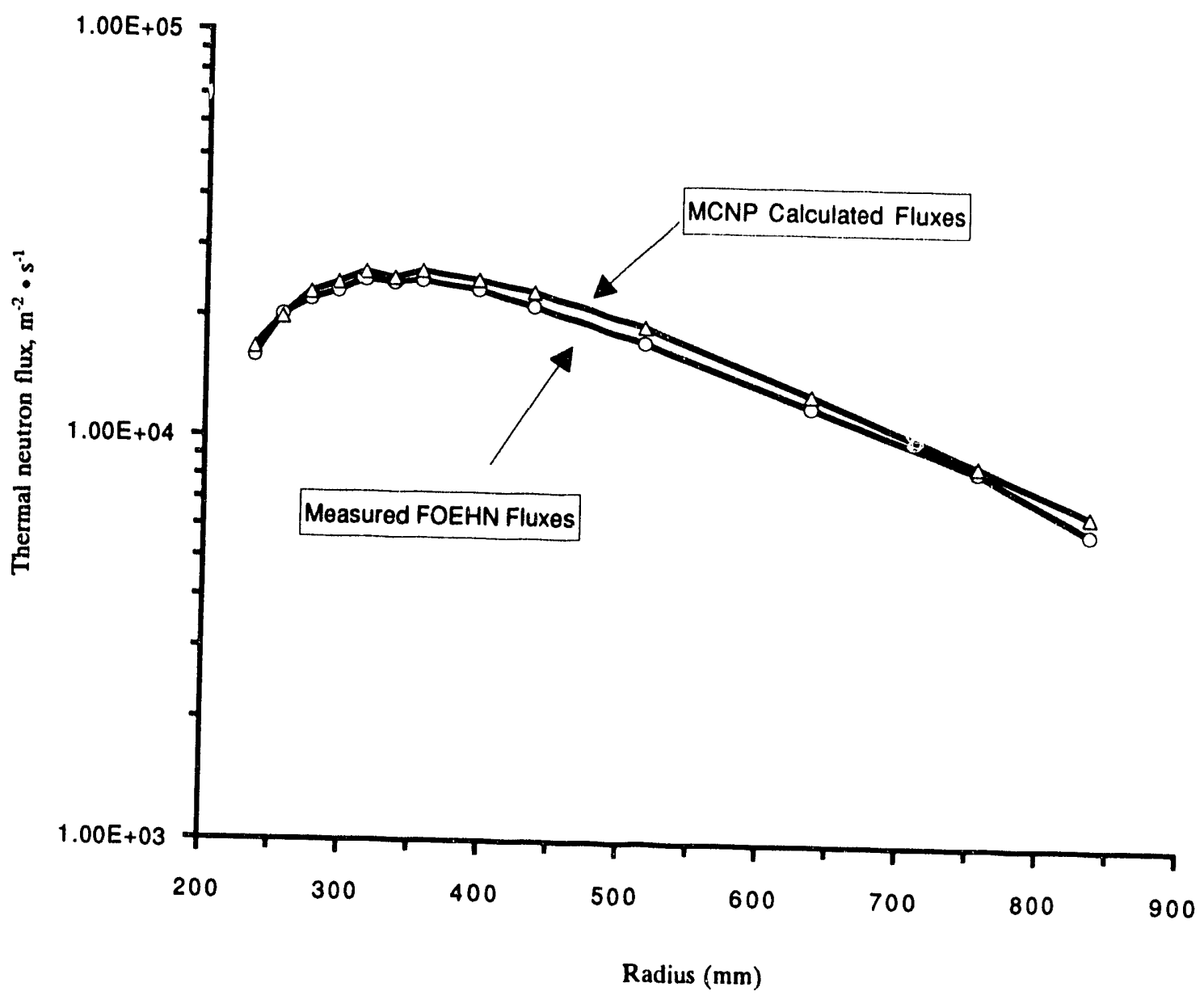

Fig. 2.1. Comparison of calculated and measured FOEHN reactor reflector thermal fluxes at core midplane.

code did not have any fuel depletion capability. To remove this limitation, an effort was initiated to develop an MCNP/ORIGEN coupling code. This would allow the use of MCNP fluxes to perform fuel and material depletion calculations that would feed information back to the MCNP code so that calculations throughout the life cycle of the fuel could be performed. At the end of this report period, the coupling was completed, and testing had been initiated.

\subsubsection{Treatment of Uncertainties}

Development of a methodology and supporting data bases for the treatment of analytical, process, and manufacturing uncertainties continued during FY 1992. Activities have addressed long-term and short-term needs. A statistical peaking factor technique based on Monte Carlo sampling was employed for the CSAR, ${ }^{3}$ while the study of more sophisticated approaches (e.g., Latin Hypercube sampling and fast probability integration) for later use progressed.

The uncertainty data base was expanded considerably in key areas, including thermalhydraulic correlations/data and fuel-plate manufacturing. Activities included optical scanning of High Flux Isotope Reactor (HFIR) fuel-plate radiographs, statistical analysis of HFIR fuel-plate channel gap data, and extensive evaluations of thermal-hydraulic correlations that included consideration of transient (accident) conditions as well as nominal operating conditions.

\section{Advanced Neutron Source (ANS) Progress Report}


Table 2.1. Comparison of core multiplication factors $\left(\mathrm{k}_{\mathrm{eff}}\right)$ calculated with MCNP and measured for the FOEHN reactor critical configurations

\begin{tabular}{lcr}
\hline Case name & Measured $\mathrm{k}_{\mathrm{eft}}{ }^{a}$ & MCNP calculated $\mathrm{k}_{\mathrm{eff}}$ \\
\hline \multicolumn{3}{c}{ Cases without solid boron and without reflector internals } \\
Core 20 & 1.0000 & $1.0028 \pm 0.0028$ \\
Core 21 & 1.0000 & $0.9998 \pm 0.0035$ \\
Core 22 & 1.0000 & $0.9937 \pm 0.0036$ \\
Core 23 & 1.0000 & \\
Core 24 & 1.0000 & $1.0036 \pm 0.0035$ \\
Core 25 & 1.0000 & $1.0036 \pm 0.0032$ \\
Core 26 & 1.0000 & $1.0003 \pm 0.0033$ \\
Core 27 & 1.0000 & \\
Core 28 & 1.0000 & $0.9992 \pm 0.0035$ \\
Core 29 & & $0.9992 \pm 0.0029$ \\
Core 30 & 1.0000 & $0.9921 \pm 0.0033$ \\
& 1.0000 & $0.9908 \pm 0.0034$ \\
& & $0.9974 \pm 0.0032$
\end{tabular}

Cases with solid boron and without reflector internals

$\begin{array}{lll}\text { Core.b1 } & 1.0000 & 1.0059 \pm 0.0035 \\ \text { Core.b2 } & 1.0000 & 1.0065 \pm 0.0032 \\ \text { Core.b3 } & 1.0000 & 1.0013 \pm 0.0029 \\ & & \\ \text { Core.b4 } & 1.0000 & 0.9986 \pm 0.0039 \\ \text { Core.b5 } & 1.0000 & 1.0090 \pm 0.0034 \\ \text { Core.b6 } & 1.0000 & 0.9981 \pm 0.0031\end{array}$

\footnotetext{
"Uncertainties in the measured $\mathrm{k}_{\mathrm{eff}}$ values are not reported in the FOEHN critical experiment report. However, examination of uncertainties reported for control rod worths imply that the uncertainty in the absolute individual $\mathrm{k}_{\mathrm{eff}}$ values is $<0.0001$.

The uncertainty values reported for the MCNP calculated values are statistical uncertainties obtained from the Monte Carlo calculation.
}

In sur $/ \mathrm{rt}^{\mathrm{c}}$ the CSAR, 16 key parameters were identified, and uncertainty probability distributions or deterministic uncertainty values were developed for each. These included control, measurement, and trip set point (i.e., process) uncertainties that were integrated with analytical and manufacturing uncertainties using the statistical peaking factor method.

\subsubsection{Neutronics and Thermal-Hydraulics Support to Design}

During this report period, detailed neutronics and thermal-hydraulics analyses were performed as part of the support for the development of the conceptual design. These evaluations are documented in the CDR and in the CSAR. ${ }^{3} \mathrm{~A}$ contour plot of the thermal flux for the reactor core evaluated in the CDR is presented in Fig. 2.2.

Although a number of reactor core geometry trade-off analyses have been performed, the physical dimensions of the reactor core are unchanged from the design concept described in the last ANS progress report. ${ }^{9}$ The focus this year has included examination of nonfuel element components and how they impact the reactor core, in addition to the continuation of detailed analyses of the reactor core per se. The major experiment 


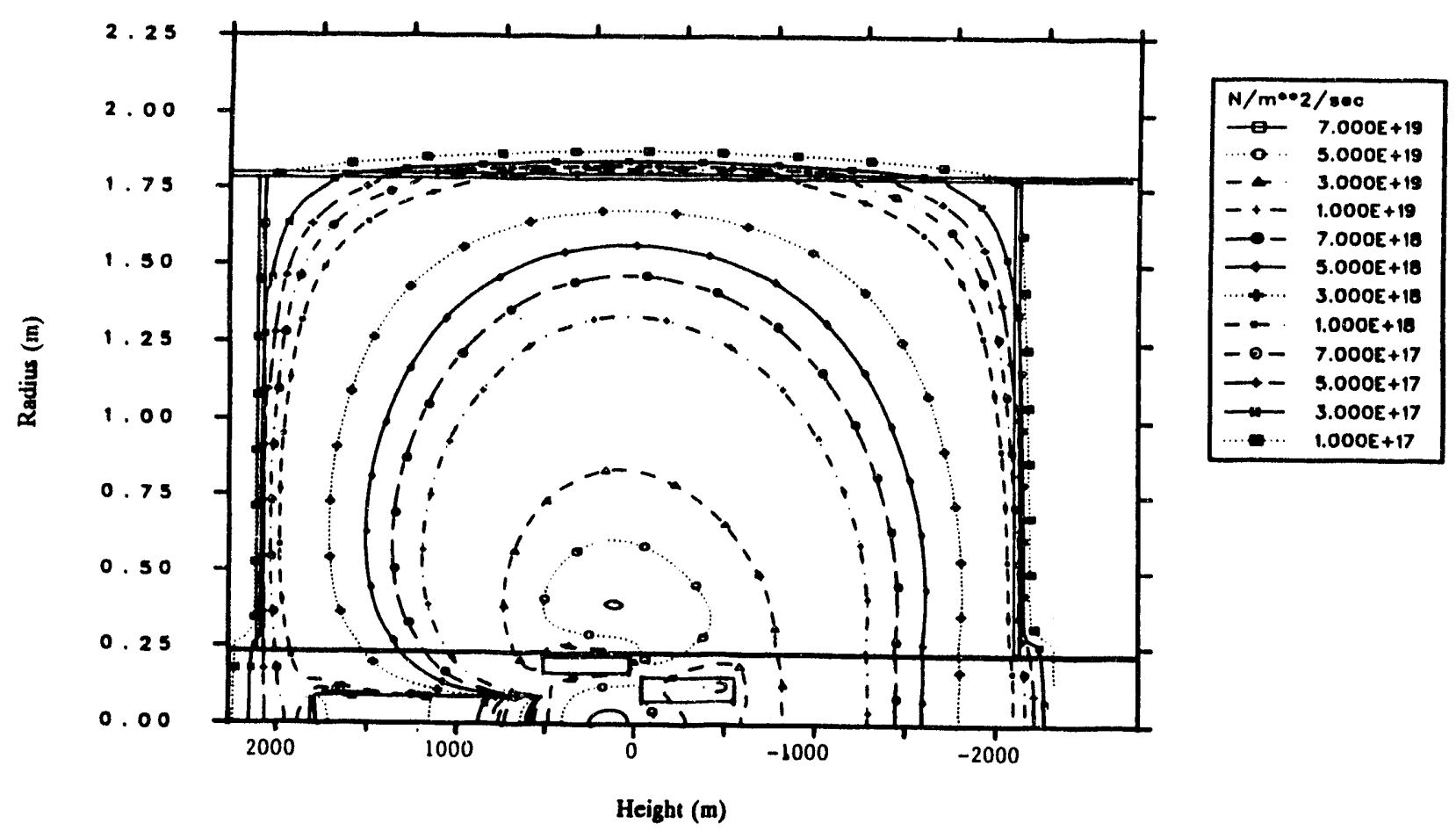

Fig. 2.2. Thermal flux contours for the $L 7$ reference ANS core at EOC.

system components (cold sources, hot source, beam tubes, irradiation facilities, and rabbit tubes) have been added to the 3-D Monte Carlo neutronics model, and evaluations have been performed to examine their impact on the reactor core. Thermal-hydraulic analyses have examined cooling of the transuranium production targets, the control rods, and the core pressure boundary tube (CPBT) to evaluate their cooling requirements as well as their potential impact on cooling conditions in the reactor core.

Fuel element criticality during refueling was an issue that received special attention. Early analysis indicated that both the fresh upper and lower individual fuel elements would go critical if moved away from the poison rods into the heavy water refueling stack or tunnel. Analyses were performed using MCNP, ${ }^{7} \mathrm{KENO},{ }^{10}$ and VENTURE " to examine various options for resolving this potential problem. It was determined that by introducing small poison material sections as part of the fuel-handling equipment and/or by adding steel or aluminum sleeves to displace $\mathrm{D}_{2} \mathrm{O}$ around the fuel, the required subcriticality margins could be maintained $\left(k_{\text {eff }}<0.8\right)$. Further neutronic and thermal-hydraulic analyses, as well as engineering and probabilistic risk examinations, will be performed to finalize a concept that meets all design requirements.

Analysis of the neutronics and thermalhydraulics data generated for the CDR implied that significant improvements in the power distribution should be possible. Therefore, as part of the initial advanced conceptional design activities, a study was initiated to examine promising options. One idea was to introduce a gray absorber section at the leading edge of the control rods. It is believed that this will reduce the power depression in the upper element at $\mathrm{BOC}$ and reduce the power peaking that occurs near the end of the cycle as the rods move out of the upper fuel element. It was also determined that the burnable poison burns up more rapidly in the CDR core than in some of the preconceptual design cores. Therefore, there is potential for adding additional bumable poison that could be placed in 
strategic locations to help with the shaping of the power distribution. These and/or other options are believed to have the potential for further improving the safety margins reported in the CDR.

\subsection{FUEL DEVELOPMENT}

Work continued in support of the $\mathrm{U}_{3} \mathrm{Si}_{2} / \mathrm{Al}$ mixture as the reference fuel for the ANS. The work was concentrated in the areas of irradiation of fuel specimens, fuel performance modeling, and fuel fabrication. In February, a review of the fuel development program was held with a panel of outside experts. The results of this review, as well as a summary of each of three major work areas, are discussed in the following subsections.

\subsubsection{Review of Fuel Development Program}

An extensive review of the ANS fuel development and qualification program was conducted February 3-5, 1992, by a committee of outside experts consisting of R. R. Hobbins (INEL), C. A. Alexander (Battelle-Columbus), and R. D. Leggett (Westinghouse Hanford, retired). The committee report was complimentary of the progress made to date with limited resources. In particular, the committee commended the close working relationships among the participants (especially the interaction between the fuel performance modeling and the irradiation performance experimenters and the involvement of the fuel fabricator in the development process). They also saw no obvious impediments to the capability of the $\mathrm{U}_{3} \mathrm{Si}_{2}$ fuel to meet ANS requirements or in the ability to fabricate the fuel. There were, however, several recommendations. The first two were related and were associated with the need to develop more definitive longrange plans that would include decision trees, interfaces, and schedules for the overall fuel qualification and the irradiation testing. The third was that investigation of burnable poison be accelerated and that alternatives to boron carbide be investigated. The fourth was that full-sized plates be included in the irradiation testing. The fifth was that more coordination be implemented between the safety program off-normal or accident fuel performance and the fuel development program for normal operating conditions. Steps have been taken to implement these recommendations.

\subsubsection{Irradiation of Fuel Capsules}

Problems continued to plague the postirradiation evaluation of the first ANS target capsule. The unavailability of the hot cells for much of the year and the allocation of manpower there allowed us to obtain metallographic analysis of only half of the 18 specimens in the HANS- 1 capsule. The microstructure of the specimens examined thus far is indicative of good fuel performance. Even at temperatures above $400^{\circ} \mathrm{C}$, the fission gas bubble distribution shows a stable fuel structure that is indicative of acceptable swelling. Typical microstructures of particles are shown in Fig. 2.3. The zone of larger fission gas bubbles in the center of the particles is surrounded by a zone of much smaller bubbles. This indicates that there may have been a much larger thermal gradient than anticipated in the fuel particles. Better resolution than we have been able to attain with the ORNL shielded scanning electron microscope (2000x) is required to characterize the bubble size distributions and to provide valuable input into the fuel performance model. Therefore, as soon as operations resume in the ORNL hot cells, we plan to ship the specimens to $\mathrm{ANL}$ and attempt to use their higher resolution microscope.

\subsubsection{Fuel Performance Studies and Modeling}

The fuel performance model is being continually improved by collaborative efforts among the modeler, the irradiation performance experimenter, and the irradiation simulation (ion and neutron bombardment) experimenter. Mechanistic processes are being added to model the behavior observed in 

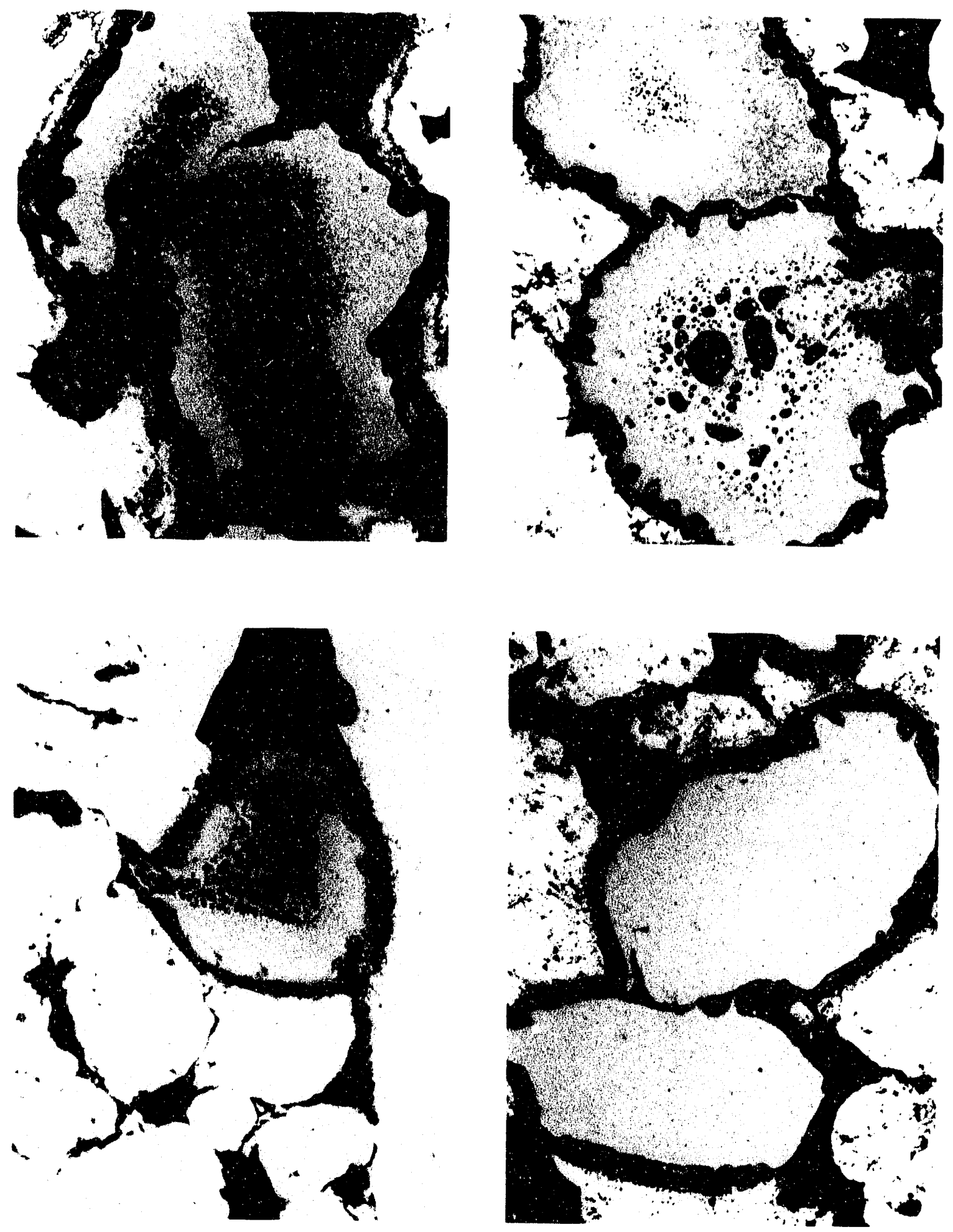

Fig. 2.3. High magnification views showing fission gas bubble morphologies found in $\mathrm{U}_{3} \mathrm{Si}_{2}$ samples irradiated in HFIR HANS-1 capsule, 500x.

10 Advanced Neutron Source (ANS) Progress Report 
the irradiation and bombardment experience. In particular, irradiation-induced grain recrystallization may explain the knee in the swelling curves and the dependence of the location of the knee on fission rate. When combined with introduction of fixed bubble sites at grain boundary corners, the irradiation-induced recrystallization also explains the fission gas bubble size distributions observed in irradiation tests in the Oak Ridge Research Reactor and in the HFIR target capsule fuel particles. Initial attempts to model the behavior of the fuel during offnormal transient conditions have also proved promising.

\subsubsection{Fabrication Development}

Fabrication development efforts this year at B\&W and at ANL have focused on improving the fuel distribution. Plates made to the HFIR configuration with $\mathrm{U}_{3} \mathrm{Si}_{2}$ show fuel distributions that appear to be as good as the $\mathrm{U}_{3} \mathrm{O}_{8}$ plates. Quantitative evaluation of the homogeneity is required to evaluate the plates further: the homogeneity scanner has been modified to provide digital data and is in the final stages of being approved for use. Efforts at ANL to improve the homogeneity of surrogate fuels have progressed to the limit of evaluation by the radiographic film technique, and these plates also await the digital scanner for further evaluation of their homogeneity.

\subsection{CORROSION LOOP TESTS AND ANALYSES}

Historically, research reactors employing aluminum-clad fuel plates have performed satisfactorily during long-term operation in a number of installations, without the excessive thermal or structural problems associated with oxide growth on the cladding. However, because the ANS may operate under a range of thermalhydraulic conditions not previously encountered or explored experimentally, this research task was initiated to investigate these processes and to develop a means to determine their importance and the magnitude of their effect on ANS reactor performance.
During this report period, the test loop was involved with a series of five long-term tests in support of the New Production Reactor-Heavy Water Reactor (NPR-HWR) program. These tests were conducted on 8001 aluminum, and, like the previous ANS loop tests, the growth behavior and physical attributes of the product oxide films were examined under conditions relevant to reactor operation. Comparisons of these results with the ANS data provided useful additional information to both programs.

\subsubsection{Summary of Results: FY-1992 Update}

The major results of the ongoing ANS corrosion test program have been reported in ANS progress reports, ${ }^{9,12-15}$ ORNL reports, ${ }^{16-19}$ and open-literature publications. ${ }^{20-23}$ During this program, the characteristics of film growth on $6061 \mathrm{Al}$ have been examined in 28 loop tests for a range of conditions pertinent to ANS operation. The experimental system parameters and their ranges for all experiments are given in Table 2.2. The whole range for some parameters was very wide, but our more recent experiments have focused on the narrower, maximum interest ranges also listed.

The extreme sensitivity of the film growth rates to coolant $\mathrm{pH}$ and inlet temperature $T_{c i}$ is illustrated in Fig. 2.4, which presents measured rate constants for film growth from the existing ANS experiments. (Each set of three connected data points was obtained from a single experiment.) The data are plotted in Arrhenius fashion according to ANS Correlation II. ${ }^{9}$ The dashed line in the figure is a current "best fit" and is given by

$$
\begin{aligned}
k= & 6.388 \mathrm{E} 7 \exp \left[-9154 /\left(T_{x / c}+1.056 \phi\right)\right] \\
& \mu m^{1.351} / \mathrm{h},
\end{aligned}
$$

where

$$
\begin{aligned}
k= & \text { empirical rate constant, } \mu m^{1.351} / h ; \\
T_{\mathrm{x} / \mathrm{c}}= & \text { local oxide-coolant interface } \\
& \text { temperature, } \mathrm{K} ; \\
\phi= & \text { local heat flux, } \mathrm{MW} / \mathrm{m}^{2} .
\end{aligned}
$$


Table 2.2. Range of experimental parameters in ANS corrosion loop tests

\begin{tabular}{lcc}
\hline \multicolumn{1}{c}{ Parameter } & Experiment range (nominal) & Maximum interest range \\
\hline Coolant pH & \\
Coolant velocity, $\mathrm{m} / \mathrm{s}$ & $4.5-6.0$ & $4.8-5.2$ \\
Coolant inlet temperature, ${ }^{\circ} \mathrm{C}$ & $9-28$ & $25-27.6$ \\
Local coolant temperature, ${ }^{\circ} \mathrm{C}$ & $39-80$ & $44-49$ \\
Local interface temperature, ${ }^{\circ} \mathrm{C}^{b}$ & $45-101$ & $50-90$ \\
Local heat flux, $\mathrm{MW} / \mathrm{m}^{2}$ & $95-208$ & $100-200$ \\
Experiment duration, d & $5-20$ & $5-12$ \\
\end{tabular}

${ }^{a}$ Mixed bed demineralizer plus $\mathrm{HNO}_{3}$ additions in bypass stream.

${ }^{b}$ Calculated via Petukhov ${ }^{24}$ forced convection heat transfer coefficient.

Except as noted in the figure, the open circles represent data from experiments conducted with $\mathrm{pH}=5$ (nominal) and $T_{c i} \leq 49^{\circ} \mathrm{C}$. The solid circles depict data for $T_{c i}>55^{\circ} \mathrm{C}$, and the coolant inlet remperatures are listed. It is clear that, for a given set of thermal-hydraulic parameters, the major departures from the dashed line are the result of $T_{c i}$ extremes and variations from the 5.0 norm in the

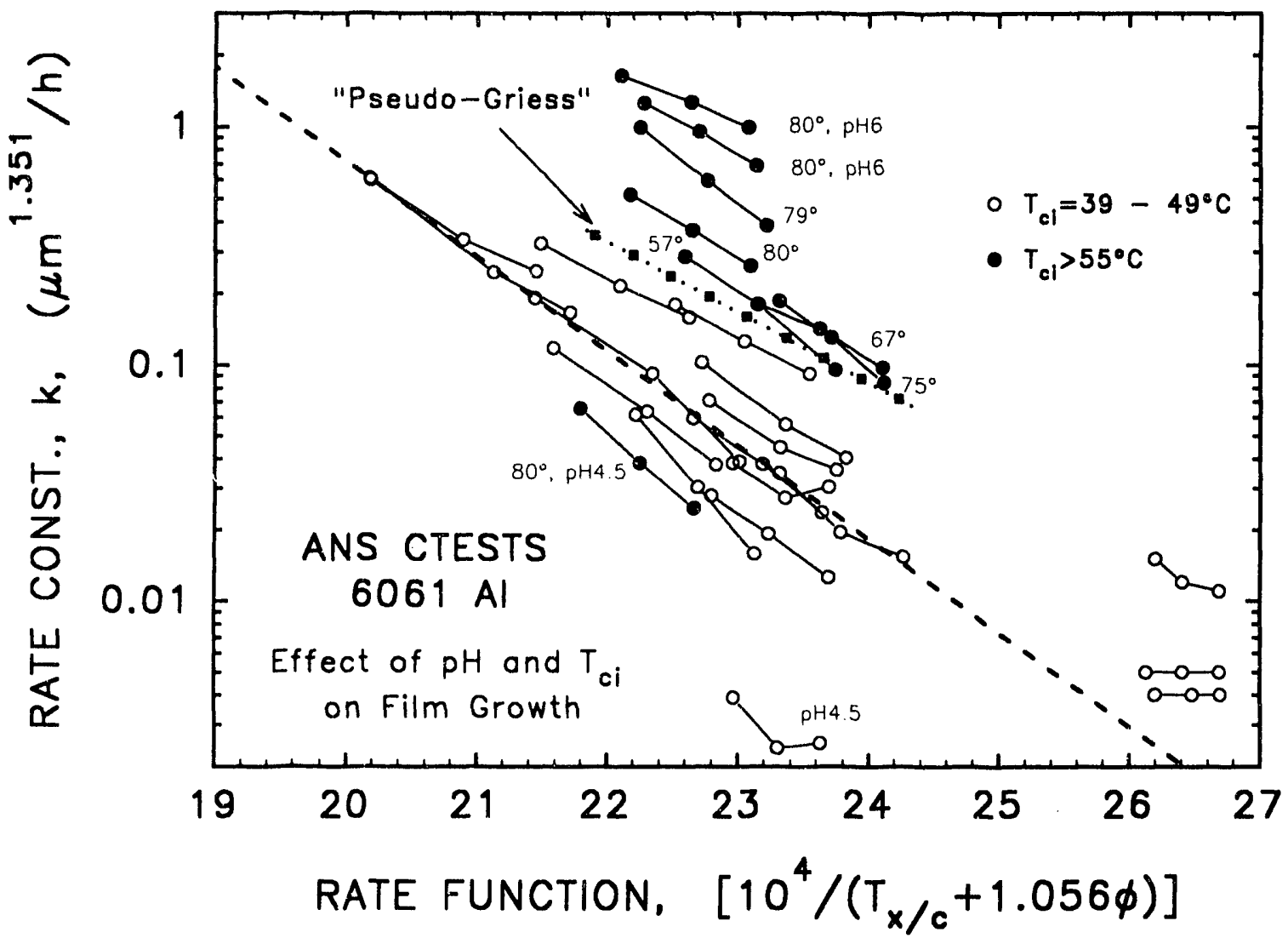

Fig. 2.4. ANS corrosion test loop experimental results showing grouping of rate constants for oxide growth on 6061-Al according to ANS Correlation II. Coolant $\mathrm{pH}=5$, unless otherwise noted on figure. Note influence of coolant $\mathrm{pH}$ and inlet temperature on experimental rate constants. 
coolant $\mathrm{pH}$. In addition, the dotted line of data in the figure labeled "pseudo-Griess" was constructed from the Griess Correlation ${ }^{25}$ data base, which specified $\mathrm{pH} 5$ coolant but utilized a range of coolant inlet temperatures that averaged about $78^{\circ} \mathrm{C}$.

Recent results continue to confirm the importance of these coolant parameters and the associated extent of the iron-rich layer, generally found on the outer surface of the boehmite $\left(\mathrm{AL}_{2} \mathrm{O}_{3} \cdot \mathrm{H}_{2} \mathrm{O}\right)$, on the kinetics of oxide film growth. The observations also continue to support the proposed model for iron transport from the stainless steel components of the loop system. Plans for FY 1993 are focusing on modified maximum interest ranges for several of these parameters, corresponding to proposed changes in reactor design.

\subsubsection{Summary of NPR-HWR A-Tests}

Five corrosion tests on $8001 \mathrm{Al}$ under heattransfer conditions were performed over a range of specified thermal-hydraulic and coolant chemistry conditions of interest to NPR-HWR operation. The characteristics of oxide-product film growth on the alloy' surfaces were studied ard compared with those of earlier investigations.

The observations of the NPR A-series of tests indicated that the nature of the corrosion of the specially prepared $8001 \mathrm{Al}$ specimens was quite similar to that found for $6061 \mathrm{Al}$ in previous ANS tests, despite the less aggressive thermal-hydraulic parameters. Boehmite was identified as the major oxidation product, and its growth rate was found to be influenced by system temperatures and heat flux as well as the coolant properties. The films were adherent and reasonably uniform in thickness, and no spallation was observed even at the hot or exit end of the specimens except in Test A-5, which was specifically designed to study behavior in thick films. An iron-rich layer, only a small fraction of the total product film thickness, was observed to a greater or lesser extent on the outer surface on all of the test specimens, and it is thought that this layer plays an important part in determining the kinetics of film growth. The observed formation of this barrier layer was also consistent with earlier results that indicated that its source was the stainless steel components in the coolant circuit, and the mechanism of transport involved the effect of coolant $\mathrm{pH}$ on the (retrograde) solubility of the metal oxide species. Thus, the concept that the corrosion process includes the entire coolant loop system, and not just the specimen and its immediate environment, has als? persisted in these tests.

\subsection{THERMAL-HYDRAULIC LOOP TESTS}

The thermal-hydraulic performance of the ANS reactor will directly influence both normal and off-normal operational limits and behavior. Characterization of this behavior will require correlations and models that accurately predict the important thermal-hydraulic phenomena such as critical heat flux (CHF), flow excursion (static instability), incipience of boiling, and heat transfer and pressure drop coefficients. This task will include the measurement and the analyses necessary to validate the correlations and models and to provide input in determining their uncertainty levels for statistical uncertainty analysis. The data obtained from these tests will, in turn, be used to assess the capability for forced and natural convection operation under expected hot-channel conditions.

\subsubsection{Testing}

Shakedown testing of the Thermal-Hydraulic Test Loop (THTL), described in earlier reports ${ }^{9,14}$ was completed during the second quarter of FY 1992. The loop is designed to provide known thermal-hydraulic conditions in a test section that simulates a full-length aluminum coolant subchannel of the ANS reactor core.

Characterization and benchmark testing of the test channel design for $\mathrm{CHF}$ and flow excursion were initiated following this functional checkout of the 
test loop. Early tests indicated problems with the original channel design (shown in Fig. 2.5).

Burnout took place in the edge (corner) regions of the channel rather than on the channel flats.

Analysis indicated that a lack of hydraulic mixing in the edge regions could produce higher bulk temperatures and lead to early failure in those regions. A design modification was made that significantly reduced the wall thickness of the channel edge (Fig. 2.5) in order to reduce the heat flux in this region. Fabrication difficulties associated with the thinner wall have caused delays in the expected test schedule. At the end of this reporting period, a successful fabrication technique has been developed, and early testing on the new design indicates significantly improved performance.

Although the earlier test series were affected by the apparent channel edge effects, these tests did provide a basis for development of data reduction techniques and analytical models for data interpretation, as well as exercising test methods used to obtain flow excursion data. The approach taken was to rely on detecting the minimum in a plot of pressure drop vs flow rate at a given heat flux using as stiff a system as possible to avoid actual flow excursion. The assumption, which is well supported by other experimental data, is that this point coincides with the onset of net vapor generation and that it also represents the point at which flow excursion would occur. This approach allows repeated use of the same test section, because it does not normally involve an actual burnout (the number of tests that can be performed per test section remains to be determined). Thirteen test runs were performed with the first test-section design in two different types of experiments. In one type, the heat flux in each run was maintained constant, while the velocity was decreased until a minimum in pressure drop was achieved. In the second type, the velocity in each run was maintained constant, while the heat flux was increased until a rapid increase in the pressure drop was observed. In all runs, the exit pressure and inlet temperature were maintained constant. It was concluded from the
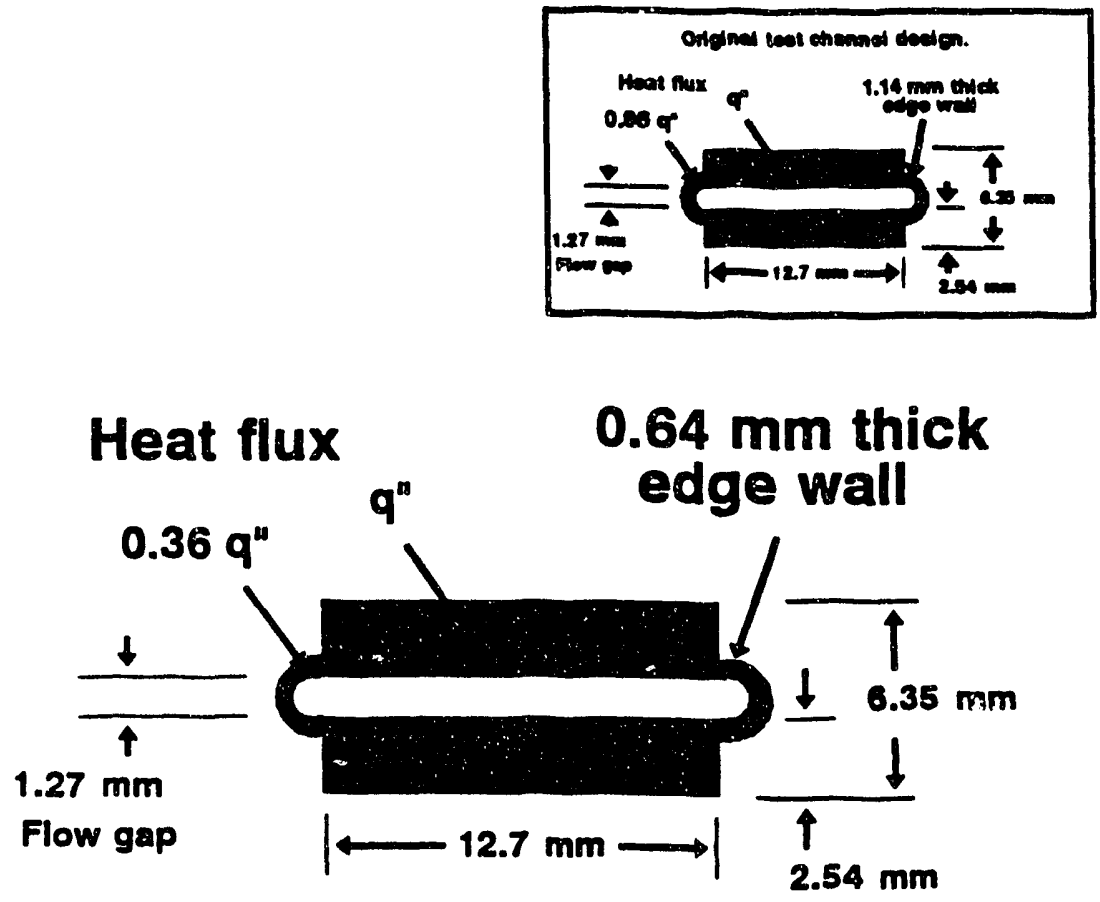

Fig. 2.5. Cross sections of the modified and original test channel designs used in the THTL.

14 Advanced Neutron Source (ANS) Progress Report 
early testing sequences that varying velocity to obtain the minimum pressure drop provides a clearer detection of the minima than does varying the heat flux and is therefore preferable for future tests.

A test series was conducted near the end of this reporting period using the new channel design. Results from this test are shown in Fig. 2.6. Four flow excursion tests were run over a heat-flux range of 6 to $12 \mathrm{MW} / \mathrm{m}^{2}$, with exit pressure at $1.7 \mathrm{MPa}$ and inlet coolant temperature of $45^{\circ} \mathrm{C}$. Velocity was varied as described earlier to obtain minima in the pressure drop across the test channe!. The process of data collection and analysis is still in progress, aild no definitive conclusion can yet be drawn. However, the trends are already reflected in the results collected so far. Clearly, a higher heat flux is required to get the pressure-drop minima (and therefore the conditions that may lead to flow excursion) as the velocity and exit pressure increase. At higher pressures, higher velocities, and higher heat fluxes, the margins between flow excursion and CHF get narrower. At the same time, the margin from incipient boiling gets broader.

A number of analytical models were developed for experimental data reduction, for general calculational purposes, and for pretest prediction. Those models calculate local heat flux, local bulk coolant temperature, test channel inner surface (oxide/water interface) temperature, local heat transfer coefficients, incipient boiling heat flux, flow excursion heat flux, and critical heat flu. These are calculated as a function of distance along the test section and are based on measured test channel power, coolant flow, coolant inlet and outlet temperatures and pressures, and test section back-surface temperatures.

\section{Tin $=45^{\circ} \mathrm{C}$, Pout $=1.7, \mathrm{TSD}-3 / \mathrm{B}$}

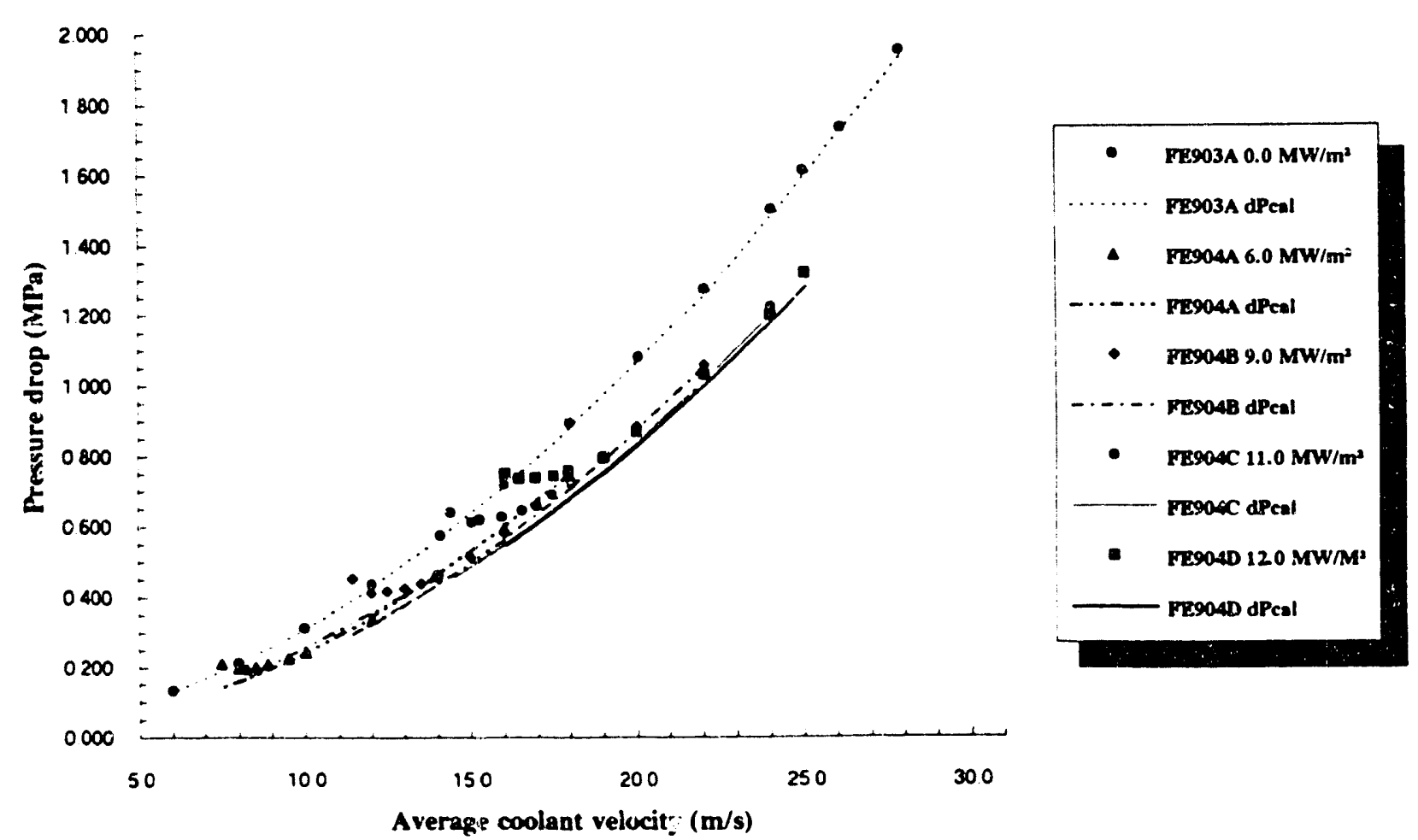

Fig. 2.6. Preliminary now excursion data obtained in the THTL over a range of heat-flux values. 


\subsubsection{Planning}

As a result of the experience gained so far in design and operation of the THTL, the next series of tests were planned. Near-term modifications to the loop have been implemented, and additional loop modifications and alternate test-section designs are being considered. Tube geometries for benchmarking against existing correlations, and alternate ways to couple the power supplies, are being examined in an effort to reduce channel wall thickness and allow more flexibility in test-section design. Further testing at higher power levels is planned for early next fiscal year in both flow excursion and CHF. Tests for incipient boiling as well as for off-nominal conditions (loss-of-coolant and loss-of-offsite-power accidents), effects of oxide on thermal limits, and the use of heavy water will follow. A comprehensive longer range testing plan for the THTL facility and its various upgrades is being developed, taking into account the project objectives and the facility constraints. Statistical design of the experiments to determine correlation uncertainty distributions for the reactor uncertainty analysis of the thermal limits will also be taken into account in the planning.

\subsection{REACTOR CONTROL AND SHUTDOWN CONCEPTS}

The central control rod system is composed of three poison assemblies that move within the central hole region of the fuel elements, serving the combined functions of shim, regulation, safety, and shutdown. Figure 2.7 provides an indication of the worth vs position at BOC and end-of-cycle (EOC) in pcm $10^{5} \log _{n} k_{1} / k_{2}$.

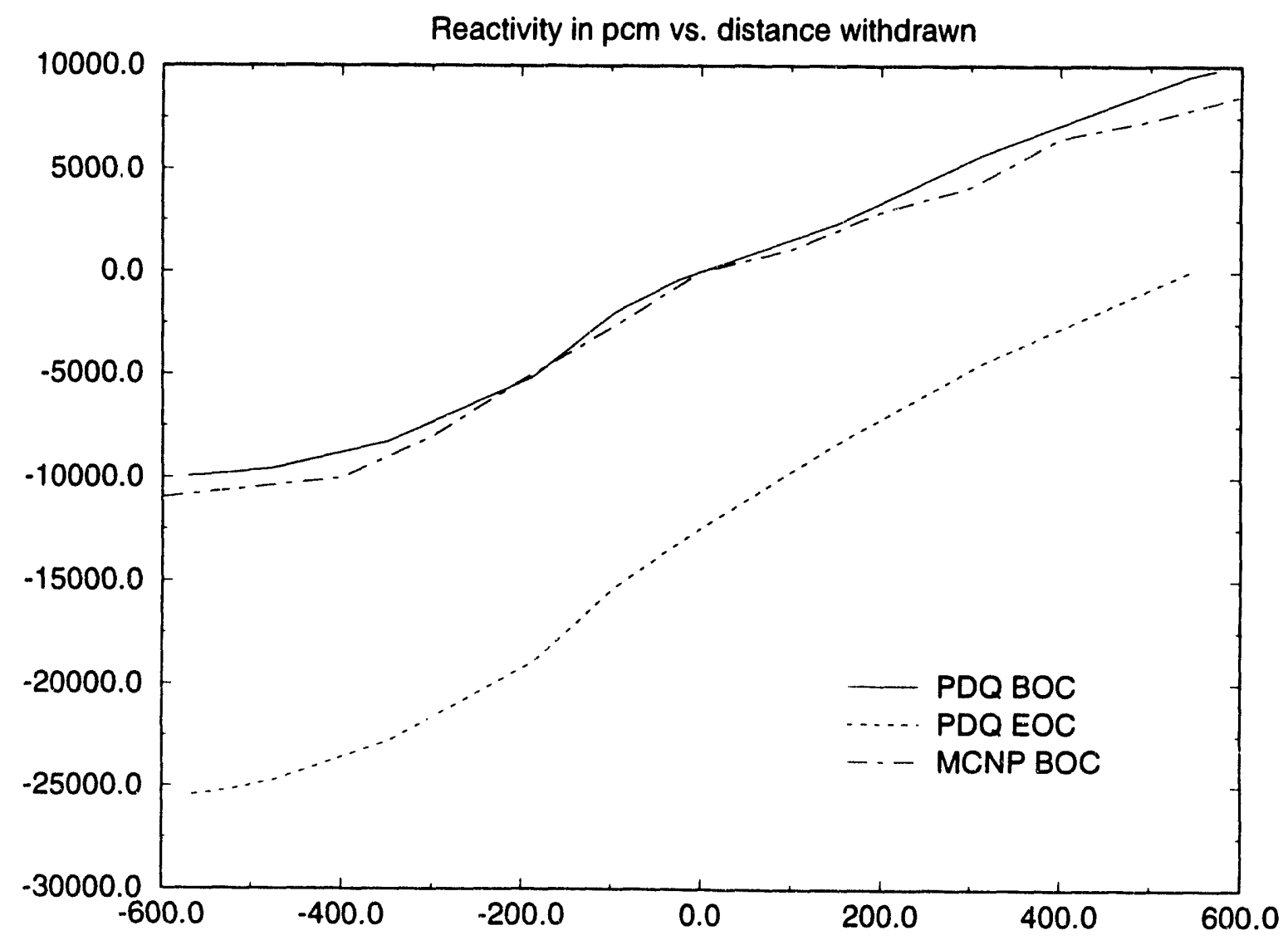

Fig. 2.7. MCNP and PDQ control rod worths at BOC and EOC. 
The worth curves and the conceptual design are based on the use of hafnium as the absorber material in the rods. It was determined that the high activation and decay heat load associated with the hafnium rods complicates rod replacement. Therefore, as part of the advanced conceptual design activities, alternative poison materials are being studied. A total of 18 poison options have been considered and evaluated based on neutron absorption properties, activation, heat load, lifetime, melting temperature, thermal conductivity, weight, reactions with $\mathrm{D}_{2} \mathrm{O}$ and other interface materials, and mechanical properties. No decision has been made. $\mathrm{B}_{4} \mathrm{C}$ has some excellent characteristics, but the helium production would probably force replacement more frequently than the goal of every 2 years. The europium oxide/ aluminum material used in HFIR has potential, but it has the same activation problem as hafnium. A study has been initiated to examine a nickel/ gadolinium material that might not have any major drawbacks.

The reactivity poison elements for the secondary shutdown system consist of eight outer rod assemblies, which are located in the reflector region and serve as safety and shutdown rods only. During normal operation, they will be fully withdrawn (bottom of poison section $800 \mathrm{~mm}$ above core midplane) to minimize the flux perturbation in the beam tube region. The reactivity effects of the eight outer shutdown rods have been calculated using the MCNP 3-D Monte Carlo transport code. A shutdown $\mathrm{k}_{\mathrm{eff}}$ of 0.934 is obtained when the eight outer rods only are inserted, i.e., without the inner shutdown rods present at all.

\subsection{CRITICAL AND SUBCRITICAL EXPERIMENTS}

Various facilities are under consideration for performing the ANS critical experiments. There are at least four sites where the experiments could be performed and where there is interest in doing so. One site already has tanks and apparatus for handling the heavy water that is already there, but at the other three, the liquid handling system would have to be installed and the heavy water obtained.

The various measurements to be performed in the critical experiments program have been defined, and they are divided into the following categories: (1) fuel loading and start-up that includes experiments to examine subcriticality monitoring for the fuel-loading scenario, isolators to decouple the fuel elements from the heavy water so that subcriticality is ensured during the refueling process, simulation of start-up measurements, and measurements evaluating the performance of the start-up instrumentation; (2) reactor criticality experiments that include measurements with a beginning-of-life core and an end-of-life core simulated with appropriate addition of neutron poisons; (3) validation of calculational methods including measurements of critical configurations, reactivity coefficients, relative fission density distribution, neutron spectrum, light water contamination, and $\beta / 1$; (4) reactor performance measurements that include determination of neutron and gamma-ray flux at various experimental locations per fission in the core; and (5) reactor operation experiments that include measurement of control and safety rod worths, evaluation of prototype detectors, and examination of light water contamination effects on normal reactor control.

\subsection{MATERIAL DATA, STRUCTURAL TESTS, AND ANALYSES}

Long-term successful operation of the ANS requires research in several areas to verify structural adequacy because of the extremely high neutron fluence and the high coolant flow rates. Work has focused on three primary areas: (1) CPBT, (2) fuel elements, and (3) inner control elements. Progress in each of these areas is discussed in the following sections.

\subsubsection{Core Pressure Boundary Tube}

The CPBT concept employs a double-walled primary pressure containment that is of just 
sufficient diameter to envelop the reactor core and a small bypass flow section. This allows the surrounding reflector vessel, which contains the various guide tubes and beam tubes, to operate at a relatively low pressure.

\subsubsection{Code Case for 6061-T6 Aluminum}

After careful consideration of candidate materials, 6061-T6 aluminum was selected as the reference CPBT structural material. Although it has been used in previous research reactors, 6061-T6 aluminum has not been included in the American Society of Mechanical Engineers (ASME) Boiler and Pressure Vessel Code for Class 1 nuclear construction. The project has formally requested the ASME Boiler and Pressure Vessel Code Committee to include 6061-T6 aluminum as an acceptable material for Class 1 components. That request must be considered and approved by a series of Code committees up through the Main Committee of the ASME Boiler and Pressure Vessel Code Committee.

Proposed fatigue curves, including a maximum mean stress correction and a weld knock-down factor of 0.5 , were approved by the Subgroup on Fatigue Strength (SC-D) and the Subcommittee on Design. Proposed requirements to ensure that nonductile fracture will not occur are still being considered by the Subgroup on Design (SC III).

\subsubsection{Fracture Toughness of Irradiated 6061-T6 Aluminum}

Even though aluminum alloys are less sensitive to irradiation embrittlement than conventional pressure vessel steels, the extremely high neutron flux is expecied eventually to cause significant embrittlement as aluminum nuclei are transmuted to silicon by capture of thermal neutrons.

An extensive irradiation testing program and a surveillance program are planned to determine more precisely the irradiation embrittlement of 6061-T6 aluminum. The first capsule assembly was irradiated at $95^{\circ} \mathrm{C}$ in HFIR to a thermal neutron fluence of $10^{26} \mathrm{~m}^{-2}$. Tests of 15 tensile specimens showed that irradiation increases the yield and ultimate strengths and decreases the ductility, in agreement with resuits of previous investigators.

Tests of seven $0.45 \mathrm{~T}$ compact fracture toughness specimens gave the first irradiated fracture toughness values for 6061-T6 aluminum. The initiation toughness values at 26 and $95^{\circ} \mathrm{C}$ are not greatly affected by irradiation; in fact, the toughness values are slightly higher after irradiation. This slight increase is probably an artifact of the data scatter. However, it is clear that there is no significant degradation of the toughness at these lower temperatures. This is a promising result. Further testing to higher fluences is necessary, but these results do indicate that there is not a catastrophic loss of toughness at the $10^{26} \mathrm{~m}^{-2}$ level of irradiation. At $159^{\circ} \mathrm{C}$, there is a slight decrease in the toughness.

Irradiation of a second capsule in the HFIR target facility began on October 30, 1991. It will be irradiated for 2 years to accumulate a fluence of $10^{27} \mathrm{~m}^{-2}$.

\subsubsection{Flow-Induced Instabilities}

The 5-mm flow annulus between the doublewalled CPBT has the potential to produce unstable flow-induced vibrations. A similar situation also exists in the annulus between the CPBT and the upper fuel element. The smaller the annulus, the more likely that unstable flow-induced vibrations can occur for given system and boundary conditions. A conservative set of boundary conditions and system parameters was assumed for each case, and the critical velocity was found to be 40 and $45 \mathrm{~m} / \mathrm{s}$ for the 3 - and 5-mm annuli, respectively. These values were considered to have ample margin above the operating velocity of $15 \mathrm{~m} / \mathrm{s}$.

\subsubsection{Fuel Elements}

The high-power density of the ANS makes designing the fuel elements a challenge. Each of the two elements consists of a few hundred 
1.27-mm-thick aluminum-clad urar $n$ silicide involute fuel plates held in concentric aluminum support cylinders. The involute shape allows the initial $1.27-\mathrm{mm}$ gap between fuel plates to remain relatively constant across the span of the plates even when the fuel elements heat up. Careful analysis and experiment are required to ensure that the required hydraulic forces from the high coolant velocity do not buckle the fuel plates.

\subsubsection{Fuel Element Hydraulic Buckling Analysis}

The analyses of hydraulic buckling of the involute fuel plates were extended to include the through-the-wall temperature profile as well as plastic softening of the plates. The calculated buckling velocity was $31.5 \mathrm{~m} / \mathrm{s}$ at EOC and $28.1 \mathrm{~m} / \mathrm{s}$ at BOC compared with about $45 \mathrm{~m} / \mathrm{s}$ for an isothermal elastic plate. Possible means of raising the calculated buckling velocity were investigated, and the most successful was to include a $150-\mathrm{mm}$-long unheated entrance section on the fuel elements. The cold entrance length stiffened the entrance to the fueled (i.e., heated) region and raised the calculated buckling velocity from 31.5 to $43.1 \mathrm{~m} / \mathrm{s}$. The apparent disadvantages are higher pumping pressure and the need to accommodate the additional material in the design. Entrance combs were calculated to be less effective (buckling velocity of 33.2 and $37.9 \mathrm{~m} / \mathrm{s}$, respectively, for one and two combs per channel) than the cold entrance section but, of course, would add less material and thus have less effect on core reactivity and neutron flux.

A hydraulic buckling analysis of the HFIR core incorporating plate heating and plastic behavior was also performed as a validation check on the methodology. The hot HFIR plates were calculated to buckle at $42.8 \mathrm{~m} / \mathrm{s}$ coinpared with the normal operating velocity of $10 \mathrm{~m} / \mathrm{s}$. Thus, the successful operation of HFIR is consistent with our current computational methodology.

The capability to perform nonlinear (large deflection) hydraulic buckling analyses was developed using a modification to the commercial finite-element code AB $A Q U S$ and was applied to the case of a coolant cha inel imperfection consisting of channel thicknesses that are uniform within each channel but unequal from one channel to the next. Nonlinear instability of the "snapthrough" or "oil-can" variety was predicted. Large amplitude deflections were found to reduce the plate stability somewhat. Channels having a thickness variation of nominal $\pm 10 \%$ buckled at a velocity of $41.2 \mathrm{~m} / \mathrm{s}$ compared with $44.8 \mathrm{~m} / \mathrm{s}$ for an assembly containing only perfect channels. At a velocity of $25 \mathrm{~m} / \mathrm{s}$, the maximum plate deflection produced by the fluid interaction was about $0.038 \mathrm{~mm}$ ( $1.5 \mathrm{mils})$ for $\pm 10 \%$ channels. At the onset of snap-through at $41.2 \mathrm{~m} / \mathrm{s}$, the deflection would have increased to $0.25 \mathrm{~mm}$ (10 mils). These maximum calculated deflections occur at the leading edge of the plate. (The wide channel tends to close up at the entrance.)

\subsubsection{Experimental Studies of the Structural Response of the Fuel Plates Because of Coolant Flow}

Tests have been conducted on arrays of five fuel plates for both the upper and lower fuel elements to examine their structural response to coolant flow. The tests ivere conducted on fullscale epoxy models of the fuel plates, which allowed for reduced test pressures and flow velocities compared with aluminum plates. The maximum plate deflections at the entrance, the quarter, the half, the three-quarter, and the exit cross sections were monitored on the three central plates of the arrays. In addition, the static pressures were monitored at the same axial positions in the flow channels surrounding the three central plates. The results were related to the prototype aluminum-clad aluminum/uranium silicide plates through model theory.

In general, the results showed the deflection of the plates to be related to the square of flow velocity. The plate deflections were directly proportional to the pressure difference across the plate. Calculated deflections using the dynamic pressure as the driving mechanism showed these simple calculations to be bounding (i.e., equal to or greater than the experimental values). There were 
no observed instabilities of the plates through the range of test velocities. The test velocities were taken beyond analytically calculated collapse velocities. It was found that alignment of the incoming flow with the plates was a sensitive and significant variable as related to plate deflections. Finally, at a flow velocity equivalent to $27.4 \mathrm{~m} / \mathrm{s}$, the plate deflections were all less than $9 \%$ of the channel thickness.

\subsubsection{Fuel-Plate Thermal Deflection}

Analyses were performed to estimate the maximum change in gap between plates due to temperature variations alone. Temperature distributions in a hot and a cold ANS fuel plate using preliminary temperature data were used. Analyses were performed for average temperature fuel plates to obtain the side-wall displacements. These displacements were then imposed on the hot fuel plates and the cold fuel plates, and analyses were performed to determine the change in gap between these plates. The results show that the gap between the lower hot plate and lower cold plate changes about $0.15 \mathrm{~mm}$, and the gap between the upper hot plate and upper cold plate changes $0.18 \mathrm{~mm}$.

\subsubsection{Inner Control Element}

The control elements are confined to a very small space inside the core and, as a result, have a large length-to-diameter ratio. Flow-induced vibration of these long slender cylinders is a concern because of the large unsupported length immersed in a turbulent flow and is being investigated.

Major modifications were made to the inner control element system design. The main change involved moving of the axial scram springs out of the core region into the lower portion of the reactor. This improved longevity of the springs by removing them from the high flux region and also placed the element in tension rather than compression during the scram accelerations, eliminating the buckling problems during the highscram accels ration. There is still a possible buckling problem during the deceleration phase of the scram, so one set of springs and damper was analyzed and shown to meet the current scram requirements on stroke and response time without buckling. The upper support to each element was fixed in space rather than built into the element.

Each of these changes increased the control element overall length-to-diameter ratio. Consequently, flow-induced vibration of these long slender cylinders is an even greater concern than before.

Analyses of the new CDR configuration indicate that the fundamental and higher frequency modes are lower than those for the old baseline configuration of last year. Added clearance on the top portion of the elements does minimize the possibility of unstable vibrations because of flow through a narrow annulus. However, the subcritical flow-induced vibrations are predicted to be large enough to cause possible contact and wear.

Analytical efforts have been concentrated on an accurate representation of the structural coupling between the elements. Study of these results has suggested several modifications that are being investigated, and a full 3-D analysis to include the fluid coupling is planned to evaluate them. Full-scale response tests are planned in the Control Element Test Facility (CETF) to verify that the flow-induced vibrations are within acceptable criteria. Preliminary scoping of the major elements of CETF, such as the pump and the heat exchanger, has been completed for the current (CDR) flow requirements of the inner control elements.

\subsection{COLD SOURCE DEVELOPMENT}

Some recommendations made by the cold source review committee (in a letter report in September 1991) have already been turned into engineering concepts, while others are still under consideration. This report covers progress in general design and supportive activities. 


\subsubsection{Cold Source Neutronics}

A horizontal cold source configuration was chosen, increasing the calculated cold neutron flux entering the guide tubes while also reducing the heat load. The boiling liquid concept was replaced with a subcooled pumped liquid system, further increasing the calculated cold neutron flux. Overall, calculations indicated the cold neutron current in the guides would be increased by $21 \%$ and the head load reduced by $25 \%$ - a major advance. Also, data from an INEL model of the ILL has been used in comparative calculations of the ANS and ILL cold source performance.

\subsubsection{Thermal Modeling}

The University of Virginia has developed a computer code to predict single- and two-phase flow behavior in the cold source system. On completion, this benchmarked code will be applied to the heat transfer mechanisms prevailing during cooldown and also to those within the cryostat during normal operation.

\subsubsection{Cold Source Mechanical Modeling}

A conceptual flow diagram of the system is shown in Fig. 2.8. A redundant pump is included to improve reliability, and both pumps have isolation valves to allow replacement without the need to interrupt operation of the cold loop. The circuit is configured to allow minimum cold source vessel temperatures without any risk of freezing. The flow rate, at $6.5 \mathrm{~L} / \mathrm{s}$, results in a temperature difference of about $4 \mathrm{~K}$ across the cold source for an anticipated heat load of $30 \mathrm{~kW}$. The liquid pressure is controlled at $0.4 \mathrm{MPa}$ to allow an operational temperature window for the loop of 18.7 to $29 \mathrm{~K}$, the freezing and boiling points of deuterium. Figures 2.9 and 2.10 show the second and third floors of the reactor building with connecting transfer lines enclosed in the concrete shielding. This affords protection for the lines themselves and allows clearance for the building cranes. The layout is designed to provide simplified filling of the loop, the pumps being required only when the system is full of saturated liquid, thereby avoiding any priming problems associated with two-phase flow. The deuterium loop operates as a closed system by means of a $30-\mathrm{m}^{3}$ expansion tank that contains the larger part of the $19-\mathrm{kg}$ inventory under ambient temperature conditions. Pressure in the system is then at a uniform $0.4 \mathrm{MPa}$, but under cold running conditions the tank pressure falls to $0.1 \mathrm{MPa}$ while the liquid pressure remains at $0.4 \mathrm{MPa}$ under the action of a diap' iragm pump and a pressure balancing system. A check valve in the return leg to the expansion tank ensures that the system is always in a fail-safe mode. The entire system concept will be subjected to major safety reviews as the cold source development process continues.

\subsection{BEAM TUBE, GUIDE, AND INSTRUMENT DEVELOPMENT}

The major effort during the past year has been directed toward finalizing design concepts for beam transport and instruments and completing the system design descriptions for the CDR. (See Sect. 3.4 for detailed layouts and Sect. 3.6 for integration with other plant systems, particularly instrumentation and control networks.) Much of the work concentrated on beam optics, and ANS and NIST cosponsored a symposium on Neutron Optical Devices and Applications at the SPIE 1992 International Symposium on Optical Applied Science and Engineering, which was held in San Diego on July 19-24, 1992. Forty-one papers from scientists in nine countries were presented. Collaborations with several external groups helped develop the design concepts for nuclear and fundamental physics instruments (Tennessee Technological University), beam transport (BNL, Ovonic Synthetic Materials Company), ultracold neutron production (University of Rhode Island), and positron production (AT\&T Bell Laboratories). Figure 2.11 shows an artist's impression of the main beam room with shielding around the instruments removed for clarity (see 


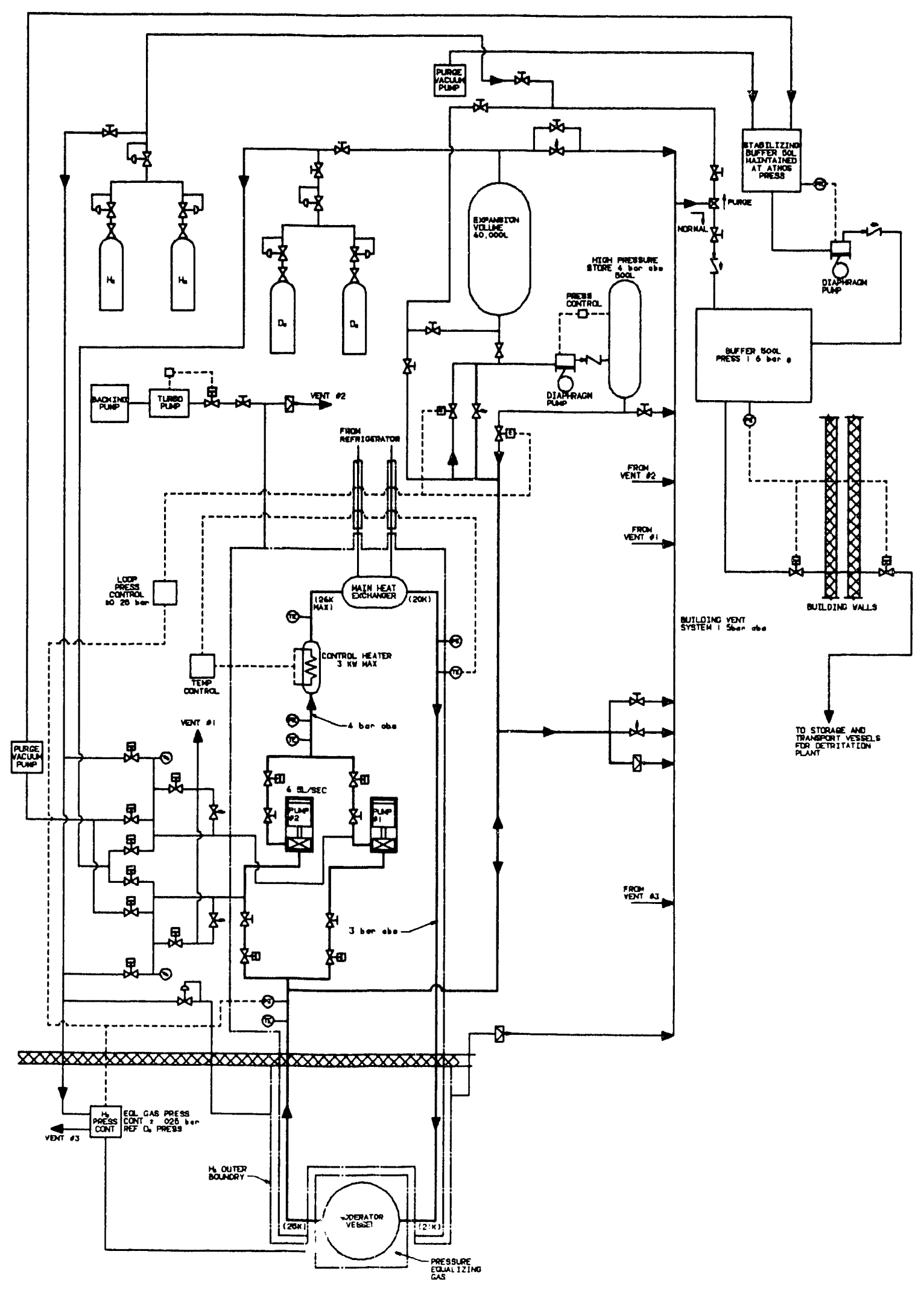

Fig. 2.8. Conceptual flow diagram.

22 Advanced Neutron Source (ANS) Progress Report 


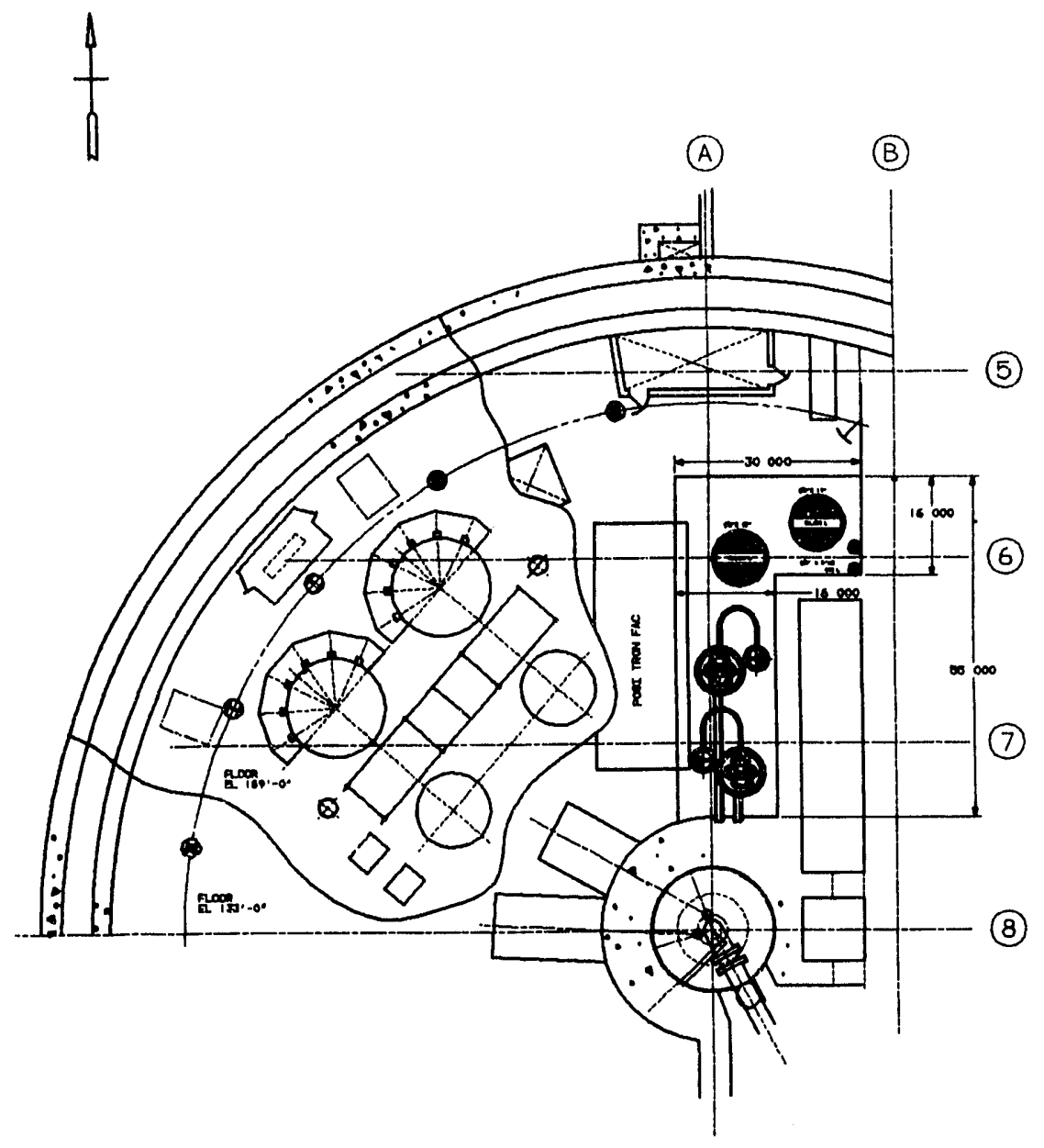

Fig. 2.9. Plan view of the cold source main live equipment.

Sect. 2.9.3); note the use of thermal guides to move certain instruments away from the biological shield to give better angular access.

\subsubsection{Evaluation of Fast Neutron and Gamma Filters for the Straight Neutron Guides}

Centers such as Saclay and ILL use curved neutron guides as fast neutron and gamma filters on cold neutron beams. These work by only transmitting wavelengths above a critical wavelength, which is a function of the guide curvature and the mirror material, with the transmitted wavelengths being bent away from the direct line-of-sight and thus away from the unwanted radiation. Curved guides have two main disadvantages. First, the minimum length $L$ and radius of curvature $R$ of the guide are determined once the critical wavelength $\lambda^{*}$ and width $d$ have been chosen: $L=(8 d R)^{1 / 2}$ where $R=2 d /\left(\gamma^{*}\right)^{2}$. Here, the characteristic angle of the guide is given by $\gamma^{*} K \lambda^{*}=L / 2 R$, where $K$ is a constant for a given mirror material. This means that, for a given filter characteristic, the width cannot be chosen independently of the length. Second, the divergence entering the guide is not preserved during neutron transport. Regardless of incident 


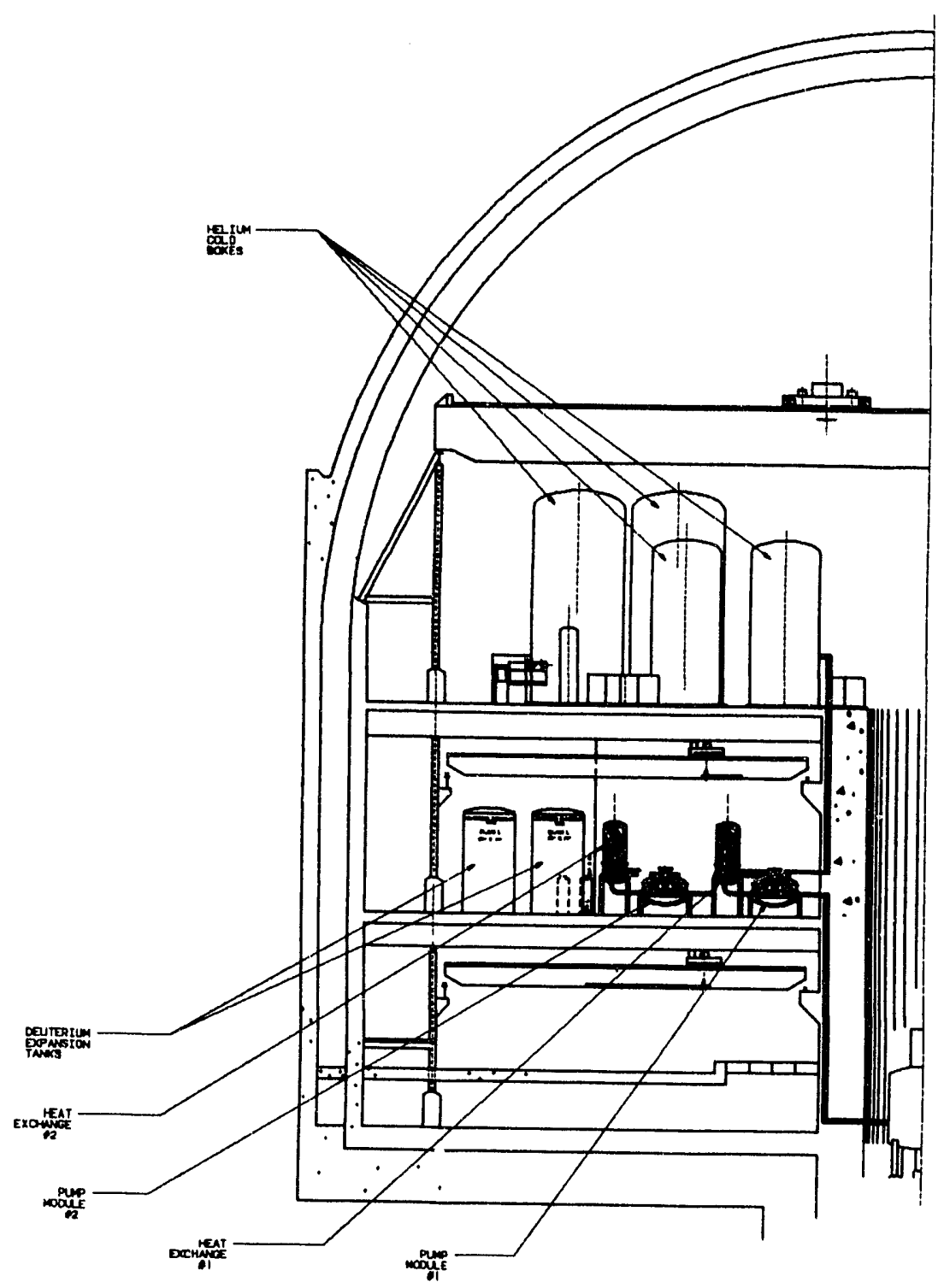

Fig. 2.10. Elevation showing $D_{2}$ equipment on seiond floor and refrigerator cold boxes on third floor.

divergence, the final divergence leaving a curved guide at wavelength $\lambda$ is $2 K \lambda$, so that a parallel beam will emerge as a divergent beam. At long wavelengths, when the critical angle exceeds the incident illumination divergence, the divergence will also be increased during beam transport. For these reasons, we have based the ANS cold neutron transport system on straight guides, which allow the width to remain independent of the length and which preserve the initial divergence. In cases whtre the presence of fast neutron or gamma contamination is critical, a study of new materials that could act as transmission filters is in progress.

We have also begun to assess the possibility of using an angled arrangement of straight guides as a filter. Conceptually, this is equivalent to a crude polygonal approximation to a curved guide, but it has the nice property, when correctly configured, of transmitting a parallel beam with unchanged divergence because only a reflection from a flat mirror is involved. The reflected beam merely changes direction, whereas unwanted radiation 


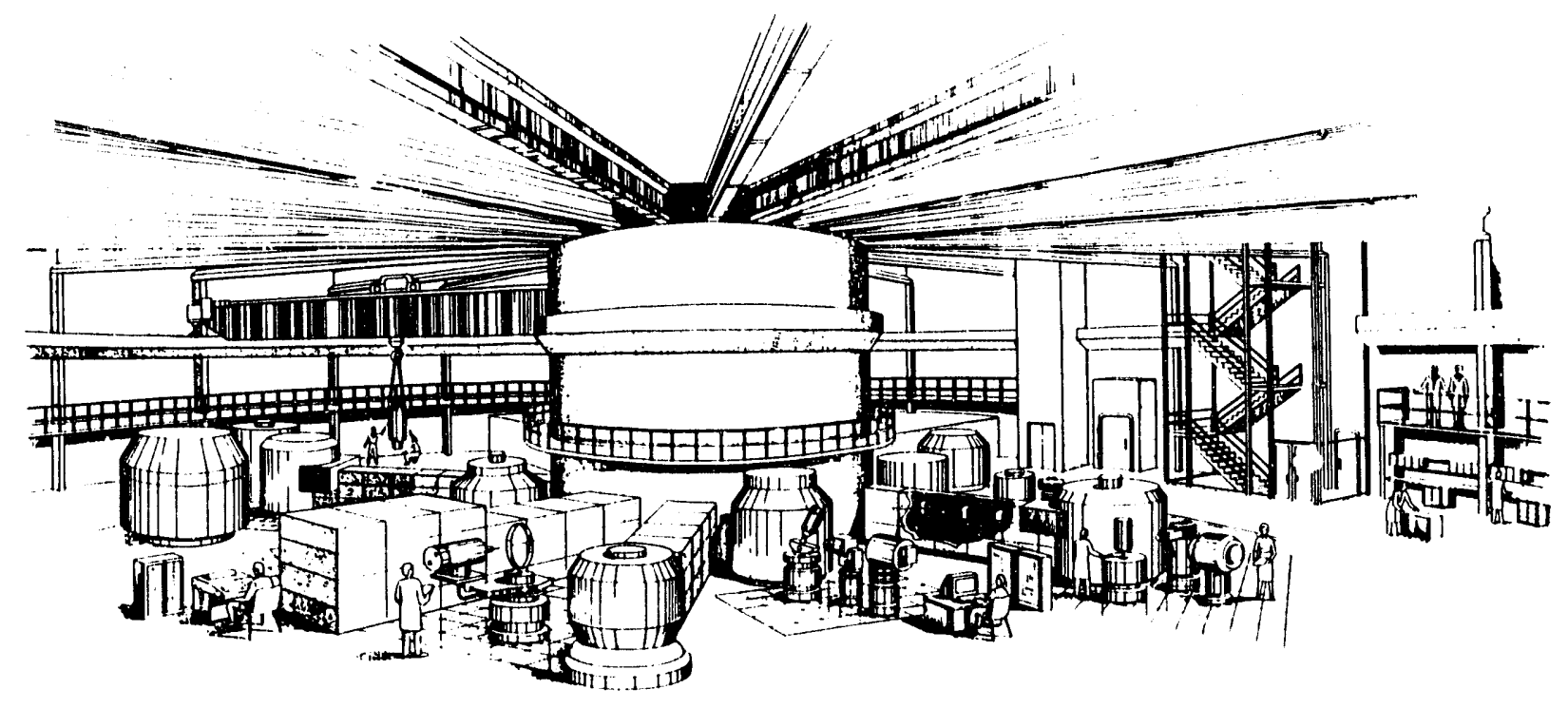

Fig. 2.11. Artist's impression of the ground foor beam room.

will be transmitted in the original direction and separated from the desired beam. Such a device has been made possible by the successful fabrication of supermirrors with high reflectivity to angles at least twice as high as the critical angle for $\mathrm{Ni}$ guides. Figure 2.12 shows a possible arrangement. A length of supermirror (SM) guide is placed at an angle $\gamma$, to the initial $\mathrm{Ni}$ guide, then followed by the continuation of the $\mathrm{Ni}$ guide turned through a further angle $\gamma$, so that the final beam is at an angle $2 \gamma$ to the initial beam. Fast neutrons and gammas continue in the forward direction and are stopped by appropriate shielding. For a Ni guide of width $d$, the SM geometry is given by

$$
\begin{aligned}
& L_{1}=L_{2}-2 d \sin \gamma, \\
& L_{2}=d / \sin \gamma . \\
& a=d \cos \gamma .
\end{aligned}
$$

A practical choice for $\gamma$ is the critical angle for $\mathrm{Ni}$ at the minimum wavelength of interest. If the latter is $0.2 \mathrm{~nm}, \gamma=0.2$ degs., $L_{1}=14.323 \mathrm{~m}$, $L_{2}=14.324 \mathrm{~m}$, and $a=50 \mathrm{~mm}$ for an initial guide width $d=50 \mathrm{~mm}$. Monte Carlo simulations have shown that the performance of such a filter can be at least as good as a curved guide without the attendant disadvantages, and this elegant approach looks very promising.

\subsubsection{Revised Very Cold Neutron/Ultracold Neutron Installations at the Horizontal Cold Source}

The University of Rhode Island physics group of Prof. A. Steyerl has started work on evaluation of ultracold neutron (UCN) production methods for the ANS. They have identified a possible fabrication problem associated with polishing the surface of the curved cylindrical very cold neutron (VCN) guide proposed in the current ANS conceptual design and have suggested a solution to the problem. They have also found a new way to feed VCN into the UCN turbine that reduces the size of the installation, both in length and in height. Figure 2.13 shows two variations of the new concept.

\subsubsection{ALARA Considerations at Instruments}

Monochromatic beam intensities at sample positions will be about $10^{12} \mathrm{~m}^{-2} \cdot \mathrm{s}^{-1}$ on ANS instruments. Although the beam may be contained, a typical sample/cryostat combination scatters $10 \%$ of the beam and may absorb about $5 \%$, 


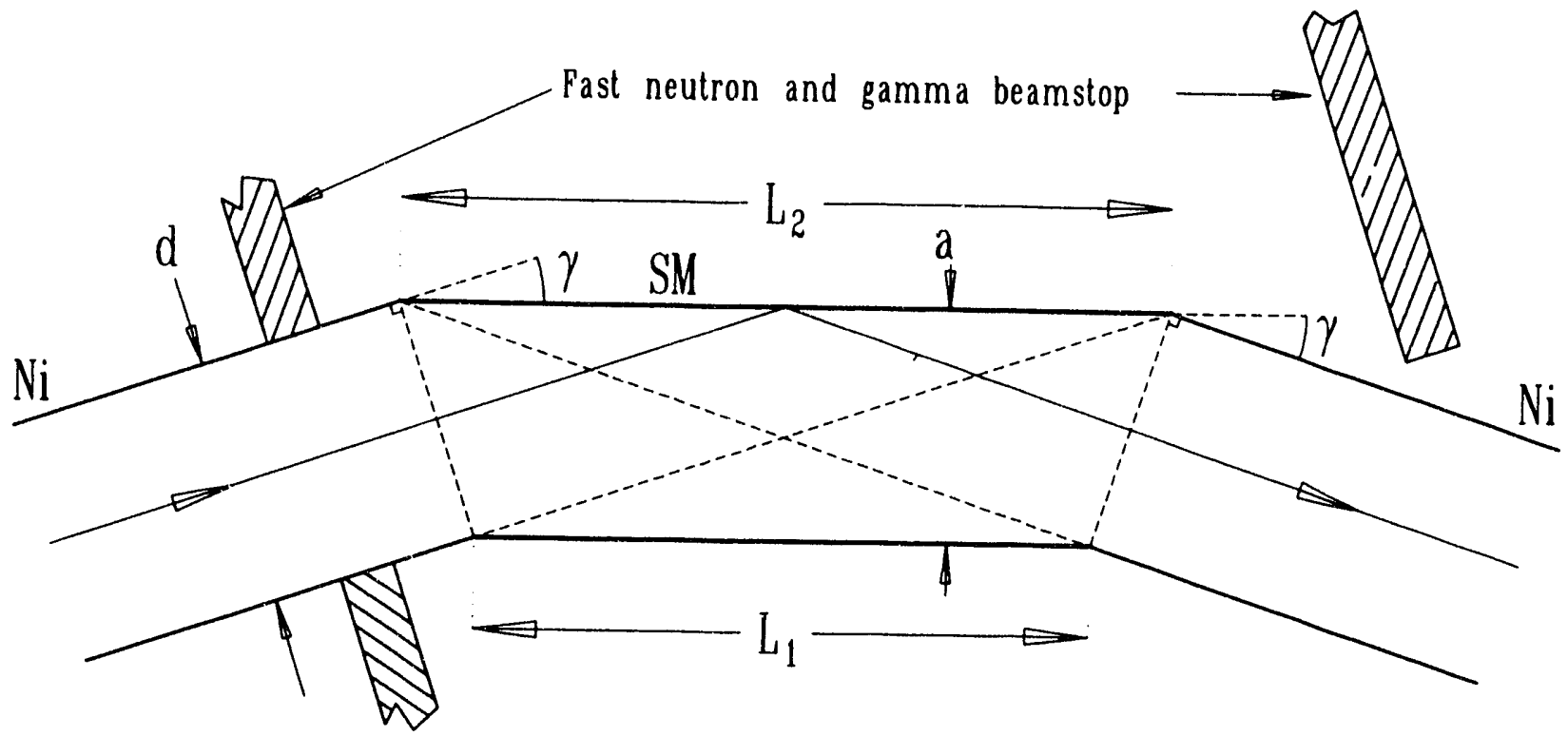

Fig. 2.12. Supermirror filter between straight guide sections.
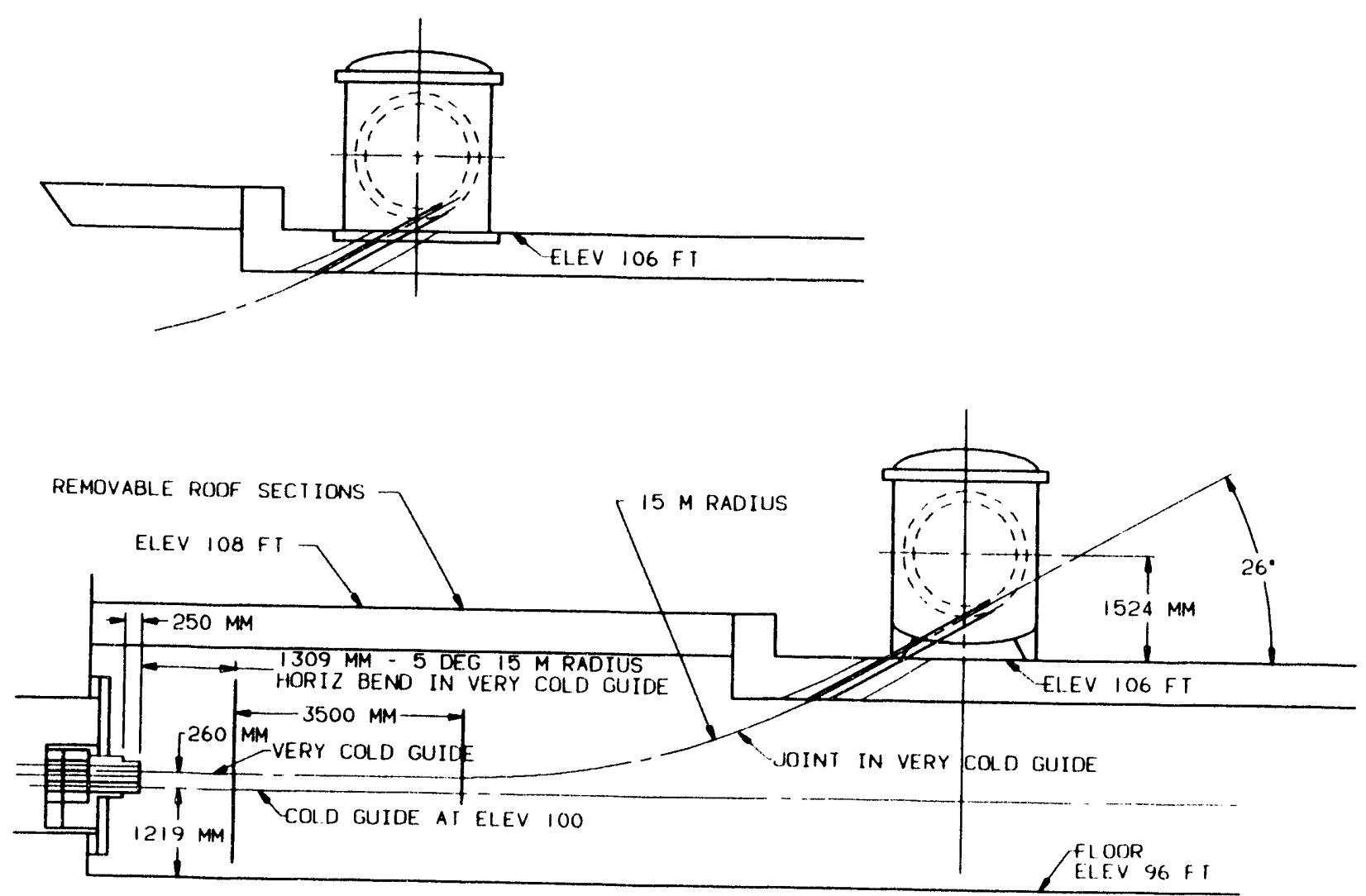

Fig. 2.13. Possible arrangements of the UCN turbine at a horizontal cold source.

26 Advanced Neutron Source (ANS) Progress Report 
creating undesirable neutron and gamma radiation fields around the sample position. A conservative estimate of the associated dose rates gives

D $\gamma=710 \mu \mathrm{Sv} \cdot \mathrm{h}^{-1}\left(71 \mathrm{mrem} \cdot \mathrm{h}^{-1}\right)$ and $D_{n}=330 \mu \mathrm{Sv} \cdot \mathrm{h}^{-1}\left(33 \mathrm{mrem} \cdot \mathrm{h}^{-1}\right)$ at $300 \mathrm{~mm}(1 \mathrm{ft})$ from the sample. The current administrative total dose limit is $D=25 \mu \mathrm{Sv} \cdot \mathrm{h}^{-1}\left(2.5 \mathrm{mrem} \cdot \mathrm{h}^{-1}\right)$. The future total dose limit is likely to be $10 \mu \mathrm{Sv} \cdot \mathrm{h}^{-1}$ $\left(1.0 \mathrm{mrem} \cdot \mathrm{h}^{-1}\right)$, and the Q-factor (Sv/Gy) for neutrons may also double, so that the estimated neutron dose becomes $660 \mu \mathrm{Sv} \cdot \mathrm{h}^{-1}(66 \mathrm{mrem}$. $\left.\mathrm{h}^{-1}\right)$, and the new total dose would become $710+660=1370 \mu \mathrm{Sv} \cdot \mathrm{h}^{-1}$ at $300 \mathrm{~mm}$. If we use only distance to protect users, they must be kept at least $3.5 \mathrm{~m}$ away to meet a $10 \mu \mathrm{Sv} \cdot \mathrm{h}^{-1}$ limit. Instrument layouts have been developed that incorporate barriers with beam interlocks to ensure that users are at a safe distance when the beam is on. There will also be shielding at the sample, so that levels at the barriers will actually be well below the acceptable limits.

\subsection{HOT SOURCE DEVELOPMENT}

Initial neutronics analyses of the ANS hot source design have been undertaken using the MCNP code. Preliminary calculations showed that the heating rate for the baseline design in the CDR was too low to meet the moderator temperature goal of $2000^{\circ} \mathrm{C}$. A modified design is being developed with the moderator moved from $1450 \mathrm{~mm}$ to $1000 \mathrm{~mm}$ from the core centerline. The new hot source is modeled as a $137.5-\mathrm{mm}$ radius sphere surrounded by two Zircaloy- 4 containment spheres and encased in a doublewalled Al-6061 thimble. The region inside the thimble is filled with helium gas, and the region between the thimble walls is filled with heavy water.

Several cases have been run to determine the heat loads and the neutron beam currents and spectrum for the new hot source model. Graphite with a graphite-felt insulation (ILL hot source materials) was the first arrangement considered. However, the heat load calculated $(0.34 \mathrm{w} / \mathrm{g})$ for this configuration was also determined to be too low to provide the moderator temperature design goal of $2000^{\circ} \mathrm{C}$. This led to the examination of other moderator and insulation materials.

Evaluations of zirconium carbide indicated that this material would provide a much larger heat load $(0.61 \mathrm{w} / \mathrm{g})$ that, when coupled with its higher density, would be expected to produce moderator temperatures well above the design goal.

However, the neutron energy transfer process was substantially less efficient, resulting in spectrum shifts that were less than desired. Near the end of the report period, it was determined that an improved carbon-bonded carbon-fiber insulation and/or the use of a hybrid graphite/zirconium carbide moderator could be used to meet the design goals.

\subsection{NEUTRON TRANSPORT AND SHIELDING}

\subsubsection{Preliminary Radial Shield Evaluation}

Using a source from previous two-dimensional (2-D) transport calculations of the near-core geometry, a one-dimensional (1-D) geometry through the radial concrete biological shield was used to estimate the effectiveness of the radial shield, including the effects of varying amounts of rebar in the concrete. Neutron and gamma-ray heating rates were also obtained from these calculations. As expected, the neutron dose rate was well below the desired $0.25 \mathrm{mrem} / \mathrm{h}$ in all cases, but the gamma-ray dose rate with no rebar was approximately two orders of magnitude too high. A rebar content of $10 \%$ resulted in an acceptable gamma-ray dose rate on the beam room surface of the radial shield.

\subsubsection{Preliminary Evaluation Of Stack Streaming}

In a manner similar to the radial shield evaluation, a 1-D geometry was used to estimate 
the streaming in the upper axial area through the stack to the refueling tunnel. The stack is approximately $1.4 \mathrm{~m}$ in diameter, contains $\mathrm{D}_{2} \mathrm{O}$, and is surrounded by $\mathrm{H}_{2} \mathrm{O}$. The 1-D cases overestimated the transmission through the stack because they did not account for the transverse leakage from the stack into the $\mathrm{H}_{2} \mathrm{O}$. Nevertheless, these calculations showed that a simple shield plug made of a combination of lead and cadmium would be sufficient to reduce the neutron and gamma-ray dose rates to acceptable levels in the refueling area.

\subsubsection{Guide Tube Tunnel Analysis}

An extensive series of 2-D calculations was completed to determine the neutron and gammaray dose rates above the concrete roof section of the guide tube tunnel because of the leakage of the beam from the thermal guide tube. The first calculations indicated a significant problem, but the resulting investigation determined that the source had been improperly calculated. The source calculation is being corrected, and the guide tube calculations will be repeated with the new source. In the interim, adjoint calculations through the guide tube tunnel geometry have been completed to determine the energy-dependent importance of the source contributing to the dose at the area of interest above the concrete roof of the tunnel. Figure 2.14 shows the result of those adjoint calculations. The three histograms in the figure show the energy-dependent relative importance of neutrons and gamma rays at the source location contributing to the neutron and gamma-ray dose rates above the concrete roof of the guide tube tunnel. The histogram label NEUTRON TO GAMMA

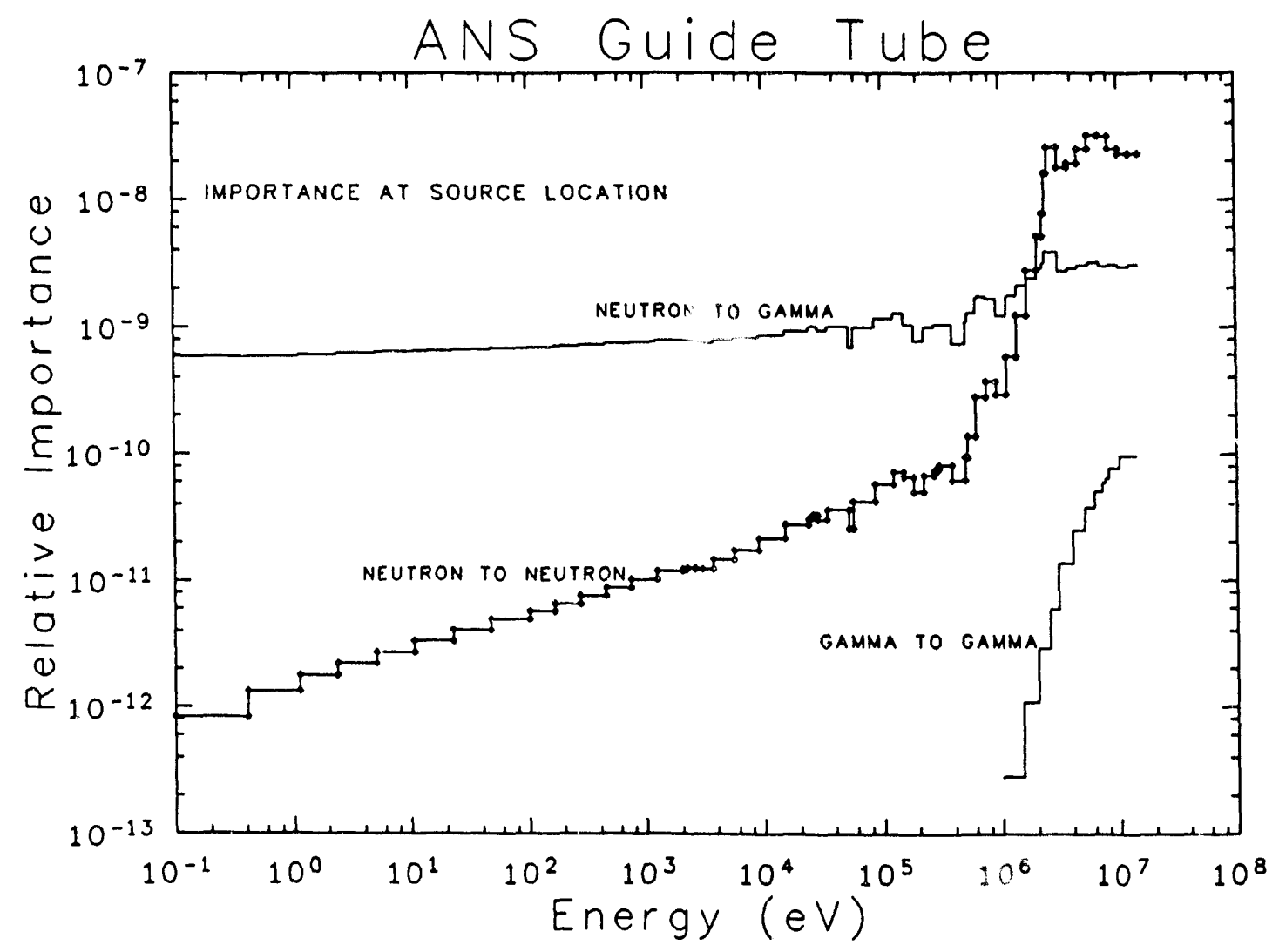

Fig. 2.14. Importance of source particles contributing to neutron and gamma-ray dose. 
refers to the importance of source neutrons contributing to the gamma-ray dose rate.

Similarly, the labels HEUTRON TO NEUTRON and GAMMA TO GAMMA refer to the importance of source neutrons contributing to the neutron dose rate and to the imporiance of source gamma rays contributing to the gamma-ray dose rate, respectively. These data will be used to determine the response dose of the corrected source relative to the source used in the previously completed calculations.

\subsection{I\&C RESEARCH AND DEVELOPMENT}

\subsubsection{Dynamic Modeling}

The ANS dynamic model has been upgraded continuously to represent the late:t reference design, and it has been used to help define requirements for control and plant protection system components. Among other applications, the model was used to simulate the 13 reactivity events that have been postulated in the CSAR and to calculate their consequences. Results of these analyses indicated that the ANS reference design should survive all the postulated events as long as the primary shutdown system is available.

Simulations that included failure of the primary system to scram indicatec that the ANS core should survive all anticipated transients-withoutscram, but core failures cannot be precluded under all these conditions for some unlikely or extremely unlikely events, such as the instantaneous flooding of multiple-beam tubes.

Figure 2.15 shows some details of the plant protection system response to the most limiting reactivity event postulated in the CSAR (a \$0.8 step). As can be observed, the present design of the hydraulic latci used for the outer rods is significantly slower ihan the inner rod latch and, in

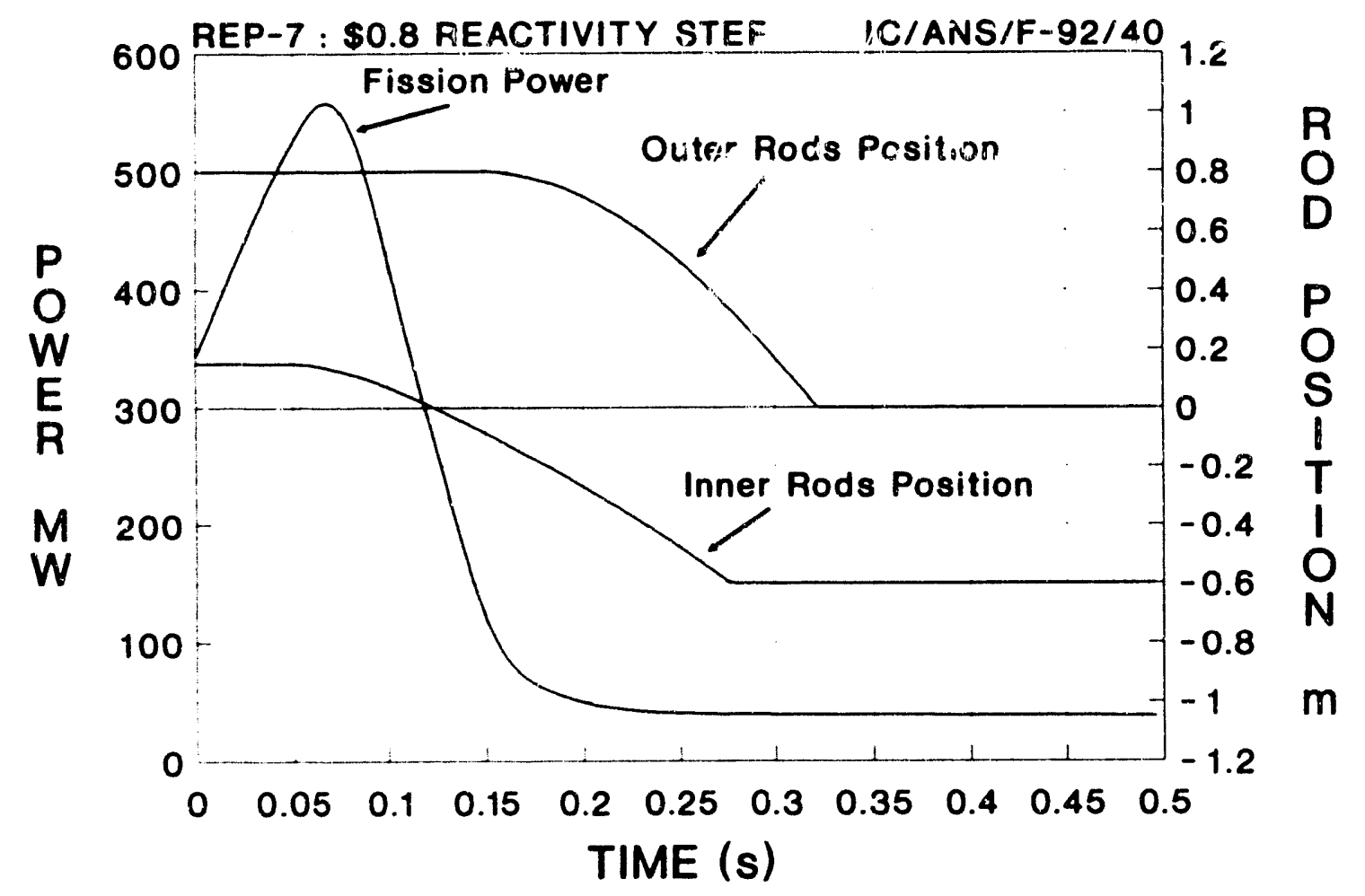

Fig. 2.15. Simulation of a $\$ 0.8$ reactivity step (largest postulated reostivity event). The inner control rods reduce total fission power to safe levels before the outer rods initiate movement. 
fact. by the time the outer rods start movement (about $150 \mathrm{~ms}$ into the transient), the inner rods have already essentially terminated all fission power. Within 200 to $250 \mathrm{~ms}$, the fission power is down to decay heat plus some residual delayed neutron activity. All specified acceptable fuel design limits are satisfied during this transient.

\subsubsection{Use of Application-Specific Integrated Circuits for Reactor Protection}

Implementing reactor protection systems (RPSs) or other engineered safeguard systems with applicat un-specific integrated circuits (ASICs) offers significant advantages over conventional analog or software-based RPSs. Conventional analog RPSs suffer from set-point drift (the most common licensee event report category for light water reactors) and from large numbers of discrete analog electronics, hardware logic, and relays that reduce reliability. Mandatory drift and accuracy testing of analog protection systems is a difficult and time-consuming task that sometimes results in spurious trips. Proposed use of software-based systems composed of multiply redundant orogrammable controllers can achieve zero set-point drift by keeping set points as digital values, digitizing input variables from sensors, and computing to determine protection actions. However, while these progrunmable systems show tremendous desig' advantages and excellent accuracy and drift characteristics over standard analog systems, software-based protection systems are virtually impcssisible to verify and validate against design specifications, regardless of the rigor used in software design. The potential of inadvertently changing program functions with any program change makes the software system almost impossible to verify as a whole. Additionally, the sequential nature of software-based protection system operations on variables can result in subtle error conditions caused by out-of-order evaluation or time-dependent computation of system variables that are difficult to detect by testing.

To resolve problems associated with conventional analog and software-based systems, a hybrid analog and digital system implemented with custom ASICs is being considered. The actual design of the ASIC RPS resembles a software-based one, but the programmable software portion of each channel, including any input variable computations, is implemented in a fixed digital logic design. Set-point drifts are zero, as in software systems, but the verification and validation of the computations is made easier because the computational logic can be exhaustively tested, and the functions are known to be fixed because there can be no such changes to the system without refabrication of the ASIC. Moreover, because the design and test inputs and outputs are maintained, changes can be made and tested reliably. Subtle errors caused by out-oforder evaluation or time-dependent evaluation of system variables are eliminated by implementing all evaluation computations in parallel for simultaneous results. This also provides the added speed of response required by the ANS reactor. The use of ASICs to implement channel electronics rather than the use of discrete electronics reduces the total number of components and interconnections to increase reliability further. The most important advantages are low drift, high accuracy, extensive on-line monitoring, and simplified calibration. These advantages, along vith the capability to achieve high reliability, make ASICs worth considering in safety systems.

The ANS may benefit from the use of ASICs in several ways. Most important, existing commercial RPSs do not meet the response time requirement for the ANS, but ASICs can meet them. An ASIC system can provide both design and hardware redundancy between the primary and secondary shutdown systems. A significant advantage is the computer-like communications capability of ASICs. A test-and-monitor circuit can be built into the circuit such that it can monitor all of the parameters and their intermediate values. This circuit can detect and alarm component failures and can monitor functional tests performed by the operators. The test-and-monitor circuits will not affect operation of circuits performing safety functions, but they can 
communicate to computers to record RPS performance of the safety circuits. A prototype protection system is planned as part of the $R \& D$ program for the ANS, but typical ASICs will be developed prior to the prototype to evaluate the viability of ASICs. A diagram of an ASIC with an on-line test and monitor circuit is shown in Fig. 2.16.

\subsubsection{Control System Features}

The control system consists of a hierarchy of local and distributed controllers to coordinate the start-up and operation of the reactor and its cooling systems. The basic control functions are listed in Table 2.3. A principal objective of the ANS operations is to maintain the reactor continuously at the highest power level that is consistent with safety and the available coolant flow. Hence, reactor power control is at the top of the hierarchy.

Reactor start-up is accomplished by first withdrawing the outer shutdown rods, then withdrawing the inner shim/safety rods under period control to determine the start-up rate. When sensible heat power is reached, control is turned over to the power-level controller, which uses the servo-controlled regulating rod motion to adjust reactivity to maintain the desired power. The regulating motion is fast-acting to accomplish smooth and accurate power regulation but has limited worth to minimize failure consequences. In the power range, the shim motion of the inner rods is used to compensate for larger reactivity changes brought about by fuel burnup, temperature coefficients, and xenon. Shim motion typically is manually controlled but can be automatic under the supervision of a reactivity computer. In addition to its normal control and regulating functions, the reactor contro! system includes contingency features to limit undesirable operation ouiside the control envelope. "Setback" is a programmed reduction in power demand to the power-level controller. "Reverse" is the forced insertion of shim rods until the initiation condition is cleared. These features are used to reduce power quickly to a safe level and to avert the need for safety action in response to certain off-normal conditions such as reduced flow, reactivity

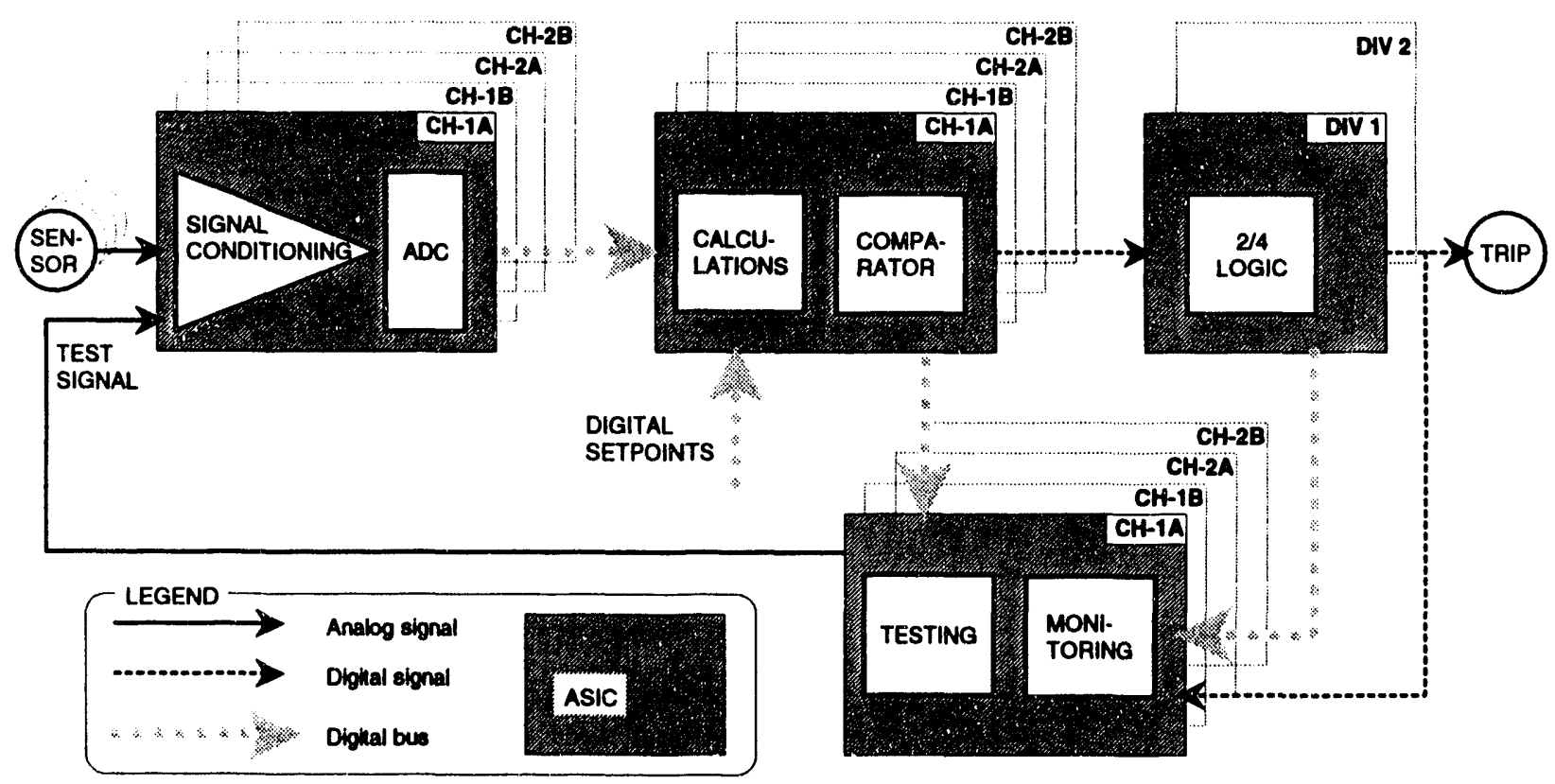

Fig. 2.16. Possible ASIC implementation of a reactor protection system. 
Table 2.3. Control parameters important for start-up and normal operation

Reactor start-up control

Control reactor period by adjusting shim rod position

Reverse shim rods if period becomes too short < set point

Reactor power level control

Control neutron flux to demand by adjustment of reactivity - regulating and shim rods

Continuously calibrate neutron flux with computed heat power - flow $\times$ delta temperature

Inhibit or reverse too-high flux rates

reactivity perturbations

Set back power demand for flux-to-flow ratio $>$ set point

pump trip

loop isolation

reflector pump trip or loop isolation (high reflector outlet temperature)

Fast reverse of shim rods (air motor) for too-high flux-to-flow ratio $>$ set point

Primary coolant inlet temperature control

Regulate reactor inlet temperature by adjusting secondary flow with secondary pump speed

Set back power if inlet temperature or heat power is out of control-range high

Trip primary pump if secondary pump trips or loop isolates

Prin y coolant pressure control

Regulate pressure by adjusting letdown flow with control valves

Control net letdown flow by adjusting charging pump speed

Trip primary pump if primary pressure < set point (safety)

Secondary temperature control

Regulate off-tower water temperature by adjusting number and speed of tower fans

For large power reductions, bypass secondary flow to tower basin with bypass valves

Reflector temperature control

Control reflector inlet temperature by adjusting secondary reflector heat exchanger (RHX) flow valve

Secondary flow changes for reactor inlet temperature adjustment will interact with RHX secondary flow

Loop isolation

Isolate secondary coolant if radioactivity is detected in secondary coolant (safety)

Interlocks

Limit loop isolation with interlocks to ensure that at least two loops are available

Prevent withdrawal of inner rods unless outer rods are all fully withdrawn

Prevent withdrawal of outer rods unless inner rods are all fully inserted

perturbations, or temperature anomalies. "Fast Reverse" utilizes unidirectional air turbines to insert the shim rods very rapidly to maintain satisfactory flux-to-flow ratio when large flow decreases are encountered, such as tripping the primary coolant pumps. By avoiding scram for a number of events, the ability to restore normal operating conditions is enhanced, and plant availability, as well as safety, is improved.

The heat removal system functions to cool the reactor and to maintain the coolant inlet temperature within design limits for any power

\section{Advanced Neutron Source (ANS) Progress Report}


level within the operating range. The cooling system follows the power-level control in the hierarchy.

\subsection{FACILITY CONCEPTS}

Work on the Reactor Components Test Facility was initiated midway through the year.

The primary effort has been to refine the objectives of the task and to establish functional requirements. The current design allows the facility to progress from screening type testing of seal configurations to more sophisticated development testing of seals and other reactor components in simulated operating environments.

The initial testing of the seal configurations will be performed in a vessel that is also designed for future development work on the hydraulically operated shutdown rods and the associated valves. The water system and data acquisition systems are designed to have the flexibility to grow as the development of the components progress.

Figure 2.17 shows a block diagram of the component systems that this facility is being designed to evaluate.

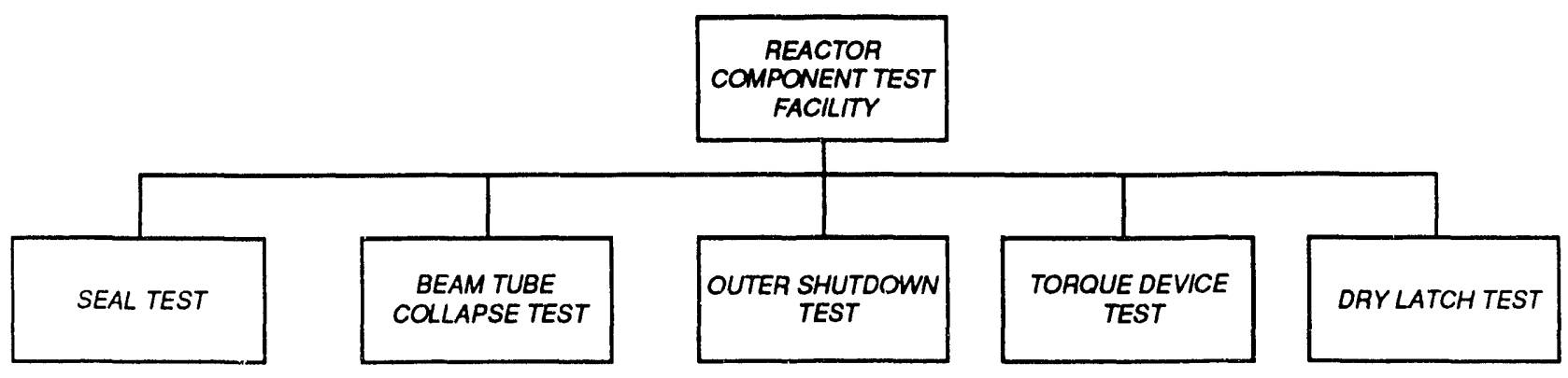

Fig. 2.17. Block diagram of component systems. 


\section{DESIGN

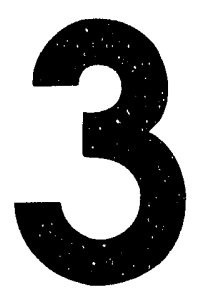

\subsection{SYSTEMS INTEGRATION}

\subsubsection{Project Documentation}

Documentation is a primary means of controlling technical, programmatic, and administrative requirements for the ANS Project. Table 10.1 of the Project Management Plan ${ }^{26}$ (PMP) lists the major ANS technical documentation and indicates the schedule for baselining and configuration control. The document tree shown in Fig. 3.1 shows the hierarchy of the key documents listed in that table.

As shown in Fig. 3.1, the PMP is the top-level document for the project. It identifies the ANS Project's technical, cost, and schedule objectives; management organizations and responsibilities; work breakdown structure (WBS); schedule and cost estimate summaries; project management, measurement, and planning and control systems; documentation and reporting requirements; systems engineering and configuration management; and quality assurance.

The documents shown below the PMP can be characterized as administrative, programmatic, or technical. Administrative documents govern the baseline scope, schedule, and budget and are integrated at the program level to control and monitor cost, schedule, and performance of all participants. These include the ANS Procedures Manual, ${ }^{27}$ the Cost and Schedule Document, ${ }^{28}$ and project reports. The project reports include a monthly status report, a monthly technical information report, and technical reports that document special topical items.

Programmatic documents include the PMP, the Quality Assurance Plan, ${ }^{2}$ the Systems Engineering Management Plan $^{29}$ (SEMP), lower-level plans that augment the SEMP, and reference documents. These provide basic programmatic requirements and indicate how engineering-related efforts and disciplines such as safety, reliability, and configuration control will be intermeshed and controlled within the project.

Technical documents specify requirements for system performance and for design and testing, and control technical changes that affect overall project cost, schedule, or performance. They include the PDR document, safety and certification documents, the Integrating System Design Descriptions (ISDDs), ${ }^{30}$ and the System Design Descriptions (SDDs). ${ }^{31}$

The PDR provides the overall design requirements for the project and is now about 450 pages long. The SDD documents govern the design of all hardware systems. Chapter I of each SDD provides the requirements for the system, and Chap. 2 provides a description of the system with a focus on how the selected concepts meet the requirements. Chapters 3 through 6 will cover operations, casualty events, system limitations and set points, and maintenance.

In some cases, a key function is performed by a combination of systems. The ISDDs define the requirements for accomplishing such functions and assign the requirements to SDDs. The ISDDs do 


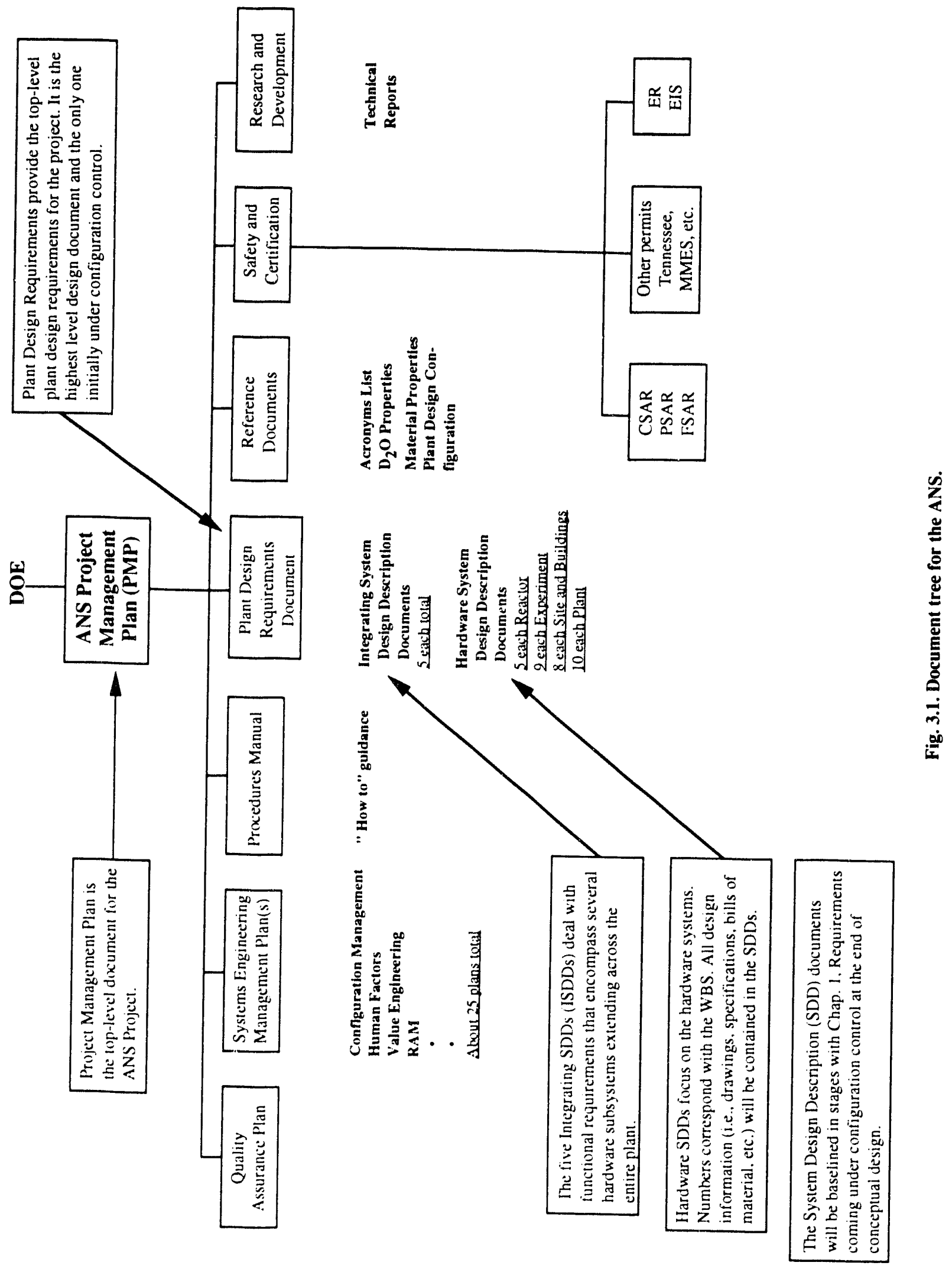

36 Advanced Neutron Source (ANS) Progress Report 
not directly cover the design and construction of any hardware items because these functions are controlled by the SDDs. Any given SDD may receive requirements from any or all of the five ISDDs. All of the SDDs receive requirements from the PDR.

\subsubsection{Project Planning}

A revised project schedule was produced as part of the conceptual design effort. Major schedule objectives for the CDR are to

1. Complete the conceptual design reportFY 1992.

2. Complete Title I design-3d quarter FY 1995.

3. Initiate construction activities-3d quarter FY 1996.

4. Complete Title II design-4th quarter FY 1999.

5. Complete construction-3d quarter FY 2001.

6. Complete project - 4th quarter FY 2002.

The project is defined to be complete upon achieving benchmark measurements of neutron source intensity and neutron transport system performance as defined in the PMP.

\subsubsection{Operations}

Preparation of the operating philosophy document began as part of the human factors engineering effort in the project. Personnel from various areas of HFIR operations were interviewed to gain pertinent information about problems comm nly encountered there. Representatives of different specialties from the ANS design team were also contacted to gain insight into issues that might need to be studied further and/or clarified, as well as to document the philosophy behind many of the design decisions being made.

This work included modifications to the original WBS, and the operations-related cost estimates were developed based upon the new work organization. Information from the ANS architect's task-analysis-derived data base was used to estimate staffing levels, as were further interviews with HFIR operations personnel and with maintenance, training, reactor technology, and health physics personnel. The estimated staffing levels were also compared with staffing information from the High Flux Beam Reactor, the University of Missouri Research Reactor, the Advanced Test Reactor, ILL, and the Fast Flux Test Facility.

Material concerning equipment replacement was gathered from interactions with the cost estimator and the ANS design team. Unlity quantities were obtained from the ANS design team and utility rates from suppliers to ORNL. The costing of the fuel elements was a combination of information from the fuel fabricator, the fuel fabrication engineer at HFIR, and Oak Ridge Y-12 Plant storage and handling costs. All of this cost information was compiled as part of the CDR. Detailed operations information was also included in the CDR documents, under the appropriate WBS heading, to provide a more comprehensive operátions description.

\subsection{REACTOR SYSTEMS}

\subsubsection{Reactor Assembly Configuration}

Design activities in this area have focused on development of the conceptual design. An elevation cross section of the reactor assembly configuration is shown in Fig. 3.2. A complete description of the assembly is contained in the CDR.

\subsubsection{Core Pressure Boundary 'Tube}

Design tasks for the pressure boundary for the past year have dealt with further development of the internal guard tube concept. Issues addressed 


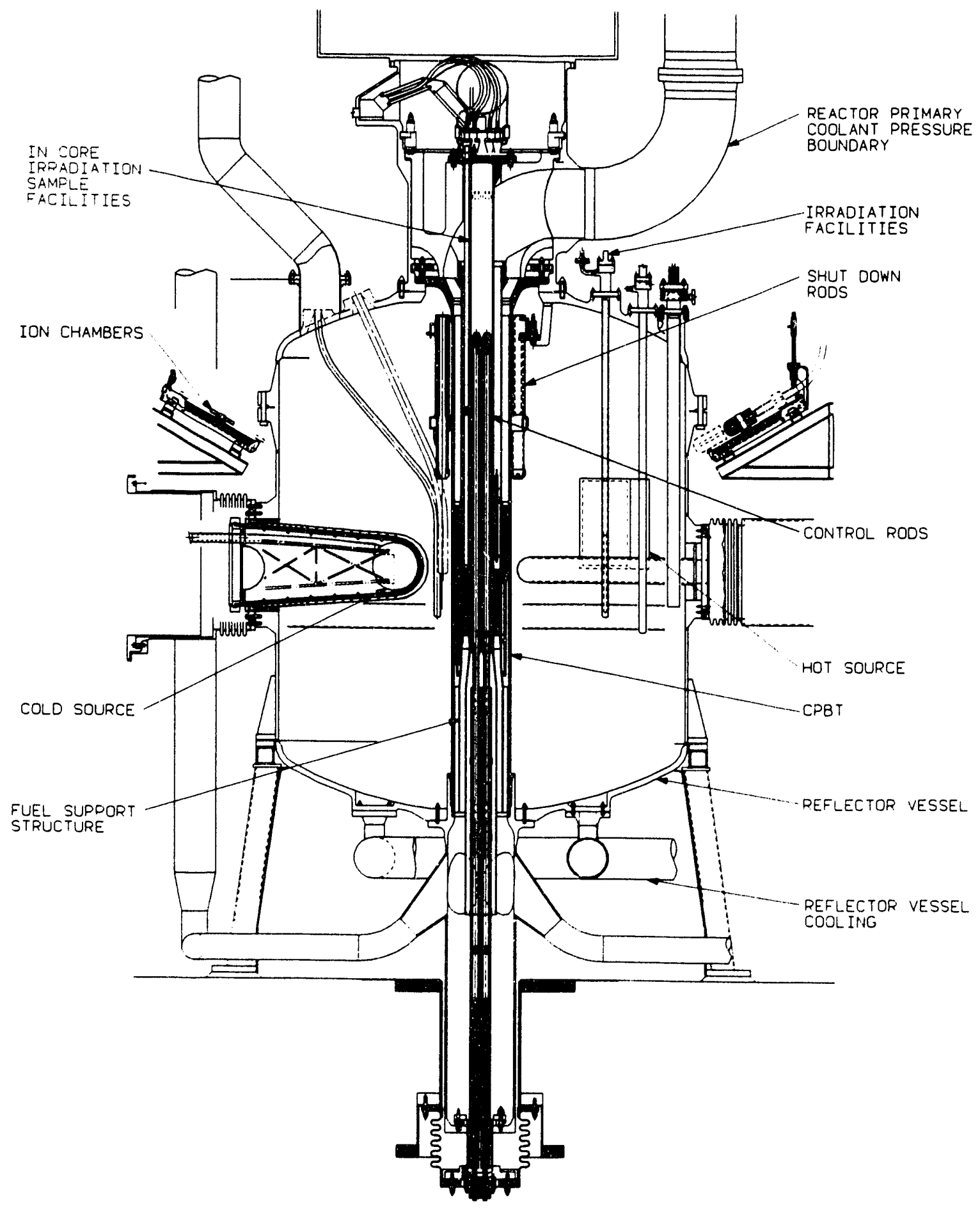

Fig. 3.2. Reactor assembly showing internal components.

38 Advanced Neutron Source (ANS) Progress Report 
include the sizing of the orifice at the annulus between the inner and outer tubes and stress/ fracture mechanics analysis of the outer tube that provides the pressure boundary during normal operation. Material properties such as fracture toughness of irradiated 6061-T6 aluminum require further investigation to finalize the design of the CPBT. Also, an aluminum-wire-wrapped, singlewall CPBT is being investigated. The wire wound tightly around the tube would maintain a compressive loading on the tube to prevent flaw growth.

Design tasks on the pressure boundary also addressed concepts to mitigate a loss-of-coolantaccident (LOCA) because of a pipe break in the core inlet or outlet pipes. LOCA mitigation proposals included thick-walled or stainless steel pipes, pipe enclosures of limited volume, doublewalled pipe, and cavitating venturis (on the outlet only). A revised seal configuration was necessary to minimize primary coolant leakage into the reflector vessel, with a metallic radial seal between the outer CPBT and the bore of the reactor inlet manifold incorporated as the conceptual baseline.

\subsubsection{Reflector Vessel}

Design effort on the reflector vessel (RV) has concentrated on structural requirements and the heat loads associated with the components. An issue was the safety classification of the vessel, which was resolved by the understanding that those components of the RV that support the core are to meet the requirements of the ASME Boiler and Pressure Vessel Code, Sect. III, Div. 1, Subsect. NB for Class 1 components. The components that are part of the pressure boundary or that support the experiment systems, but that do not affect the core support function, are to meet the requirements of the ASME B\&PV Code, Sect. III, Div. 1, Subsect. NC for Class 2 components. With the current monocoque design, however, the pressure vessel function cannot be separated from the core support function, and the entire vessel is being designed to meet the requirements of Safety Class 1.
Analysis based on the ASME B\&PV Code, Sect. III, yields a required thickness for the reflector vessel sidewall of $25.4 \mathrm{~mm}$ ( $1.0 \mathrm{in}$.). The critical load case is a combination of external pressure plus axial compression because of requirements for an evacuated vessel submerged in the reactor pool. The upper and lower heads have been sized, for pressure loads only, at $50.8 \mathrm{~mm}$ (2.0 in.).

Heat transfer analysis indicates that the RV sidewall is adequately cooled by the bulk flow through the vessel, but the RV thimbles will require forced flow to dissipate the high heat flux because of their proximity to the core. The total required heavy water coolant flow through the RV is $108 \mathrm{~kg} / \mathrm{s}(1740 \mathrm{gpm})$.

During this period, the beam tube thimbles have been changed slightly. The thickness of the tube wall and the ellipsoidal endcap is now 14.1 and $3.6 \mathrm{~mm}$, respectively. A 3-mm-thick cooling jacket surrounds the beam tube thimble. The coolant gap varies from 2 to $40 \mathrm{~mm}$ and the $\mathrm{D}_{2} \mathrm{O}$ mass flow rate is $2.4 \mathrm{~kg} / \mathrm{s}$. This yields a beam tube wall temperature of about $100^{\circ} \mathrm{C}$. These results are based on a coolant entrance temperature of $65^{\circ} \mathrm{C}$ and a heating rate at the beam tube tip of approximately $16.5 \mathrm{~W} / \mathrm{g}$. The current cooling jacket dimensions result in a dynamic head pressure loss of $0.37 \mathrm{MPa}$, excluding losses because of friction and entrance characteristics. By increasing the maximum temperature of the aluminum to $110^{\circ} \mathrm{C}$, the pressure loss can be reduced to only $0.2 \mathrm{MPa}$.

A preliminary design of the support stand assembly was also completed during this period. The support stand assembly consists of a square section-support ring $(152 \times 152 \times 13-\mathrm{mm}$ wall thickness) attached to the vessel, nine square legs $(203 \times 203 \times 13 \mathrm{~mm})$ that are $40^{\circ}$ apart, and corresponding base plates that are fastened to the floor of the reactor pool. All structures are aluminum weldments designed with a maximum allowable stress of about $50 \mathrm{MPa}$. The current design does not include any lateral supports, but these may be added during the advanced conceptual design period. 


\subsubsection{Control and Shutdown Rod Assemblies}

Concepts for the inner control and shutdown rods were further developed and refined. Conceptual details were developed for those components located in the subpile room. These include a buffer gas and $\mathrm{D}_{2} \mathrm{O}$ sealing system, a rod seat position-indica ng system, a lower control rod drive motor and control system, a structural support and stabilization system, and a subpile room safety enclosure. Supporting calculations and analyses were performed to verify the basic design and operating features and to back up the design presented in the CDR.

That design uses a spring-driven scram system combined with a motor-driven control rod system. Each of the three control rod assemblies contains a hafnium neutron-absorbing cylinder that is driven up and down vertically to serve the function of normal regulation and control of the reactor. Each absorber cylinder is attached to its drive shaft with a mechanical latch mechanism. During normal operation, the latches are engaged, and the three drive shafts and absorber cylinders move together as a single control unit with a common drive motor.

When a scram is required, the latches are independently released, and the absorber cylinders are in turn released from the drive shaft control system. The absorber cylinders are driven downward independently by preloaded mechanical springs into their scram position. A $D_{2} O$ hydraulic system for each rod will be used to provide a signal indicating that the rod is fully inserted (seated). Mechanical switch operators will be used to provide signals to indicate the position of the magnet armatures that operate the latching mechanisms in each of the rods.

Conceptual design details and assemblies were further developed for the outer shutdown rod system. The shutdown elements for the outer shutdown system consist of eight assemblies as shown in Fig. 3.3. These shutdown rods are located in the reflector region, immediately outside of the CPBT and above the core.
Each of the eight outer shutdown rod assemblies consists of a neutron absorber cylinder mounted on a hydraulic piston, with each piston located in its own hydraulic cylinder. These cylinders are symmetrically spaced around the CPBT and are connected to a common $\mathrm{D}_{2} \mathrm{O}$ hydraulic system by means of a manifold. The $\mathrm{D}_{2} \mathrm{O}$ supply system, located outside the pool, provides pressurized $\mathrm{D}_{2} \mathrm{O}$ through two lines to the manifold and subsequently to the cylinders. The dual supply lines contain redundant control (shutoff) valves and a pressure/flow relief valve. In normal operation, with the shutoff valves open, the rods are hydraulically driven upward to their withdrawn positions, simultaneously compressing coil springs that provide part of the insertion force wh $2 n$ a scram is required.

The valves cut off the flow and reduce the hydraulic pressure to the neutron-absorber pistons when a scram is required. The pistons with the neutron-absorbing material are driven into the scram position by the compressed springs. $\mathrm{A}_{2} \mathrm{O}$ hydraulic system provides a signal (pressure and flow-rate change) for a two-point position indicator system (fully inserted or fully withdrawn) on each of the eight rods.

\subsubsection{Refueling}

The design of the stack-and-tunnel refueling system has evolved during this reporting period. A cross-section layout of the refueling system is shown in Fig. 3.4. There have been several important modifications to the concept.

The $\mathrm{D}_{2} \mathrm{O}$ processing facility now has sufficient purification capacity to allow the spent fuel to be placed in a transfer lock for movement into the light water storage pool. Water is exchanged between the $\mathrm{D}_{2} \mathrm{O}$ and $\mathrm{H}_{2} \mathrm{O}$ systems by mixing after $21 \mathrm{~d}$ from the time the fuel is removed from the reactor. This is significant because it eliminates the necessity to hold the fuel in a $\mathrm{D}_{2} \mathrm{O}$-filled canister for the 2 years needed before an air transfer can be implemented. 


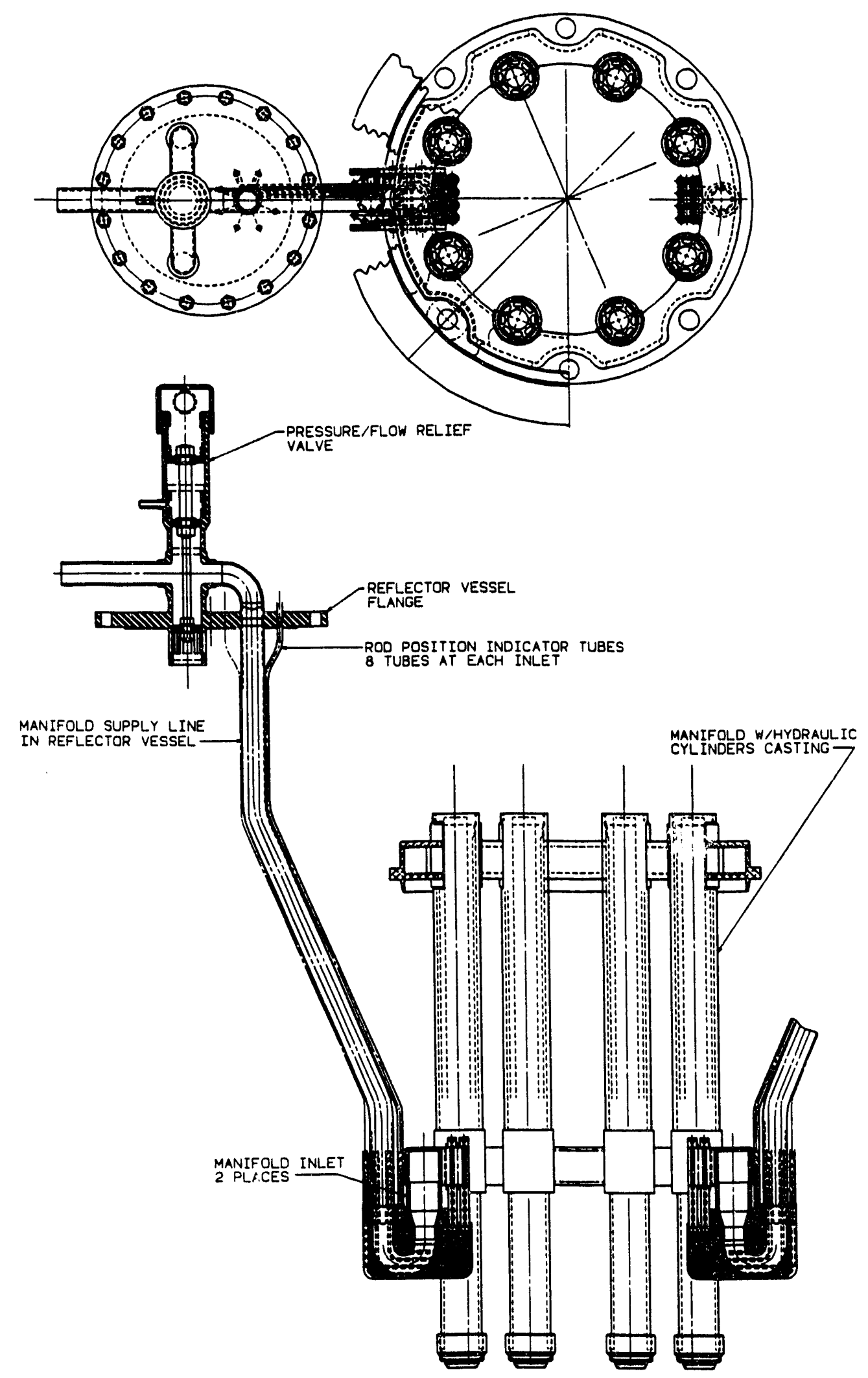

Fig. 3.3. Outer shutdown rod with supply lines and relief valves-assembly. 


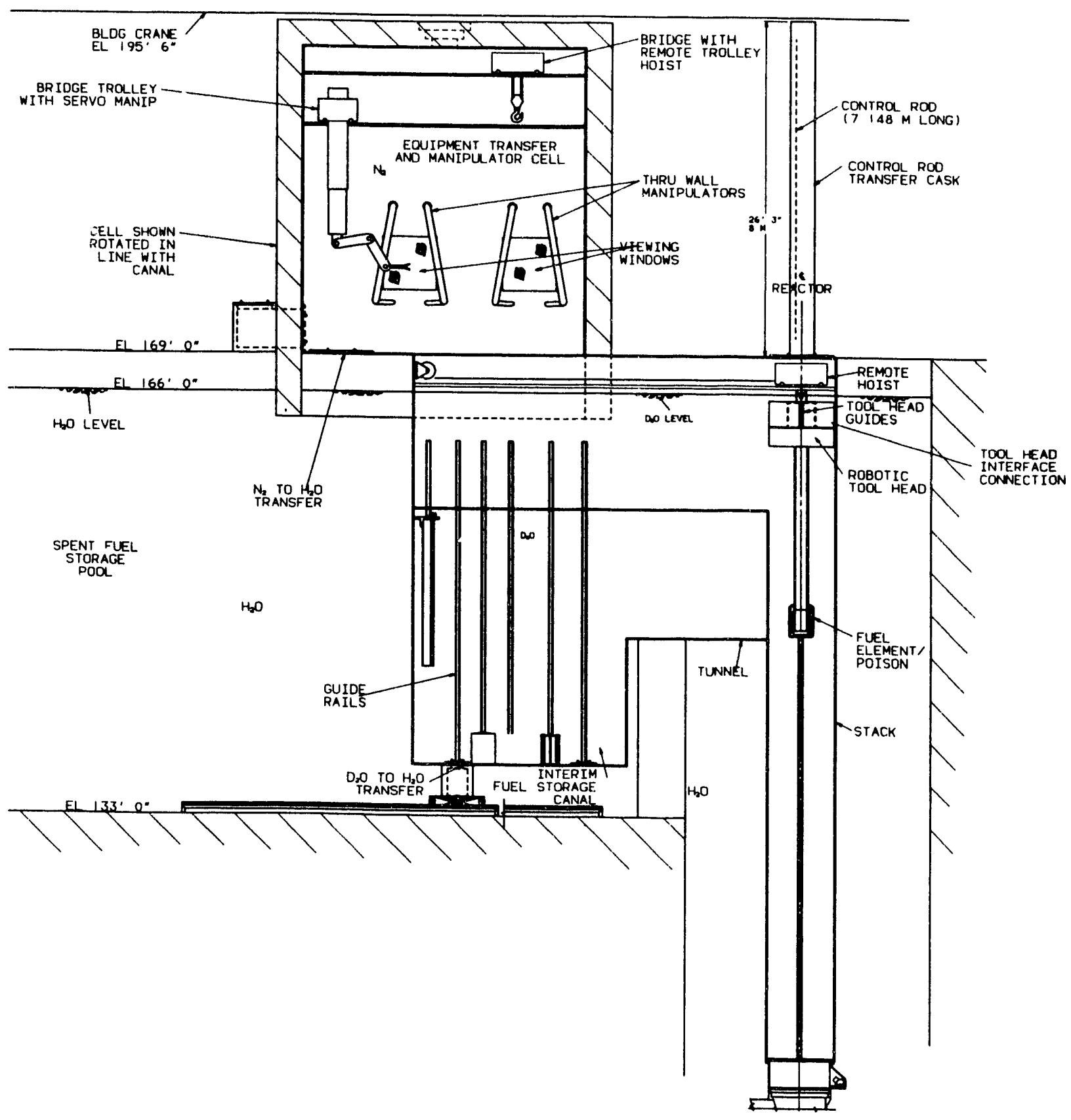

Fig. 3.4. Refueling concept showing fuel assembly removal.

Another significant development is the use of a neutron-absorbing plug in the stack region to eliminate neutron streaming in the tunnel portion of the system. This allows the top of the tunnel to be raised above the level of the light water reactor pool, permitting some critical transport equipment to operate in a controlled-gas environment rather than in a water environment. This also makes the refueling equipment more accessible for nonroutine maintenance and emergency recovery. 


\subsection{EXPERIMENT SYSTEMS}

\subsubsection{Overview}

All experiment system facilities were documented in the CDR issued in June. The principal changes that have occurred in the last year were the incorporation of the horizontal cold source concept, the development of design concepts for installing and removing material irradiation and isotope production experiments in the reflector vessel, subcontractor input into the guide system design, and the design of cask systems for replacing the beam tube thimbles and the hot and cold sources. In addition, design work has continued on the hot and cold sources since the CDR was issued.

\subsubsection{Neutron Beam Transport}

The neutron beam transport systems colssist of 7 thermal beam tubes, 1 through tube, 1 large slant thermal beam tube, 14 horizontal cold guides, 2 slant cold guides, and 2 very cold guides. All of these include penetration assemblies through the biological shield and are described in the CDR. In addition, there are cask systems for the replacement of activated beam tube thimbles, for cold sources, and for the hot source. Figure 3.5 is an overall plan view of the ground floor of the beam room, and Fig. 3.6 shows the second floor. The cold guides pass through a dry shielded section within the beam room. The UCN convertor is located on the roof of this shielding $2.4 \mathrm{~m}$ above the floor levei. Figure 3.7 shows an elevation view of the cold source penetration. The two very cold guides are routed above the cold guides and then up to a UCN convertor and an experiment station above the shielding within the beam room.

The horizontal cold guides will have internal dimensions of 200 by $50 \mathrm{im}$, the large dimension being vertical. The portions of the guides within the biological shield will be nickel to avoid radiation damage to the glass. The sections outside the shield will use nonborated glass for the first section and borated glass for the remaining sections. All sections within containment will have supermirror coatings for improved performance, while cutside of containment a combination of supermirror and ${ }^{58} \mathrm{Ni}$ will be used, with the choice based on the instruments on the guides. Isolation valves will be provided on the horizontal guides on both the inside and outside of containment.

Replacement of the cold sources will be required periodically (estimated life of 12 to 18 months) because of radiation damage. A shielded cask has been proposed for removing the activated components as shown in Fig. 3.8. This same cask will also be used for replacing the thermal beam tube thimbles and the hot source. Two other casks will be needed for replacement of the through tube and the slant cold guides and large slant beam tube.

The second floor will have an isotope separation on-line facility, a neutron depth-profiling station, a positron facility, and a station for instrument development as shown in Fig. 3.6. Positrons will be produced by activating krypton gas within the reflector vessel and cryopumping the gas at the experiment station on the second floor.

The horizontal cold guides extend into the guide hall as shown in Fig. 3.9.

\subsubsection{Neutron Scattering and Physics Instruments}

Design requirements and descriptions have been documented in the CDR for 38 neutron scattering instruments and for 10 instruments for nuclear and fundamental physics and analytical chemistry. These requirements were developed principally by research scientists in the applicable disciplines. The scattering studies to be undertaken are in the following areas: singlecrystal diffraction; powder diffraction; time-offlight spectroscopy; triple-axis spectroscopy; small-angle neutron scattering, including 


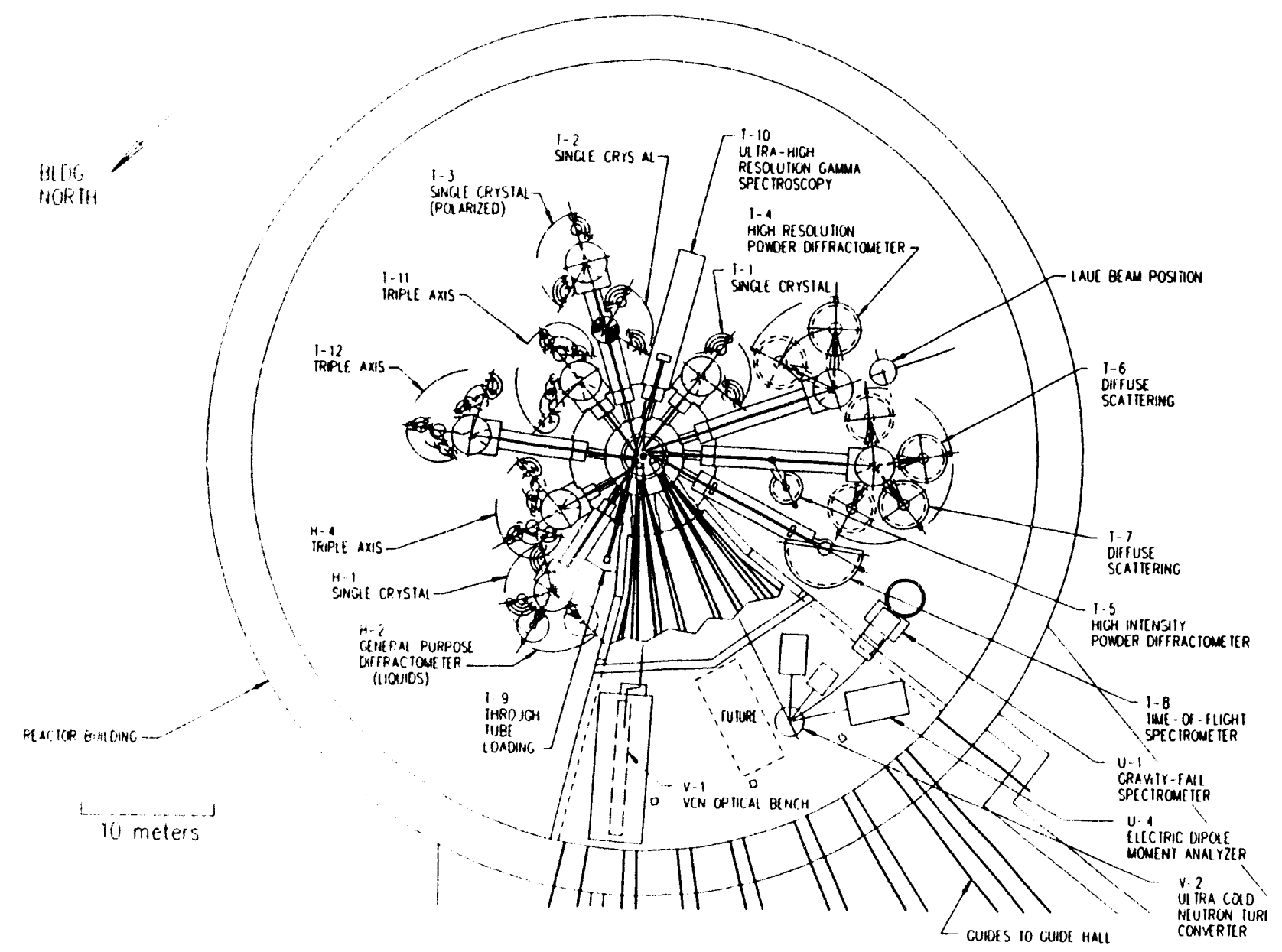

Fig. 3.5. Plan view, ground noor beam room.

reflectometry; liquids and amorphous materials scattering; high-resolution spectroscopy; neutron optics; ultracold neutron research; and instrumentation development. Instruments in support of thermal nuclear physics will be provided on the through tube, with a loading station and an ultrahigh resolution gamma spectrometer on the opposite station. Polarized nuclear physics stations will be located on cold beams for a precision gamma-ray bolometer, a weak interaction station, and a parity violation station that will allow experiments with multiliter quantities of liquid hydrogen. General nuclear physics stations will be located on cold beams, and an isotope separation on-line facility will be located at the end of the large slant beam tube on the second floor. This facility will produce neutron-rich fission-product nuclides and separate them. A neutron depth-profiling station for analytical chemistry is located on a slant cold beam on the second floor, and two gamma-ray spectrometers are located on a low-background cold guide in the guide hall.

Overall instrument layouts are shown in Figs. 3.5, 3.6, and 3.9, and detailed descriptions are in the CDR.

\section{Advanced Neutron Source (ANS) Progress Report}




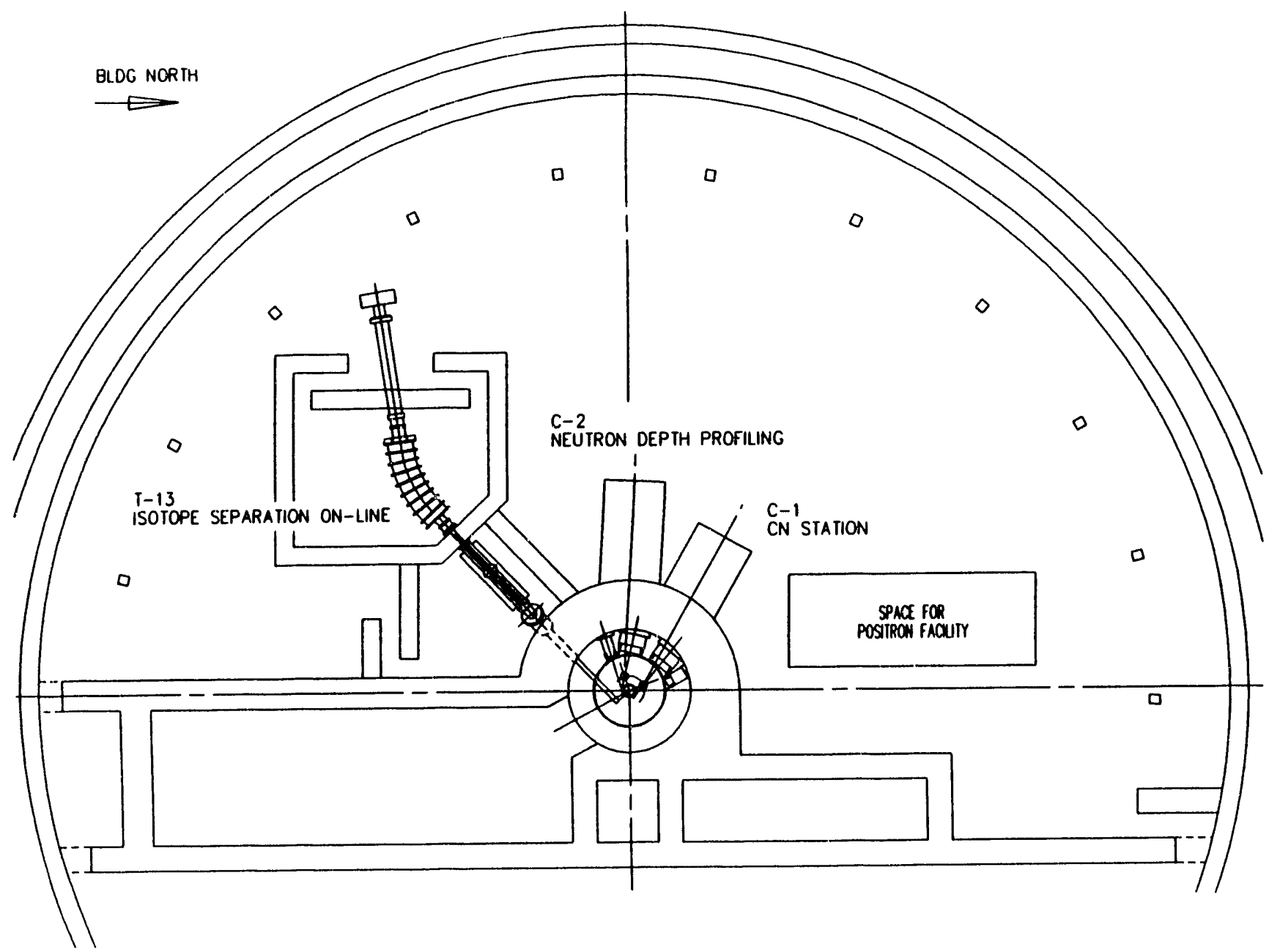

Fig. 3.6. Plan view, second foor beam room.

\subsubsection{Irradiation and Isotope Production Facilities}

The baseline design includes material irradiation and isotope production facilities both within the CPBT and the RV. Currently, five instrumented and five noninstrumented material irradiation capsules are planned for the upper fuel element; options are being evaluated for replacing the noninstrumented positions with instrumented ones. During the last year, a concept has been developed for locating two slant tubes between the outer shutdown rods at $330 \mathrm{~mm}$ from the centerline and for providing a handling system in the light water pool for installing and removing irradiation experiments in them.
Isotope production, including transuranic isotopes, is provided by an array of 30 target positions outside of the lower fuel element and by 4 hydraulic tubes and 4 "vertical-hole facilities." Calcrlations have shown that the production goals for ${ }^{2:} \mathrm{Cf}$ and ${ }^{254} \mathrm{Es}$ can be met with the 30-target array using 3 campaigns per year. The four hydraulic tubes have been designed to meet the flux goals, including one with a high epithermal flux for transuranic production. They have also been designed with a separate return line to isolate them from pressure changes in the RV. The vertical-hole facilities have been designed to allow targets to be removed or installed while the reactor is running. This is done by operating them in a manner similar to hydraulic tubes, with a section 


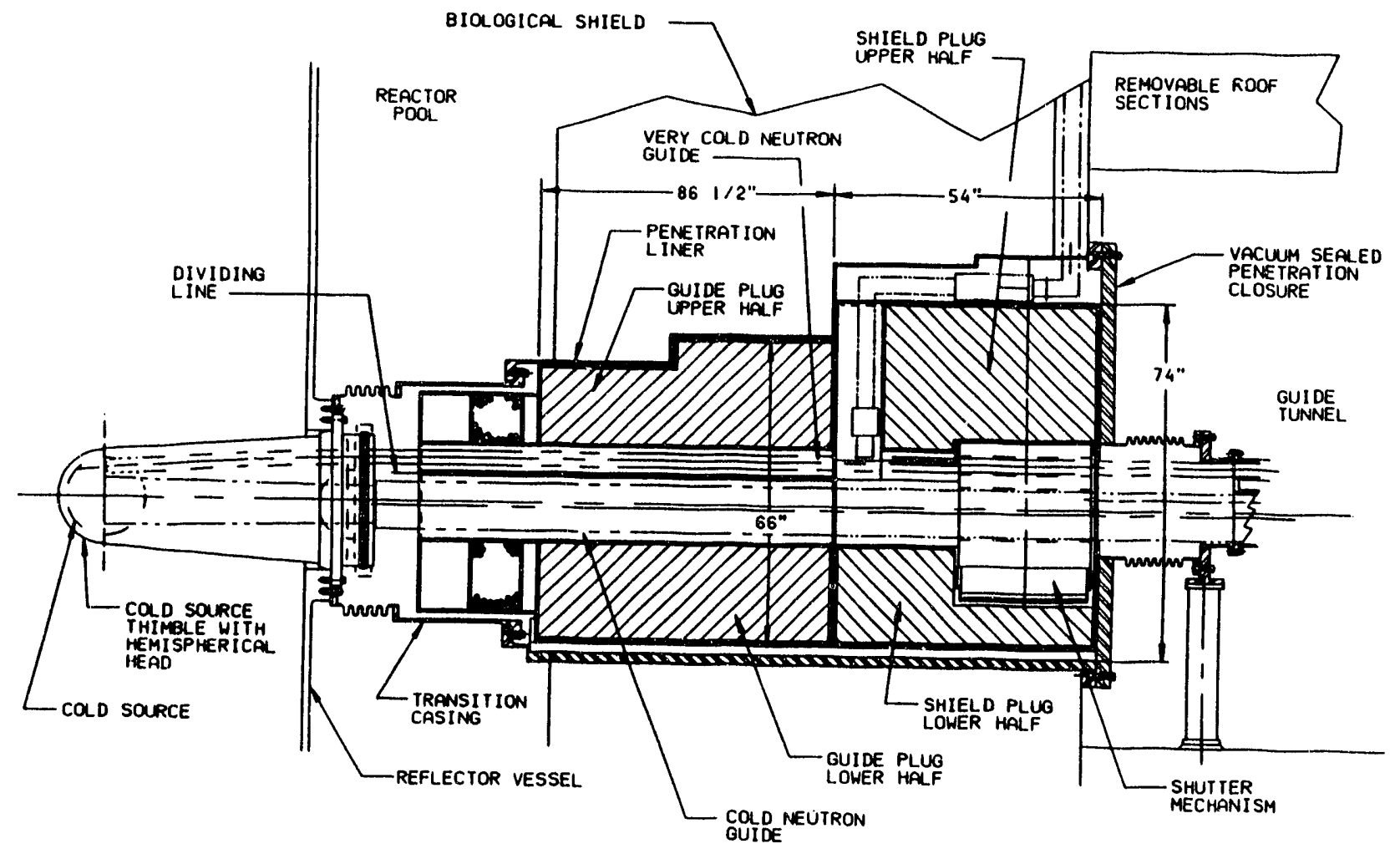

Fig. 3.7. Elevation view of cold source biological shield penetrations CS1 and CS2.

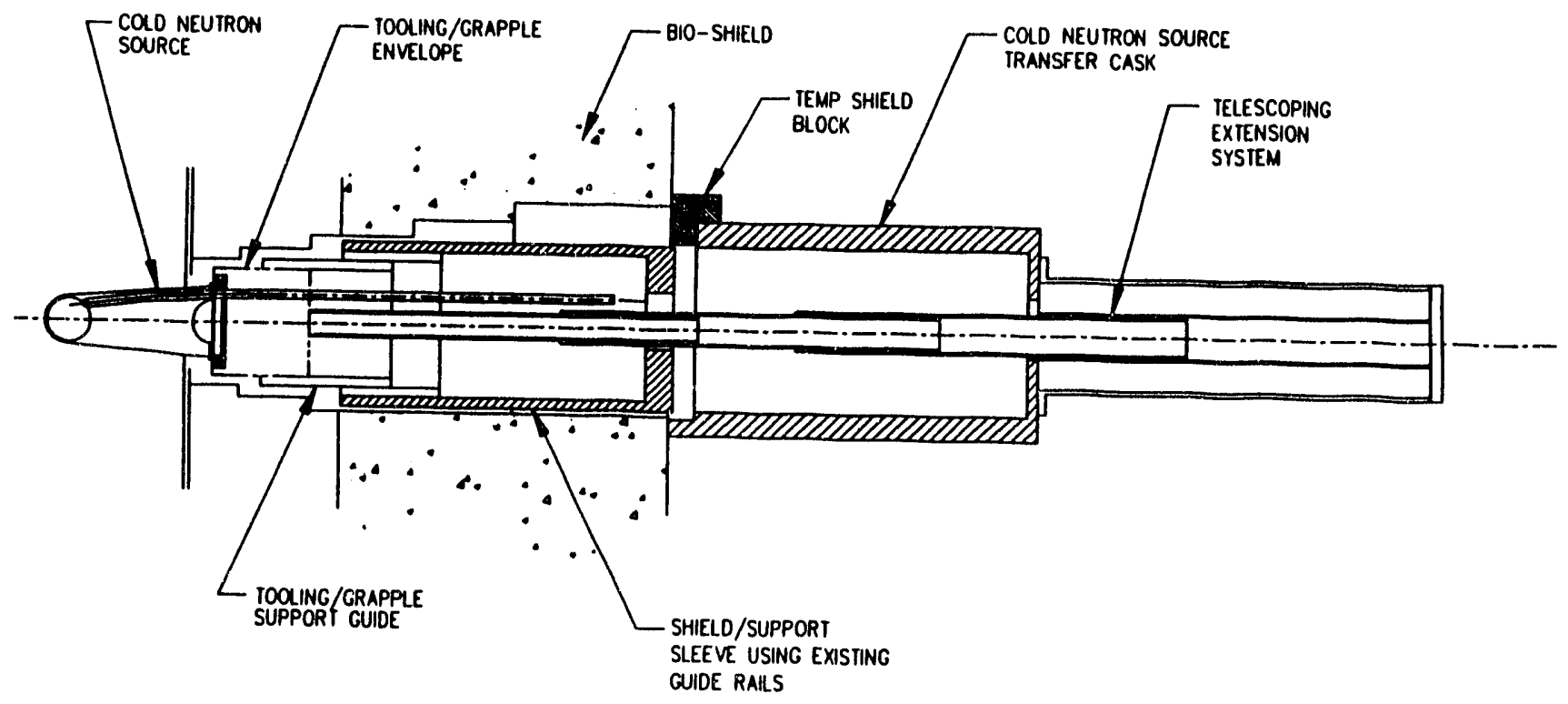

Fig. 3.8. Proposed cold source cask with tooling extended to remove source.

46 Advanced Neutron Source (ANS) Progress Report 


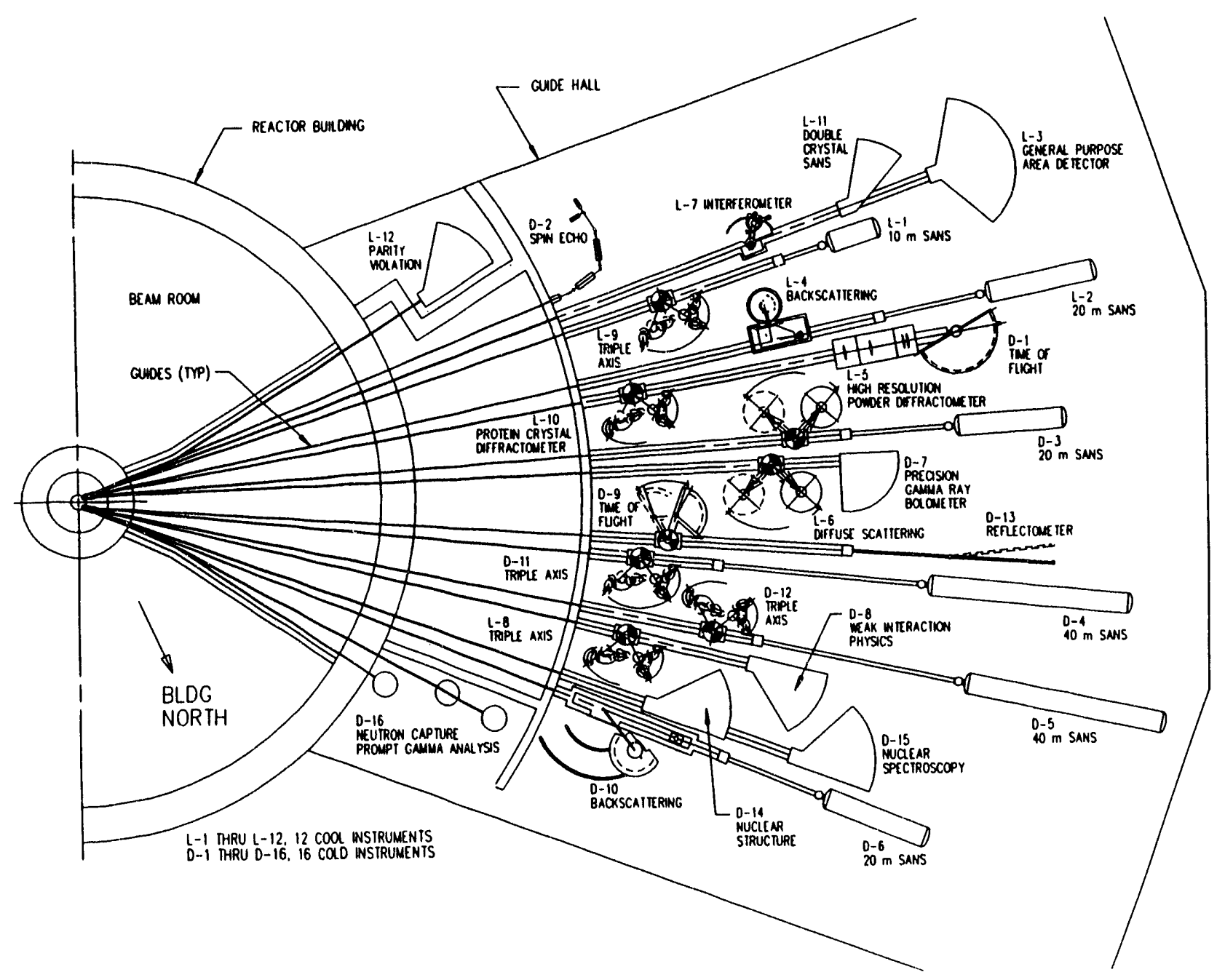

Fig. 3.9. Plan view, guide hall.

of line in the light water pool that can be isolated between double valves. Targets would be transferred under the light water pool for shielding by means of the crane system.

Handling areas in light water have been located for the material irradiation experiments and for the isotope targets. Three hot cells have also been included to support all of the irradiation and isotope production requirements.

\subsubsection{Activation Analysis Facilities}

The pneumatic tube systems have been changed to incorporate comments from the community. The current design is for a system with one 2-ml (cc) rabbit tube and four 40-ml (cc) rabbit tubes within the RV. In addition, two large 120-ml rectangular rabbit tube systems have been added just outside of the RV in the light water pool. All of these connect to a transfer or counting station within containment on the third floor neutron activation analysis facility (NAAF-1). A set of pneumatic tubes connects NAAF- 1 with NAAF-2 outside of containment in the basement of the research support building. Rabbits may only be sent out of containment with these tubes for security reasons. A plan view of this facility is given in Fig. 3.10. 


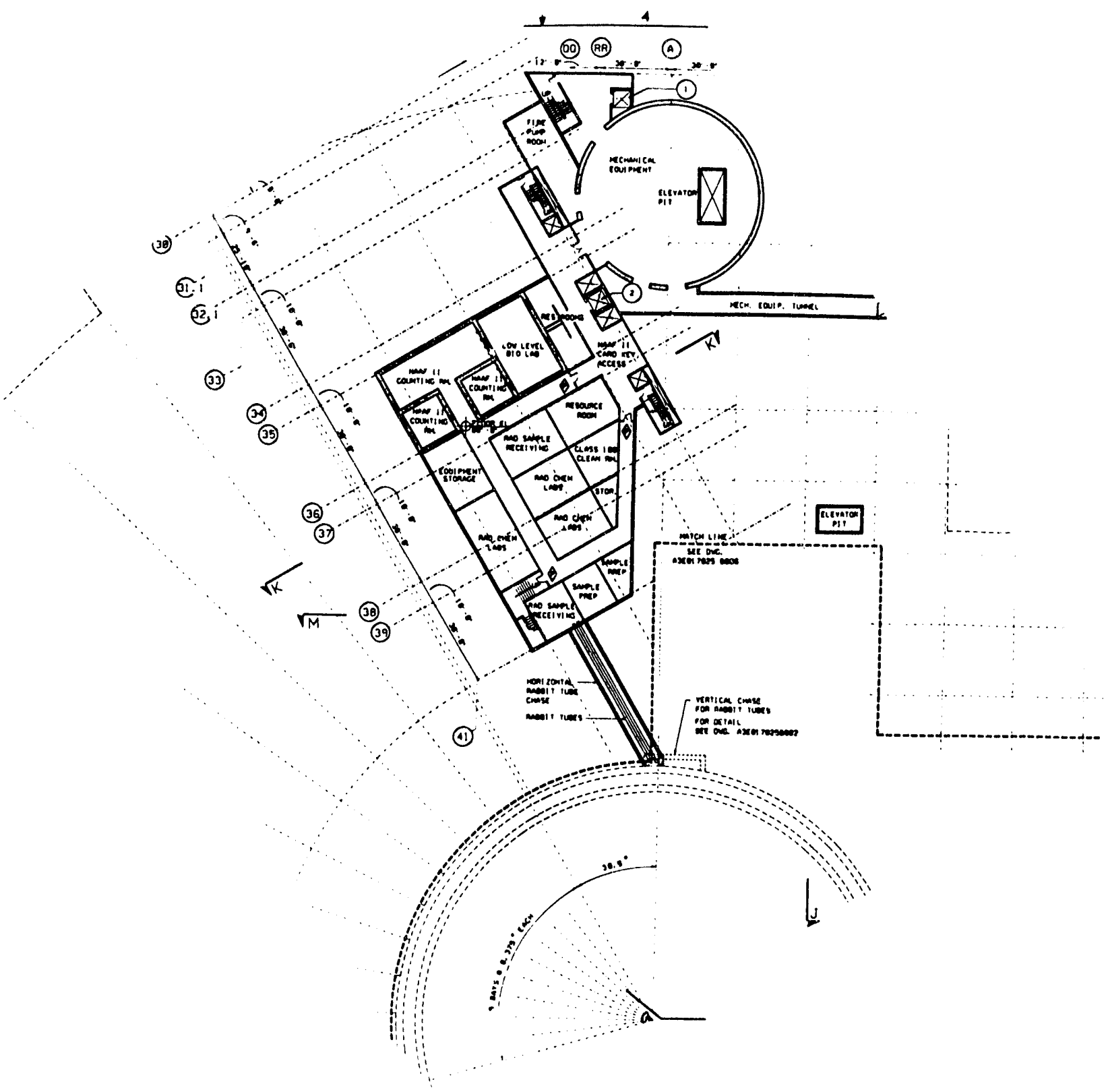

Fig. 3.10. Plan view, NAAF-2.

\subsubsection{Cold Source System}

A horizontal cold source configuration has been adopted principally because it appears to increase significantly the cold flux delivered to the guide systems by eliminating the heavy water gap and the additional structural walls required in a vertical cold source arrangement. In addition, the cold source is topologically outside the RV pressure boundary, which simplifies the safety considerations. The baseline concept uses two independent liquid deuterium cold source systems to moderate neutrons to an energy spectrum corresponding to an effective moderator 
temperature below $40 \mathrm{~K}$. Each moderator vessel is located $750 \mathrm{~mm}$ from the vertical centerline of the reactor core; the thermal neutron flux at that location is about $4 \times 10^{19} \mathrm{~m}^{-2} \cdot \mathrm{s}^{-1}$. With the reactor at full power, the source brightness (at wavelengths from 0.286 to $0.981 \mathrm{~nm}$ ) is approximately $2.2 \times 10^{18} \mathrm{~s}^{-1} \cdot \mathrm{ster}^{-1} \cdot \mathrm{m}^{-2} \cdot \mathrm{nm}^{-1}$, and the cryogenic heat load is about $30 \mathrm{~kW}$. Each system uses centrifugal pumps to circulate liquid deuterium continuously through a cryogenic loop containing a moderator vessel (located in a reflector vessel horizontal thimble) and through a cryogenic heat exchanger (located outside the biological shielding), where energy is transferred from the deuterium to cold helium gas. During normal operation, the lower end of each system (heat exchanger, pumps, cryogenic deuterium plumbing, and the moderator vessel) will be flooded with liquid deuterium to a level just above the heat exchanger core. The nominal operating pressure of the cold deuterium system is $0.5 \mathrm{MPa}$ (72.5 psia), and, with the reactor at power, the temperature of the deuterium when entering and leaving the moderator vessel is nominally 20 and $24 \mathrm{~K}$, respectively. Each cold source deuterium system uses a large low-pressure receiver $\left(60 \mathrm{~m}^{3}\right.$ at 0.5 to $0.8 \mathrm{MPa}$ ) to hold the deuterium vapor during warmup, thus avoiding the need to vent the deuterium inventory $(77 \mathrm{~kg})$. The entire deuterium system is surrounded by monitored vacuum and/or helium envelopes to minimize the probability of a deuterium-oxygen reaction, and each vacuum space surrounding cryogenic deuterium components is surrounded by a helium space.

\subsubsection{Hot Source}

A hot source design was developed in the CDR, based on the ILL installation. A graphite moderator block heated by radiation to a temperature above $2000 \mathrm{~K}$ is used to produce an increase in neutron flux in the wavelength range of approximately 0.04 to $0.08 \mathrm{~nm}$. The graphite block is insulated and supported by carbon felt in a helium atmosphere within a double-walled zirconium vessel. This assembly is located within a horizontal thimble, similar to the cold source. The baseline design uses a cylindrical moderator $200 \mathrm{~mm}$ in diameter by $300-\mathrm{mm}$ tall located $1450 \mathrm{~mm}$ from the reactor vertical centerline and $400 \mathrm{~mm}$ above the midplane.

Recent neutronic calculations indicate that although the thermal neutron flux is adequate, the heating rate and temperature at this location will be only a fraction of that at ILL. Design options are being developed, and it appears possible to meet the temperature and flux goals by using an improved carbon-based insulation and relocating the moderator closer to the core.

\subsubsection{Support Facilities}

Detailed requirements for experiment, instrument, and crystal support facilities have been developed to support the cost estimates and building layouts. Laboratories are included for cryogenics, high temperature, high pressure, magnets, chemistry, biology, polymers, and physics experiment support. In addition, there will be laboratories for crystal growth, characterization, and mounting.

All experiment systems will be connected to a common dedicated computer network, principally for data archiving and data import and export.

\subsection{SITE AND BUILDINGS}

The principal activity of the balance-of-plant team was the preparation of the conceptual design for the major facilities on the candidate site, concentrating on those with the most impact on facility operation and site layout. The design of the remaining facilities was developed only to the extent necessary to validate a concept or to verify that they could fit on the defined site. The following text summarizes the results of that work.

\subsubsection{Architectural Concept}

To design a physically compact complex that includes secure reactor operations areas, as well as 
research facilities easily accessed by many visiting scientists, is a challeng. The user-friendly approach to dealing with visiting scientists has been compromised in other research reactor facilities, largely because of tightened security measures in buildings designed to less restrictive requirements, as well as to increased awareness of health physics and ALARA requirements. The design of the ANS complex keeps the two distinctly different functions of research and reactor operations physically separate, while maintaining the link between the two entities through a common entry point into the complex. The entry point leads into an interface area that is the main circulation artery-a focal point-from which the staff are directed to their respective work locations. Physical and architectural barriers focus the security monitoring capability into this specific area, thus integrating the security zones with a centralized security control point. There are straightforward internal traffic patterns and minimal distances between different functions, as shown in Fig. 3.11. The general arrangement of the buildings is such that future expansion needs are not compromised. Each function can grow without impacting the shape and function of adjacent areas.

Figure 3.11 also depicts the arrangement of the buildings on the candidate site. The site is divided into distinct security and activity zones. Additional graded levels of security are provided inside the main building complex. The portion on the north, with the minimum required security services and controls, is dedicated to research facilities. The south, which employs stringent security controls, is limited to reactor operation activities. All employees and visitors, as well as some delivery and service vehicles, enter the north portion of the facility via the security-manned main gate. Employees' and visitors' parking is included within the single site-boundary fence. Entrance to the double-fenced operations support zone is limited and is obtained via a manned security gate in the southwest.

The buildings have been located on the site in a manner that effectively utilizes the existing contours, that places the foundations of the reactor and reactor support buildings on sound bedrock, and that provides a stable foundation for the guide hall. The arrangement also allows room for future expansion of the individual buildings and/or construction of additional buildings when the need and opportunity arise.

\subsubsection{Reactor Building}

The building systems have been designed so that personnel on site will have access to those areas where there is a need; access to areas where there is an infrequent need will be limited. The reactor building, because it contains the reactor, is the most secure. This building must accommodate both free access of scientific personnel on the lower floor and free access only to operations personnel on the top floors. The design evolved into an arrangement that will accommodate both requirements by placing experiments on the first floor and reactor operations on the third floor and by separating the second floor by a wall into an operating and experiment area.

The reactor is located in the center of the building (Fig. 3.12), with beam tubes and guides fanning out into (and, in the case of the cold guides, through) the beam room surrounding the reactor. The steel containment vessel and the secondary containment structure (which serves as secondary containment and also protects the interior of the building from external phenomena) are separated by an annular gap. The floor of the beam room is sufficiently smooth and flat to allow the use of air pads for positioning of the instruments and employs a material equivalent to polished marble at the actual instrument locations. A polar crane is also provided in the beam room. A personnel airlock provides access to this level. Entry to the first floor of the reactor building is directly from the security portal in the interface building. Access is limited to scientists who meet badging requirements.

The second floor of the reactor building has been reserved for additional experiments, for cells and pools for the primary and reflector heat transport systems, and for refueling and reactor 


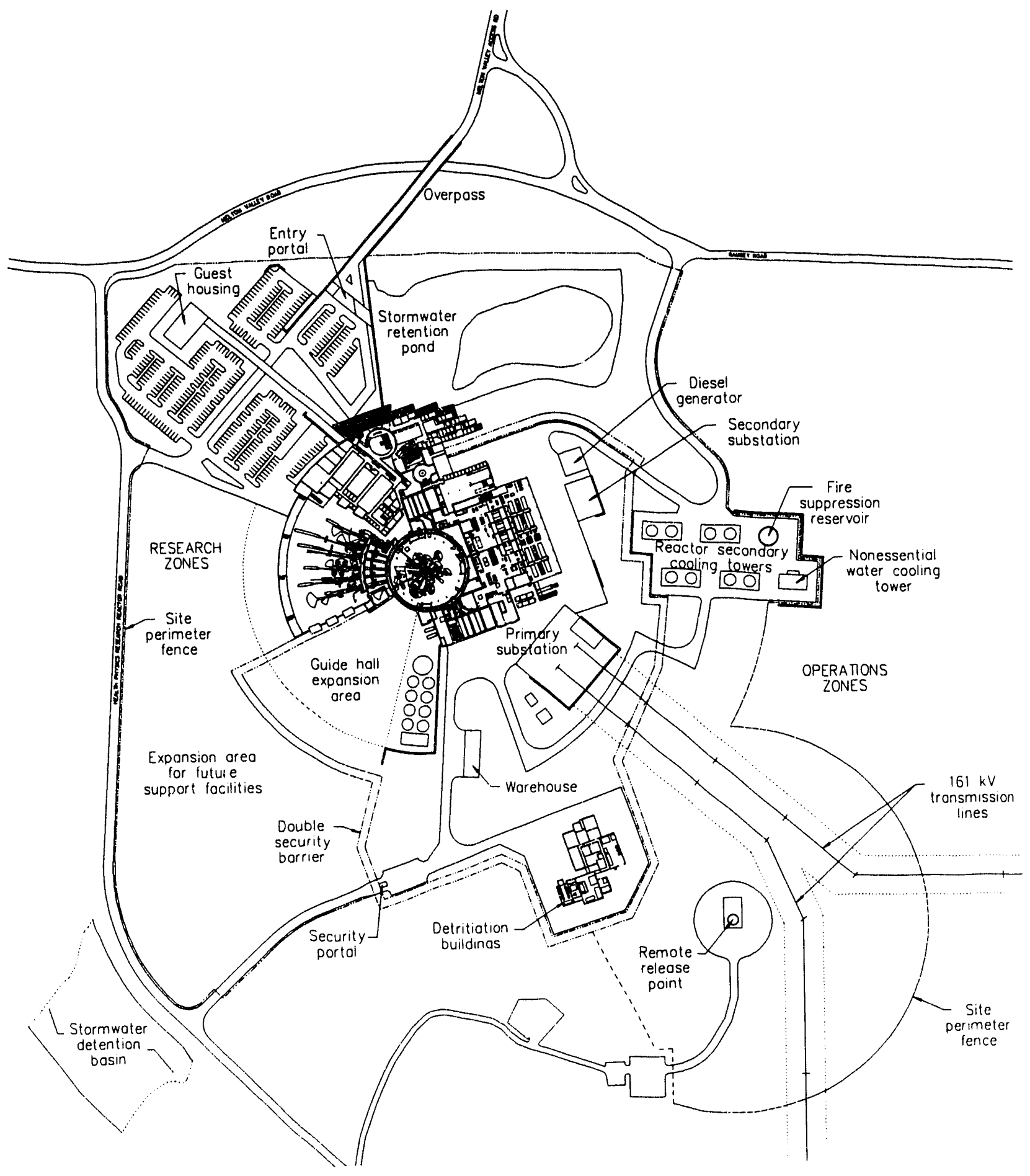

Fig. 3.11. Site plan for the ANS candidate site. 


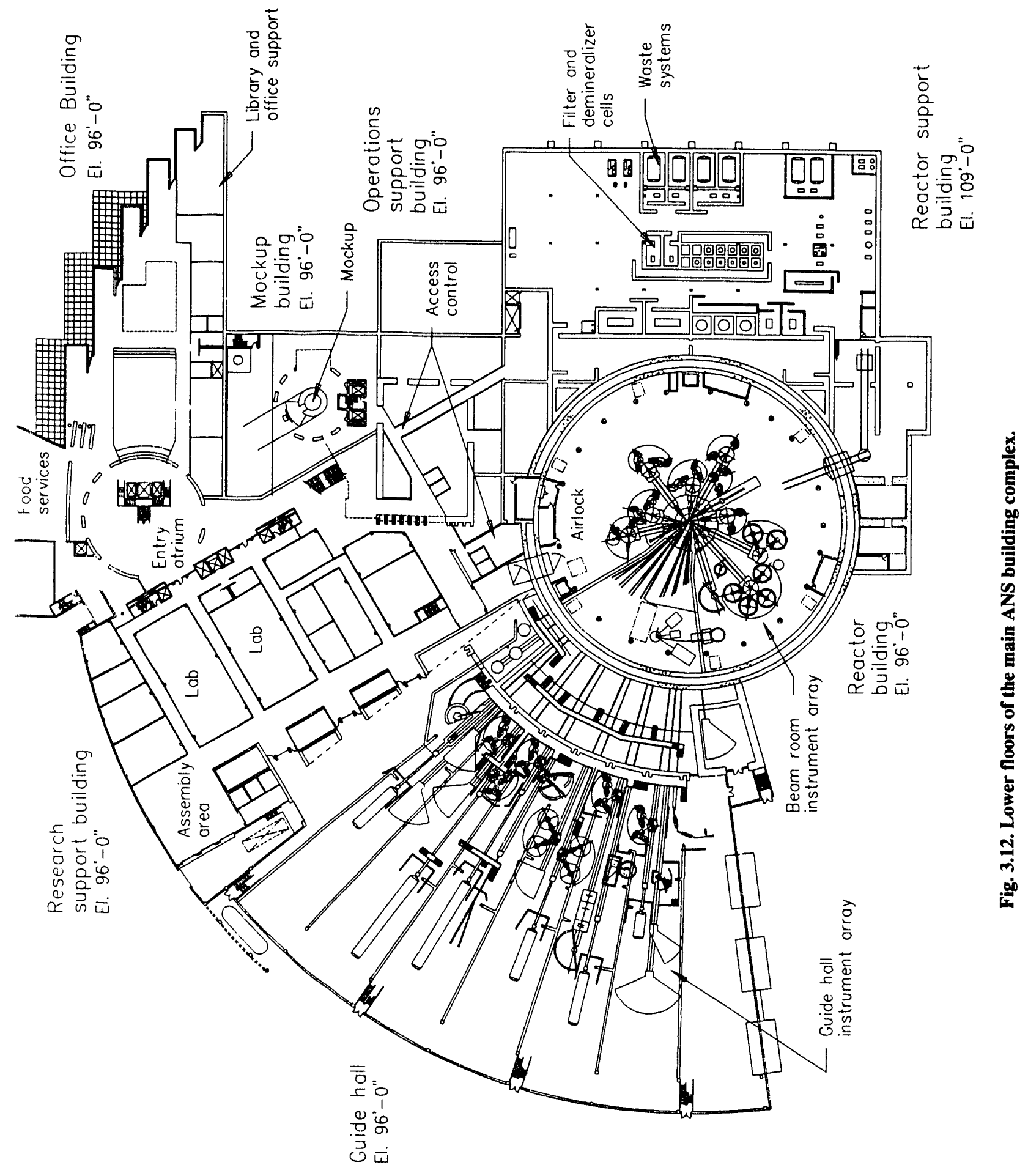

52 Advanced Neutron Source (ANS) Progress Report 
maintenance activities. Access to this floor is through the reactor support building.

The third floor of the reactor building

(Fig. 3.13) is principally an area relating to reactor operations and contains equipment for refueling, cold boxes for the cold source, pools for storage of spent fuel, and other equipment associated with reactor maintenance and operations. Normally, scientific experiments will not be conducted in this area of the reactor building, although there will be limited access for some scientific personnel to the NAAF-1, which is on this floor.
The section through the main structure (Fig. 3.14) shows the relative elevations of the reactor in the reactor building, the reactor support building, the compressor building, and the guide hall.

\subsubsection{Reactor Support Building/Operations Support Building}

The design of the reactor support building and the operations support building integrates the two functional areas of the reactor and operations

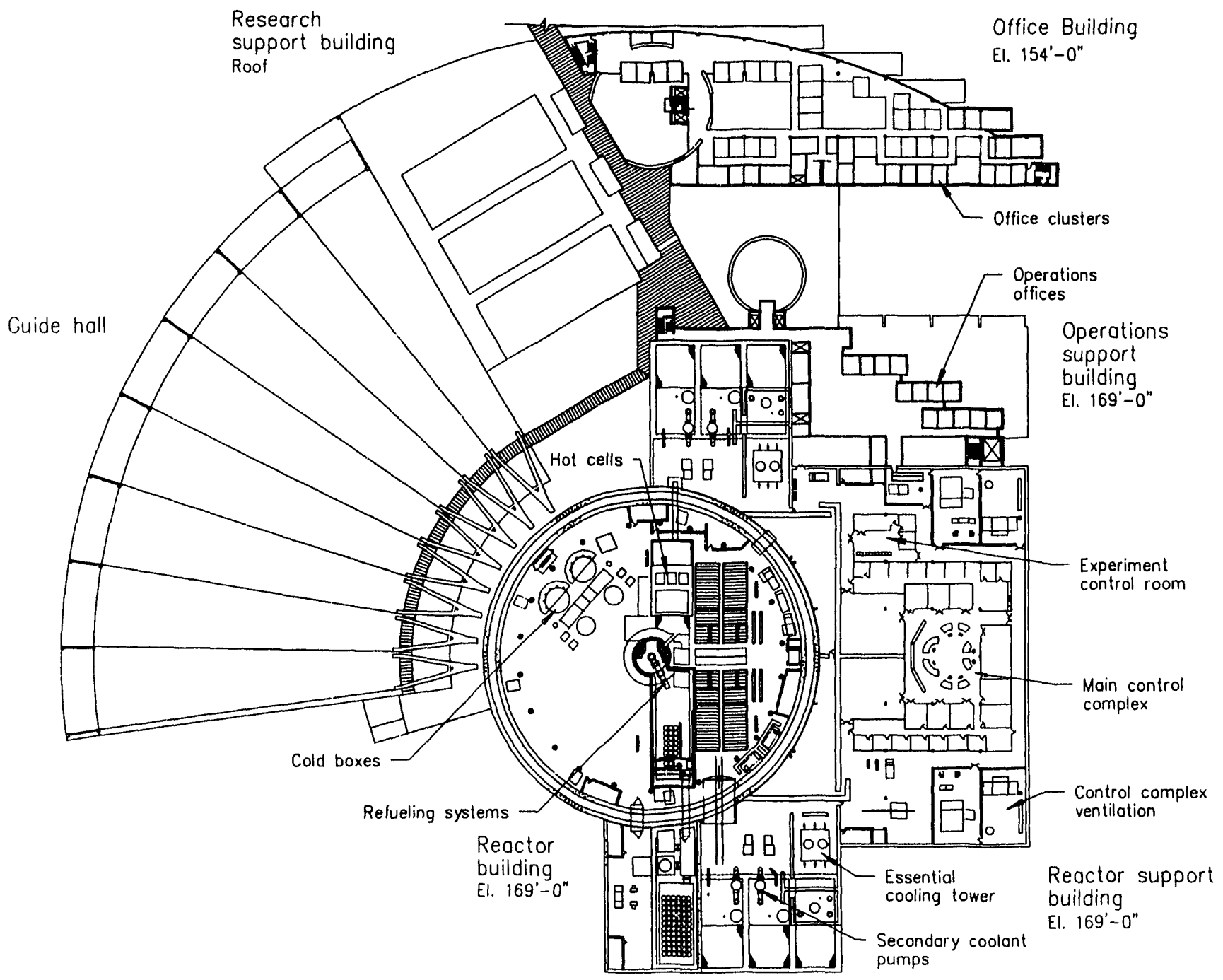

Fig. 3.13. Intermediate floors of the main ANS building complex. 


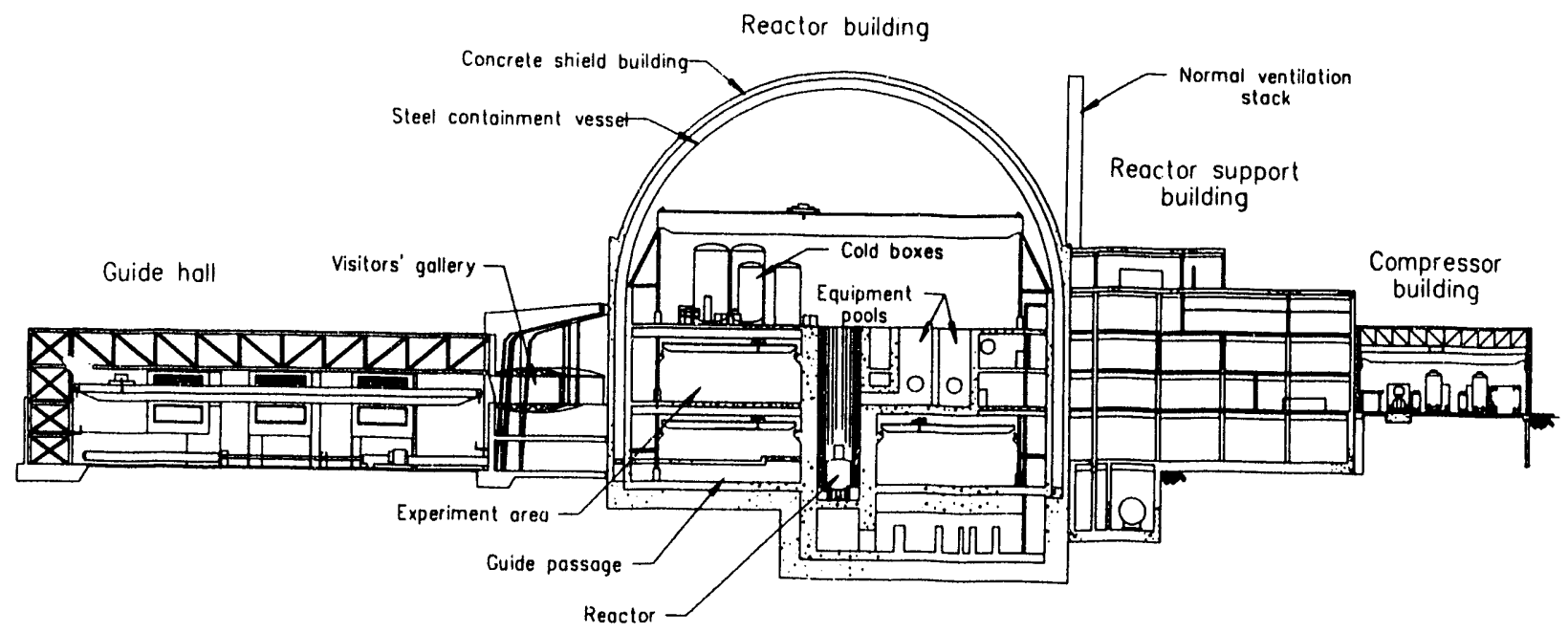

Fig. 3.14. Section through the guide hall, reactor building, reactor support building, and compressor building.

support into a single structure. Access to these areas is controlled by the security portal in the interface building. The reactor support building contains the operating equipment that controls and supports reactor operations. The operations support building, however, provides accommodations for personnel, maintenance shops, offices, and simulators (i.e., those functions essential to, but not directly supporting, reactor operations). The first three floors of the reactor support building house reactor operating equipment. The filters, demineralizers, transfer pumps, and storage tanks of the light water and heavy water cleanup systems are on the first floor of the building. On the second floor are the ventilation systems for the structure, penetrations of the reactor building, access to equipment in lower floors, and cooling pools. The personnel airlock from the second floor experiment area in the reactor building is also located on this floor. The third floor houses electrical distribution equipment and a line of battery rooms. Basin pools and the spent-fuel handling areas continue into this floor. The transfer tunnel between the spent-fuel pool inside the reactor building and the pool in the reactor support building is on this floor, as is much of the secondary coolant piping. In contrast to the lower floors, which contain most of the mechanical and electrical equipment, the fourth floor houses the control room and the associated technical and operator-support areas essential for reactor control.

The lower levels of the operations support building are devoted to the personnel access control functions of the interface area, the change rooms, the reactor mockup, training, the control room simulator, the maintenance shops, the remote shutdown control room, and offices. The upper floors house offices and other facilities for the reactor operations staff, including the DOE on-site staff.

\subsubsection{Guide Hall/Research Support Building}

The guide hall was designed as a single-story structure (Fig 3.12) with a large, clear span that will house most of the scientific instruments outside containment. A polar-type bridge crane provides coverage over all the guides and instruments. The section of the guide hall adjacent to the reactor building is a gallery for visitors to observe the activities within the guide hall. This observation gallery provides a view of the guide hall, while maintaining a physical separation of the gallery and research areas. 
The research support building is a facility where samples and instruments are prepared prior to installation in the guide hall or in the reactor building. The basement of the building contains the NAAF- 2 facility, including counting rooms and sample receiving and handling areas, all of which benefit from the shielding effect (from background radiation) of the below-ground location. Laboratories and shops are also located on the main floor to provide off-line setup areas for assembly of instruments and samples.

\subsubsection{Office Building/Interface Area}

The office building provides the main entrance for all personnel entering the ANS facility. The arrangement is such that personnel can be directed to the office building, the operations buildings, or the research buildings from this location. The office building is designed to provide a suitable environment for scientific and technical interaction between assigned or visiting personnel. All closed offices or open work areas have some exposure either to the outdoors or to an atrium. Open work areas will also provide opportunities and encouragement for interactions among the scientists. The entrance serves as a reference point to conduct traffic to offices or services available within the building. The ground floor includes the lower service entrance into the office building and provides passage to the research support building and to the guide hall. This floor of the office building includes food services, the library/media center, and other support areas.

The normal entry into the complex is on the second level. The main entrance leads into the entry atrium, and a direct corridor is available between parking areas and the major internal passageway into the buildings for those personnel assigned to the research or operations areas. Reception and security check-in facilities are provided just inside the entrance. The auditorium is located on this floor of the office building. A series of offices and conference rooms occupies the remaining floors.

\subsubsection{Detritiation Building}

The detritiation building houses the process equipment that removes the tritium from the heavy water in the reactor and from the deuterium in the cold source. The building ronsists of two structures: a detritiation and upgrade process building and a services building. The process building contains the actual detritiation equipment. The services building contains the local control room, the helium refrigeration system, analytical laboratories, and offices and other personnel areas, and it is physically separate from the process building to avoid unanticipated leaks from involving the services building. Covered walkways are provided between the two buildings. In the conceptual design, the detritiation building is shown as a steel superstructure covered with metal panels. Blowout panels are provided in the process building to minimize the extent to which a fire or explosion could damage process equipment and lead to additional releases of tritium or deuterium.

\subsubsection{Reactor Cooling Systems}

The reactor primary cooling system consists of four independent loops, three of which are normally in operation and the fourth of which is an isolated spare. Normal operating parameters are given in Table 3.1, and a diagram of the reactor water systems is shown in Fig. 3.15. Primary coolant flows up through the core and branches out to the four primary heat exchangers. Heavy water primary coolant flows through the primary heat exchangers, which give up heat to the light water secondary cooling system, and then through the emergency heat exchanger. Both heat exchangers are immersed in light water pools for safety reasons. The emergency heat exchangers function in the event of a loss of normal secondary heat sink and transfer heat directly to the pool by natural circulation of pool light water through the heat exchanger. In normal operation, the coolant entering the emergency exchanger is already cool, 
Table 3.1. Reactor primary cooling system normal operating parameters

\begin{tabular}{|c|c|c|}
\hline Parameter & SI units & Alternative units \\
\hline \multicolumn{3}{|c|}{ Full power operation } \\
\hline Reactor inlet temperature & $45^{\circ} \mathrm{C}$ & $113^{\circ} \mathrm{F}$ \\
\hline Reactor outlet temperature & $81^{\circ} \mathrm{C}$ & $177.8^{\circ} \mathrm{F}$ \\
\hline Heat to primary coolant & $316.6 \mathrm{MW}$ & $1081 \times 10^{6} \mathrm{Btu} / \mathrm{h}$ \\
\hline Reictor assembly coolant flow & $2112 \mathrm{~kg} / \mathrm{s}\left(1.923 \mathrm{~m}^{3} / \mathrm{s}\right)$ & $4656 \mathrm{lb} / \mathrm{s}(30500 \mathrm{gal} / \mathrm{min})$ \\
\hline Reactor assembly inlet pressure & $3.5 \mathrm{MPa}$ & 508 psia \\
\hline Fuel inlet pressure & $3.2 \mathrm{MPa}$ & 465 psia \\
\hline Reactor assembly outlet pressure & $1.69 \mathrm{MPa}$ & 245 psia \\
\hline $\begin{array}{l}\text { Normal core pressure boundary } \\
\text { joint leakage }\end{array}$ & $0.315 \mathrm{~L} / \mathrm{s}$ & $1 \mathrm{gal} / \mathrm{min}$ \\
\hline $\begin{array}{l}\text { Maximum core pressure boundary } \\
\text { tube joint leakage }\end{array}$ & $0.315 \mathrm{~L} / \mathrm{s}$ & $5 \mathrm{gal} / \mathrm{min}$ \\
\hline $\begin{array}{l}\text { Reactor secondary cooling system } \\
\text { supply temperature }\end{array}$ & $29^{\circ} \mathrm{C}$ & $84.2^{\circ} \mathrm{F}$ \\
\hline $\begin{array}{l}\text { Reactor secondary cooling system } \\
\text { return temperature }\end{array}$ & $46^{\circ} \mathrm{C}$ & $114.8^{\circ} \mathrm{F}$ \\
\hline $\begin{array}{l}\text { Reactor secondary cooling system } \\
\text { flow rate (total) }\end{array}$ & $4450 \mathrm{~kg} / \mathrm{s}$ & $9800 \mathrm{lb} / \mathrm{s}(64200 \mathrm{gal} / \mathrm{min})$ \\
\hline \multicolumn{3}{|c|}{ Shutdown operation/pony motor } \\
\hline Pony motor speed ( $\%$ fo full rated speed) & 10 & 10 \\
\hline Main pump coastdown & $2 s$ to half-speed & $2 \mathrm{~s}$ to half-speed \\
\hline Pony motor IE battery power & $4 \mathrm{~h}$ & $4 \mathrm{~h}$ \\
\hline
\end{tabular}

Note: Pressures are defined at the reactor assembly/reactor primary coolant system interface points, which are at piping flanges in the reactor pool.

and only a small amount of heat is transferred to the pool. From the emergency heat exchanger, coolant flows into the primary circulating pumps and is returned to the reactor assembly where flow from the three operating loops is recombined. The primary pumps have dc pony motors, powered by a bank of batteries and a set of emergency generators, capable of providing $10 \%$ flow for the system should primary power be lost. The elements of the primary coolant system are arranged so that natural circulation will occur upon loss of both normal and dc pony motor pumps. All the components of the system are in either light-waterfilled or limited-volume cells to maintain primary system pressure and inventory in the event of a major leak or break in the system.
The inventory and pressure within the primary system are maintained by means of a series of components that are part of the reactor pressure and inventory control system. The main components are the letdown control valves on the reactor primary cooling system, the letdown tank, the makeup pressurizing pumps, and the gas-filled accumulators. Flow through the system is established by setting the flow rate at the pressurizer pumps, and pressure in the reactor primary cooling system is maintained by the letdown control valves on each of the three operating loops of the reactor primary cooling system. A gas-charged accumulator is connected to each of the four reactor primary cooling system loops. The accumulators provide pressurization of

\section{Advanced Neutron Source (ANS) Progress Report}




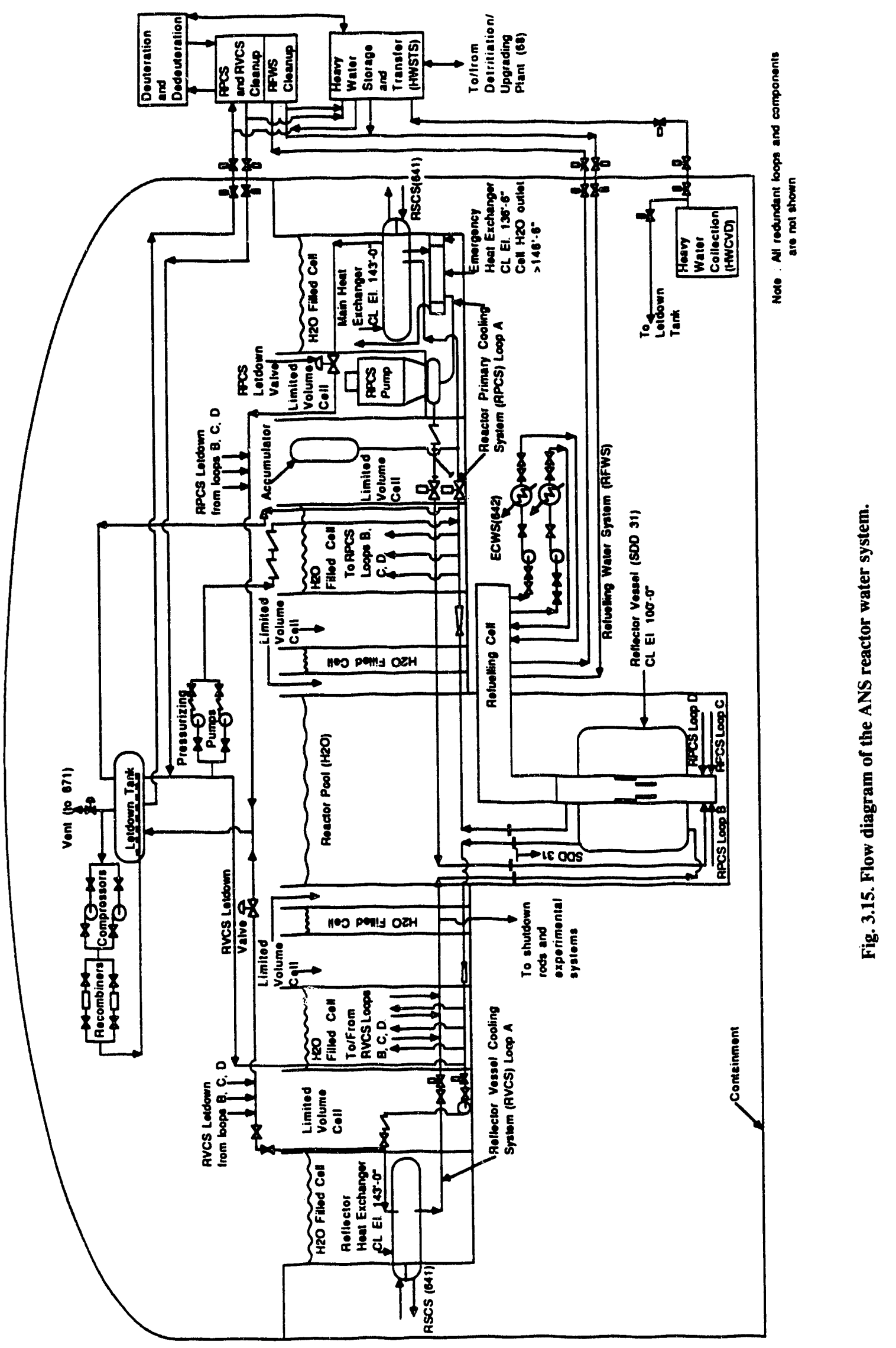

Advanced Neutron Source (ANS) Progress Report 57 
the reactor primary cooling system following loss of pressure in the system (e.g., failure of power to the pressurizer pumps) and contain a sufficient volume of heavy water to fill any limited-volume cell.

\subsubsection{Electrical Power}

The source of off-site power for ANS is based on a two-substation design: a primary substation and a reserve substation. The primary substation is fed by $161-k V$ transmission lines from two independent sources of electrical power. The first source is Tennessee Valley Authority's (TVA's) Ft. Loudoun Dam, and the second is the El>a substation at The Y-12 Plant, which is fed directly 'jy TVA's Bull Run Steam Plant. The reserve substation has a dedicated $13.8-\mathrm{kV}$ feed from the ORNL-0901 substation. In the event of a failure of the Bull Run Steam Plant, each of the buses in the primary substation is a full-capacity bus to provide power from Ft. Loudoun Dam for both ANS and for the Elza substation. Two primary plant service transformers are each capable of carrying the entire ANS load.

The reserve substation consists of a single reserve plant transformer with a primary breaker. The secondary of the transformer breaker feeds to the Class 1E switchgear. To maintain independence between the two Class $1 \mathrm{E}$ power divisions, the reserve substation can connect only to one Class $1 \mathrm{E}$ power division at any time.

The Class IE, or essential power for reactor operation or shutdown, power distribution system draws power from two independent $480-\mathrm{V}$ buses (Division 1 and Division 2), each of which may be powered from the preferred or reserve off-site power sources or by a Class $1 \mathrm{E}$ diesel generator set. Power is further subdivided into four independent subdivisions and then (where needed for reactor shutdown) into electrically independent primary and seconciary load groups for a total of eight load groups. Class $1 \mathrm{E}$ power distribution system subdivisions are kept separated physically, with no electrical cross-connections and with appropriate fire barriers (spacing or physical barriers or both) between equipment and raceways. In general, the plant is laid out such that reactor power and support systems are arranged in symmetric layouts around a centerline, with power $\therefore$ isions on each side of the centerline. The Class $1 \mathrm{E}$ dc power distribution system includes eight independent battery systems, corresponding to the eight load groups of the Class $1 \mathrm{E}$ distribution system. Inverters (connected to the Class $1 \mathrm{E}$ dc power distribution system) supply the Class 1E uninterruptible power distribution system for loads that require uninterruptible ac power.

\subsubsection{Containment Ventilation and Treatment}

The containment ventilation and gas treatment system provides filters, co:iditioners, and (for research areas) silencers for reactor building ventilation supply air. It also provides both filtered and nonfiltered paths for exhaust air (with the filtration system activated upon detection of activity in the air). Cooling of incoming air in the reactor building is provided by the nonessential chilled water system; heating is provided by hot water from the building nonessential heating system. Ventilation systems for operations and research areas are kept independent of each other. Similar systems serve the reactor support building, including the fuel-handling area.

The confinement ventilation and off-gas treatment system provides confinement, off-gas control, and air cleanup from contaminated processes and areas within the reactor and reactor support buildings. This system is divided into primary confinement systems, which are provided with high-efficiency particulate air-filtered inlet and outlet paths, and secondary confinement systems, which are provided with high-efficiency particulate air-filtered outlet paths. The reactor building annulus exhaust system directs outleakage from primary containment into a filter bank, provides filtration for iodine and particulates, and directs the discharge through a remote stack located on a hilltop on the southeast edge of the ANS candidate site such that the 
impact of the plume on site evacuation is minimized.

\subsubsection{Heavy Water Detritiation and Upgrade}

The $\mathrm{D}_{2} \mathrm{O}$ feed and product purification system receives and stores all heavy water entering or leaving the detritiation and upgrade facility, including fresh heavy water arriving at the site. Heavy water is also processed at the facility to remove the excess deuterium and tritium as a result of irradiation by the reactor. Tritium will be stored in a solid matrix and furnished to DOE for sales or disposal. The detritiated heavy water will be returned to ANS for use in the primary cooling water system.

\subsubsection{Plant Instrumentation, Computing, and Telecommunications}

Instrumentation, control, computing, and telecommunications systems integrate control, security, business, and experimental computer networks. These systems implement a philosophy of using distributed-control technology as much as possible, using highly integrated operator displays, and grouping control and computing systems in a manner that allows their particular requirements to be adciressed uniquely.

System connectivity is shown in Fig. 3.16. The distribution of control rooms, process instrumentation, computing facilities, research instruments, communication hubs, and their interconnecting plant communication backbone throughout the building is shown in Fig. 3.17. The SDD responsible for each function is shown in parentheses on Fig. 3.16. Cabling is included in SDD 62 unless shown otherwise.

The main features of the instrument systems are

1. The main reactor control complex including computer rooms, equipment rooms, and cable spreading rooms where reactor operators control the operation of the reactor.

2. A remote shutdown control room for shutdown of the reactor if the main control room is not available.

3. Control rooms for the cryogenics and detritiation facilities.

4. A control room simulator.

5. A computing and telecommunications center.

6. An on-site central alarm station for security.

7. A plant data communications backbone that provides a high-speed fiber-optic network for information transfer.

8. Fiber-optic links to ORNL facilities.

9. Separate communications systems for security, business and experiment data, and facility instrumentation and control.

10. A four-channel reactor/experiment protection system and Class 1E Plant Control and Data Acquisition System (PCDAS) for reactor shutdown and safety-related functions.

11. A two-channel multichannel nonsafety PCDAS system.

12. A data-handling system for integrater? information management system.

13. A highly reliable experiment system computer network that provides a path from experiment instruments to redundant mass data storage devices.

All of these systems are integrated via a flexible architecture that allows the systems to be subdivided where necessary to meet licensing and safety requirements. Systerns can also be grouped into major procurement packages to minimize the number of different kinds of equipment procured and thus minimize system interfaces, provide greater maintainability, and provide more efficient training. As an example, the non-Class IE PCDAS, plant simulator, remote shutdown, cryogenics, detritiation, and irradiation control room equipment will be obtained under one procurement package. Further, the architecture can accommodate separate qualified panel or hardwired instrumentation where they are needed 


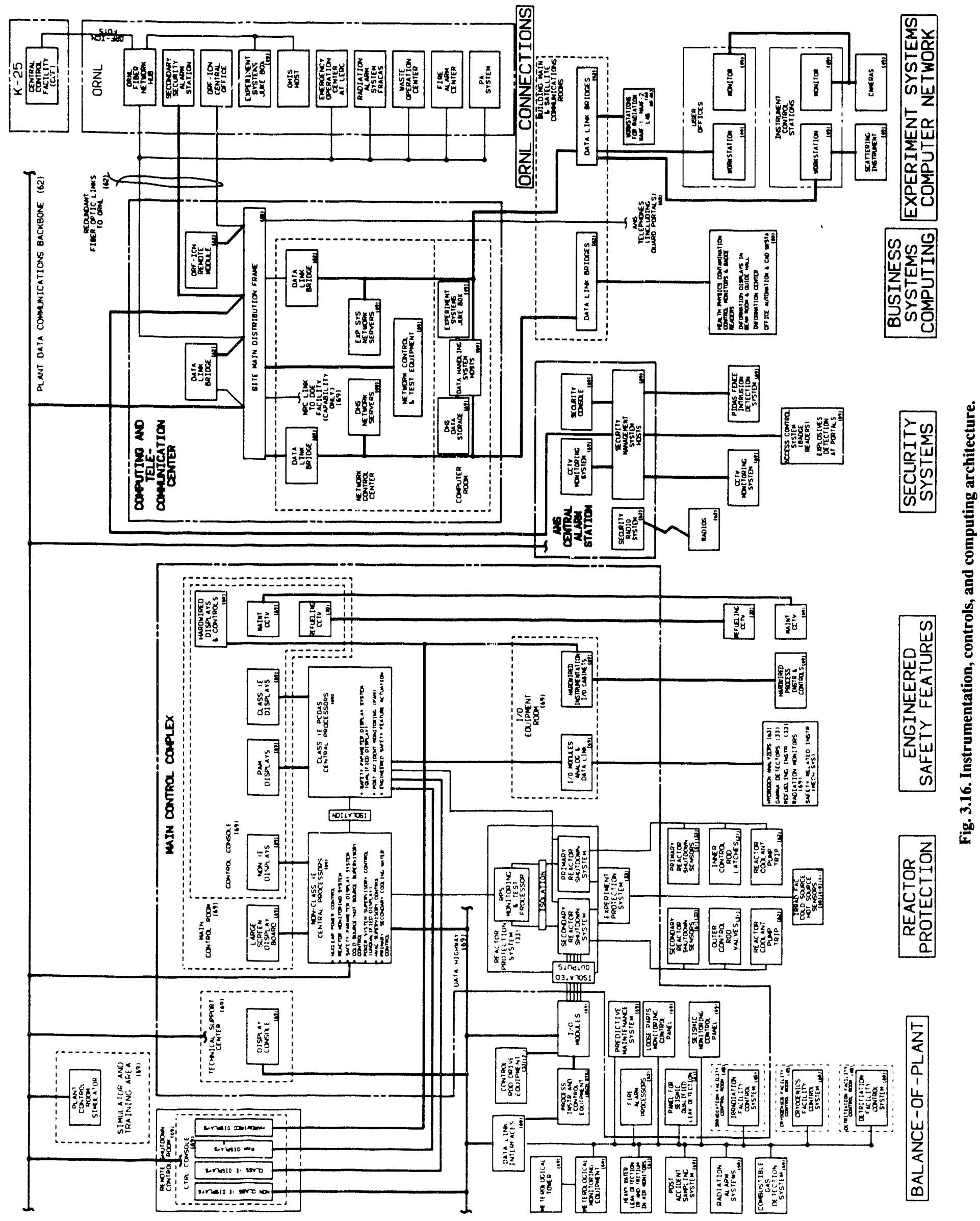




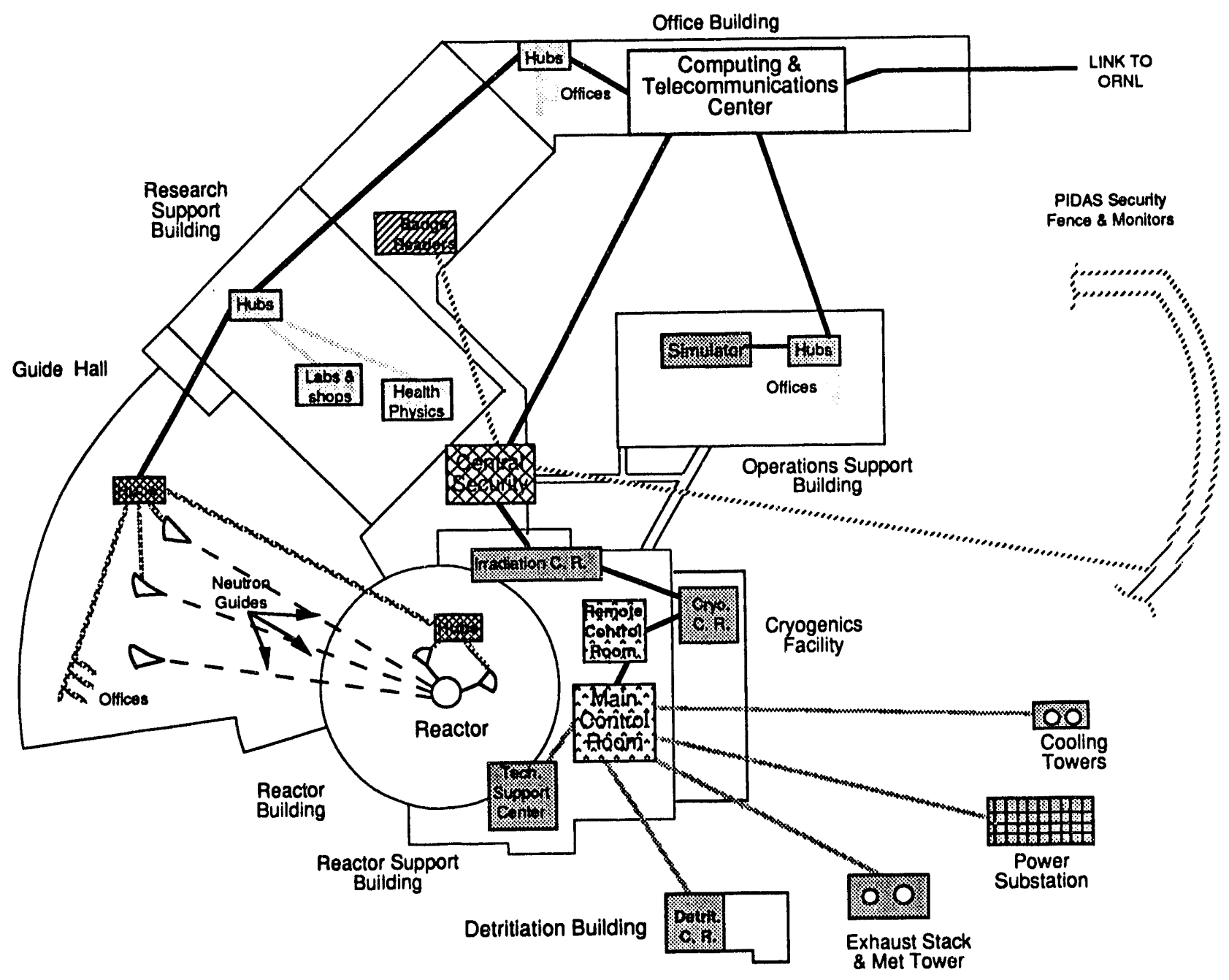

Fig. 3.17. Instrumentation, controls, and computing equipment.

to accommodate different technologies or to resolve licensing or safety issues.

Because of the explosive growth in the telecommunications and computing technologies, premature commitment to a particular technology is to be avoided. Thus, final selection of many of the details will be delayed until late in the design phase or early procurement phase of the project. The design concept provides the capability to use the latest commercially proven technology existing at the time of procurement. 


\section{SAFETY}

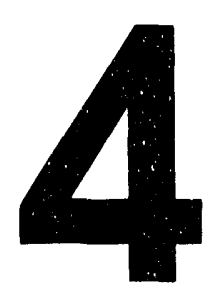

\subsection{ANS CONCEPTUAL SAFETY ANALYSIS REPORT}

The ANS CSAR was submitted as part of the CDR on June 30, 1992. The next issue of the safety analysis report (SAR) will be the preliminary safety analysis report (PSAR), which is scheduled for release in 1995 and which will be updated annually until the final safety analysis report (FSAR) is issued. The CSAR is based on the NRC Standard Format and Content of Safety Analysis Reports, ${ }^{4}$ as required by DOE Order $5480.6{ }^{32}$ The CSAR varies from the guidance for power reactors in some respects because:

1. According to NRC definitions ( 10 CFR 50, 50.2), the ANS is a test facility and not a power reactor.

2. In comparison with power reactors, the ANS will be operated at low temperatures and pressures.

3. In some instances, the format is inapplicable (e.g., the format specification of Chap. 10, Steam and Power Conversion, was replaced with a new ANS-specific chapter called Experiment Systems).

4. Of course, the detailed design data required in a PSAR or FSAR (see RG 1.704) are not available in a conceptual design but will be included in the later safety analysis reports.

\subsection{PROBABILISTIC RISK ASSESSMENT}

The ANS Project has established risk limitation goals for both core damage $\left(10^{-5}\right.$ per year) and large off-site releases $\left(10^{-6}\right.$ per year $)$, the former being attributed solely to internal events and the latter to both internal and external causes. During preconceptual and early conceptual design, the probabilistic risk assessment (PRA) team conducted studies and interacted with designers to incorporate risk minimization features into the design, thereby enhancing the prospect of meeting the ANS Project risk goals. Beginning in the early part of FY 1992, preliminary efforts began on a more comprehensive and detailed risk assessment: the Phase I, Level I PRA of the ANS conceptual design. The outcome of this analysis will yield a core damage frequency based on internal initiating events and on the performance of systems that must function to mitigate the effects of such events. At the time of this writing, the PRA is in the prequantification stages with the draft plant model complete (including event sequence diagrams, event trees, and doc nentation) and the draft system analyses nearly complete, with $90 \%$ of the fault tree models constructed and comments received on model descriptions from ANS designers.

With regard to meeting the off-site release goal, the report Advanced Neutron Source Containment Reliability Analysis ${ }^{33}$ was published to assess the ability of the conceptual ANS containment design to contain and filter fission products resulting from a hypothetical core damage accident. The results of this study are summarized in last year's progress report ${ }^{9}$ for those desiring further information. Containment integrity is analyzed as part of a Level II PRA (scheduled to be completed in 1995) and is a required step before calculating the risk of off-site releases in a Level III assessment. 


\subsubsection{Methodology}

The method used to achieve results for the ANS PRA will quantify system fault trees to evaluate functional availability (top event availability) and to form a master frequency file that will be used in quantifying event trees that model the sequence of events following the initiating event. Component failure data from the HFIR have been used, where applicable, with other data coming from accepted sources such as IEEE Standard 500-1984 ${ }^{34}$ and from military handbooks. To perform the vast number of calculations necessary for this type of analysis, the PC version of Riskman, ${ }^{35}$ Version 3.0, was licensed from PLG, Inc., of Newport Beach, California, whose services were also contracted to assist in plant modeling and analysis.

\subsubsection{Key Components and Systems}

In modeling the various cooling and protective systems of the ANS, several components and systems have been identified as playing a significant role in plant availability (discussed below) and/or core damage frequency. These include:

- The reflector vessel cooling system (RVCS) necessary for cooling the outer shutdown rods. Failure of the RVCS in a scenario in which the inner rods have failed to scram would have to be counted as a failure of the secondary shutdown system to scram, and this is conservatively assumed to lead to core damage.

- The potential for flow blockage as a result of strainer failure or of dropping foreign material into the system during refueling or maintenance. At this time, any flow blockage is assumed to result in core damage, but experiments are planned to identify the maximum allowable blockage size.

- Unavailability of the instrument air system (IAS) for pressure and inventory control. The IAS is discussed in more detail below.

- The likelihood of mishandling during refueling resulting in recriticality of a fuel element. Though not an operating event, the potential for severe contamination makes this a concern of importance to health and safety, as well as to plant availability.

Because of the current early stage in design, some areas of potential risk, such as refueling, can be examined only qualitatively. The results of the PRA will provide insight into the emphasis that needs to be placed on these and other issues related to plant availability and to the potential for core damage.

The ANS design goal for plant availability is $80 \%$, excluding planned maintenance outages and refueling periods. Achieving such a goal will require highly reliable support and frontline systems with sufficient redundancy to allow for intermittent failures and extremely tight tolerances on all maintenance practices to correct those failures. Such a small margin for error will inevitably place a heavy burden on human reliability. The ANS experiment systems place additional constraints on plant availability, most prominently with the presence of the cold source. While the results of the PRA mainly will provide insights into the probability for core damage, systems that are high contributors to core damage frequency or whose failure will initiate a transient are also an availability concern.

Failure of the IAS would result in the secondary cooling system natural circulation valves failing open, with a consequent trip of the secondary cooling pumps. This would require a reactor scram on primary low-low flow or high flux/flow following the required tripping of primary pumps because of lack of sufficient oil cooling from the secondary cooling system. In addition, the primary and reflector coolant letdown valves fail closed on loss of air, causing a loss of pressure control on the primary side and of inventory control to both systems. The impact of failure of the IAS on availability and core damage frequency will be clearer following completion of the PRA.

The nonessential cooling water system (NECWS) provides support to the helium compressors of the cryogenics support system as 
well as to the compressors of the IAS. Loss of either of these systems will result in a reactor scram. The reliability of the NECWS, then, becomes a concern to plant availability.

Although neither the cold source nor its supporting cryogenics support system are modeled in the PRA, it is apparent that the reliability of these systems and their supports will play a major role in the continued operation of the ANS. The impact of the cold source on plant availability will become more clear as success criteria are established for the number (if any) of compressors and cold boxes that must be available for continued operation without necessitating an unplanned outage of the reactor.

\subsubsection{ANS Plant Model}

The ANS plant model is divided into three parts-initiating events; support system response to the initiator; and frontline system response to the initiator, as well as the support system response. The end states of the support system model define the limiting parameters on the frontline system model. Following a review of the plant responses to several initiating events, event sequence diagrams were constructed for (1) a LOCA that results in rapid system depressurization, (2) a LOCA that causes a slower primary depressurization during which the makeup pumps and letdown valves can maintain pressure and inventory while safely scramming the reactor, and (3) a general transient that includes the plant response to many different initiating events. Throughout the modeling process, it has become apparent that the most important functions following a transient are a successful reactor scram followed by sufficient primary and reflector cooling.

A direct product of plant modeling is the definition of top events, functions of different systems that may be required to mitigate successfully the effects of the initiating event. Currently, there are 48 top events in the ANS model, one or more of which represent various combinations of failures within the following systems:
- electric power system,

- non-Class IE PCDAS,

- Class 1E PCDAS,

- RPS,

- reactor power level control system,

- NECWS,

- IAS,

- reflector vessel cooling,

- reactor pressure and inventory control,

- reactor primary cooling system, and

- reactor secondary cooling system.

Preliminary quantitative results will be available early in FY 1993. It is expected that common-cause component failures, although of low probability, will appear high in the list of scenarios contributing to core damage risk because of the many redundancies in the conceptual design, which make the probability of non-common-cause failures extremely small.

\subsubsection{Other PRA-Related Activities}

\subsubsection{Analysis of Start-up Rod Withdrawal Sequence Failure}

An analysis was performed to determine the failure frequency of the start-up rod withdrawal sequence. The currently designed sequence for rod withdrawal at start-up requires the outer rods to be withdrawn fully before the inner rods can be modulated out. One of the reasons is that the outer rods have no intermediate position; they are either completely inserted or fully withdrawn. Thus, having the inner control rods withdraw while the outer rods are still inserted, despite existing interlocks, could result in an excess positive reactivity insertion if the outer rods are subsequently withdrawn, rather than returning the reactor to shutdown. For this to happen, two failures would have to occur: (1) the outer rods fail to withdraw on demand, and (2) the inner rods are allowed to withdraw because of interlock failure, operator error, or spurious actuation. A fault tree was constructed to represent the most likely paths 
to sequence failure and was quantified using Riskman. ${ }^{35}$ The result of the quantification, a sequence failure probability of $2.38 \times 10^{-6}$ per year, placed this event in the design-basis category of extremely unlikely; even so, a limitation on outer rod withdrawal speed was recommended to limit reactivity insertion rate should the inner rods somehow be withdrawn out of sequence. A suitable limitation on speed will make this event a benign occurence by limiting the peak power level reached as a result of the reactivity insertion.

\subsubsection{Primary Coolant Loop Reduction Availability Study}

This study examined the changes in plant availability for several different primary cooling system designs ranging from the baseline concept of four $33.3 \%$ loops (three running with one in standby) to two 50\% loops (both running and no standby). The analysis also considered whether or not the reactor could operate at a reduced power level following failure of one or more primary loops. Fault trees were constructed for each design assuming that all support was available, so that the results would reflect only failures of primary system components. The quantifications were based on failures per fuel cycle (i.e., $17 \mathrm{~d}$ of operation). The system failure rates were converted to unavailability using repair times to account for the degree of loss resulting from the failure.

The results showed that the best alternatives, from an availability standpoint, are found with the four-loop primary coolant system designs where only three available loops are required for continued operation, whether the loops are $33.3 \%$ or $25 \%$ capacity. For both of these designs, less than $4 \mathrm{~h} /$ year was lost because of component failures. The worst configurations were the threeand four-loop designs in which all loops were required to function for continued operation, with at least $3.5 \mathrm{~d} /$ year lost because of the lack of operating margin.

Because of the potential gains in availability, a four-loop primary cooling system was recommended for the ANS baseline design concept. It should be kept in mind that the unavailability of support systems (electric power, secondary cooling, and pressure/inventory control) will also impact the performance and availability of the primary cooling system, as will the constraints placed on the conditions for continued plant operation.

\subsection{TRANSIENT THERMAL HYDRAULICS}

Four major areas of effort continued during this reporting period: (1) statistical uncertainty analysis to determine appropriate probability levels for transient analysis, (2) RELAP5 modeling and caiculations for the ANS CSAR accident analysis, (3) RELAP5 verification and validation efforts, and (4) investigation of the effect of core inlet flow blockage on the thermalhydraulic behavior of the ANS fuel.

A graduated system of statistically based acceptance criteria for transient analysis was put into place this year and utilized for the CSAR calculations. To minimize risk in a cost effective manner, the acceptance criteria for more frequent events must be evaluated at a higher nonexceedance probability, which has the effect of requiring more margin for events that are expected to happen more often. For example, the basic criterion for avoidance of burnout during either anticipated events (frequency $>10^{-2} /$ year) or unlikely events $\left(10^{-2} /\right.$ year $>$ frequency $>10^{-4} /$ year $)$ is the same: the heat flux at any spot in the core must not exceed the CHF predicted by the Gambill-Weatherhead correlation, and the heat flux integrated along any hot streak must not exceed the flow excursion (FE) limit predicted by the Costa correlation. But the margin to bumout required in each case is not the same: for the more frequently occurring anticipated events, the nonexceedance of CHF or FE limits must be proven at a $99.9 \%$ probability level, whereas for an unlikely event it need be proven only at a $95 \%$ nonexceedance probability. The difference between the 99.9 and $95 \%$ nonexceedance 
probabilities has the effect of requiring about $22 \%$ more margin for anticipated events than for unlikely events. The method for assessing compliance with statistically based acceptance criteria is discussed below.

\subsubsection{Statistical Uncertainty Analysis}

To perform an adequately conservative evaluation against the acceptance criteria, the following uncertainties must be accounted for: manufacturing parameters (such as fuel-plate fabrication tolerances), operating parameters (such as inlet pressure and temperature), and analytical models used (such as the CHF correlation). The merits of several methods to perform thermalhydraulic uncertainty analysis, both statistical and nonstatistical, were evaluated. These included:

1. The approach in which each parameter is assigned a constivative constant value reflecting, typically, 2 or 3 standard deviations from the mean, and then assuming that all the parameters exist simultaneously at their conservative values. This approach, although simple, was judged to be unnecessarily conservative and, perhaps more seriously, does not provide any quantitative measure of the level of risk involved.

2. The square root of the sum of the squares approach, which assumes that all the uncertainties are independent and incorporates them via standard deviations. Although this approach is statistically based, it generally provides only an approximation of the relationship among uncertainties and therefore may provide nonconservative results.

3. A full statistical approach that combines input uncertainties randomly (via sampling of individual uncertainty distributions) in repeated simulations. The Monte Carlo? technique, which is the most basic one for implementing this approach, is fully statistical and provides a definitive statement of the safety margins or probability levels achieved.
However, it was judged to be impractical to complete a full-transient statistical method before the end of conceptual design, so a combination of the fully statistical approach and the deterministic approach was adopted. Uncertainty factors based on this simplified approach were used for the transient analyses reported in the CSAR.

In the simplified approach, two statistically based peaking uncertainty factors are first generated separately and are then incorporated into the RELAP analysis along with a number of other parameter uncertainties that are treated deterministically. Only one RELAP calculation is therefore required to determine reactor transient response, while still allowing a statistical interpretation of the results.

One peaking uncertainty factor is defined to account for uncertainties in parameters directly affecting the fuel-plate heat flux and is denoted as the hot-spot peaking factor. The other is defined to account for uncertainties in parameters directly affecting the bulk coolant temperature rise and is denoted as the hot-channel peaking factor. Uncertainties in parameters that scale proportionally with power directly affect either the fuel-plate heat flux or the bulk coolant temperature and, therefore, can be incorporated statistically into peaking uncertainty factors. For the hot spot they include reactor power; power distribution; incipient boiling (IB), CHF, or FE limit correlations; and fuel segregation/nonbond. For the hot channel, they include reactor power, power distribution, fuel-plate heated length, and integrated hot streak.

Monte Carlo analysis is used to determine both hot-spot and hot-channel peaking uncertainty factor probability distributions using the probability uncertainty distributions of their respective individual input parameters. Next, the peaking factor distributions are used to define the appropriate peaking factors at the desired probability and confidence level.

The other parameter uncertainties are treated deterministically. All parameter uncertainties included in the present approach are given in 
Table 4.1. Table 4.2 presents the net peaking uncertainty factors for the limiting criteria at both 95 and $99.9 \%$ probability levels. The factors in Table 4.2 account only for uncertainty. Therefore, they are multiplied by the appropriate calculated power distributions to determine the RELAP5 input. For each probability level, there is one hotspot uncertainty factor for CHF and IB and one for FE. The factor for FE is based on the heat-flux hot-streak factor rather than the fuel segregation/ nonbond heat-flux factor that is applied to CHF, since some significant physical length is required to establish a flow excursion condition.

The development of a thermal-hydraulic data base, initiated during the last reporting period, continued. The data base was expanded; additional correlations were evaluated; and correlation uncertainty values were determined for use in the statistical uncertainty analysis. Based on the experience of others, ${ }^{36,37}$ in several instances (e.g., CHF, FE, and IB correlations) the uncertainty levels used in this uncertainty analysis represent extrapolations to values expected and achievable in the future with a specific ANS experimental data base.

Manufacturing uncertainties were also addressed. Activities included optical scanning of HFIR fuel-plate radiographs and statistical analyses of HFIR fuel-plate channel-gap data.

\subsubsection{RELAP Model and Accident Analysis Calculations}

Three major regions of the primary system are incorporated in the RELAP model (see Fig. 4.1)-the core, the heat exchanger loops, and the pressurizing/letdown system.

Table 4.1. Probability distributions used in simplified statistical uncertainty analysis for transient analysis

\begin{tabular}{|c|c|c|c|c|}
\hline Parameter & $\begin{array}{l}\text { Probability } \\
\text { distribution }\end{array}$ & $\begin{array}{c}\text { Distribution } \\
\text { level }\end{array}$ & $\operatorname{Mean}^{a}$ & $\begin{array}{c}\text { Standard } \\
\text { deviation or } \\
\text { deterministic value } a\end{array}$ \\
\hline CHF correlation & Normal & Core & 1.0 & 0.10 \\
\hline FE correlation & Normal & Core & 1.0 & 0.10 \\
\hline Power del isly cistribution & Normal & Core & 1.0 & 0.03 \\
\hline Integrated hot sistak ${ }^{b}$ & Log-normal & Plate & 1.030 & 0.00425 \\
\hline Reactor power & Normal & Core & 1.0 & 0.018 \\
\hline Fuel-plate heated lingth & Normal & Plate & 1.0 & 0.0036 \\
\hline IB correlation & Normal & Core & 1.0 & 0.10 \\
\hline Local fuel segregation plus nonbond & Deterministic & & & 1.31 \\
\hline Fuel beyond radial boundary ${ }^{c}$ & Deterministic & & & 1.02 \\
\hline Fuel beyond axial boundary ${ }^{d}$ & Deterministic & & & 1.05 \\
\hline Friction factor correlation & Deterministic & & & 1.1 \\
\hline Inlet coolant temperature & Deterministic & & & 1.014 \\
\hline Exit pressure & Deterministic & & & 0.896 \\
\hline Flow & Deterministic & & & 1.0 \\
\hline Channel gap & Deterministic & & & $1.14 \mathrm{~mm}^{e}$ \\
\hline
\end{tabular}

${ }^{a}$ These are used as unitless multipliers against the indicated parameter unless otherwise indicated.

${ }^{b}$ A statistical average of the hot streak along plate axial length.

'Edge subchannels only.

${ }^{d}$ Entrance and exit nodes only.

${ }^{e}$ This value is $20 \%$ of the nominal $1.27-\mathrm{mm}$ gap and is assumed to apply to the whole length of the hot channel. 
Table 4.2. Hot-spot and channel peaking uncertainty

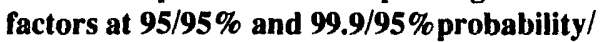
confidence levels

\begin{tabular}{lc}
\hline \multicolumn{1}{c}{ Peaking factors $^{a}$ 95/95\% } \\
Hot spot (IB, CHF) & 1.59 \\
Hot streak (FE) & 1.33 \\
Hot channel & 1.10 \\
$\quad$ Peaking factors & \\
Hot spot (IB, CHF) & \\
Hot spot (FE) & 1.94 \\
Hot channel & 1.63 \\
\hline
\end{tabular}

${ }^{a}$ Peaking factor is the appropriate local or integrated area heat flux divided by the core average heat flux.

Major modifications to the RELAP5 core region model have been made since the last reporting period to improve model fidelity with the conceptual design. The core model is now more complex, but it is more complete. An additional hot channel and an additional hot stripe were added to provide CHF and FE monitoring at the 95 and $99.9 \%$ nonexceedance probability levels. Modeling of the core bypass paths was modified to describe more accurately the doublewalled CPBT and the inner control rod flow channels. Input of gamma heating of the nonfuel structures was updated to reflect new calculations, and a simulation of the slower decay of gamma heating in nonfuel structures was added. These changes, and their associated input data, are discussed in detail in the CSAR.

The loop model remains similar to that reported last period and contains four independent heat exchanger loops, three active and one standby. Each loop consists of a check valve, a hot/cold leg, an accumulator, horizontal U-tube main and emergency heat exchangers, a centrifugal main circulation pump, and a flow diode (a preferred-direction flow device). The open-loop representation of the letdown and pressurizing system used previously is maintained in this model.

As examples, three of the accident analyses reported in the CSAR will be discussed in this section-the station blackout event, an instantaneous core exit break, and a timedependent core inlet break. In all cases, initial conditions were conservatively assumed to be perturbed from nominal conditions to the edge of the operating region to reflect instrument measurement and control uncertainty during normal operation.

\subsubsection{Station Blackout Analysis}

This event is initiated by a loss of off-site power that interrupts ac power to plant equipment such as the primary coolant pumps, the pressurizing pump, and the secondary coolant pumps. To demonstrate the high degree of passive safety inherent in the ANS coolant system design, the diesel generators are assumed not to start, and off-site power is assumed to remain unavailable. Therefore, after the diesels fail to start during the first minute or so (ANS does not employ faststarting diesels), the loss of off-site power becomes a station blackout event. Direct current from the station batteries powers the primary coolant pony motors for the first 30 min after scram, and natural circulation takes over after the assumed battery depletion at $30 \mathrm{~min}$.

To demonstrate the robustness of the ANS design and its compliance with regulatory requirements, this calculation is performed with a variety of further concomitant equipment failures. The failures are chosen to affect the apparent safety margins during different parts of the calculation and are, therefore, not really simultaneous multiple failures. For example, only the primary inner shutdown rods are utilized for reactor shutdown, and this has a slight effect on reactor power at the time of the scram. A preexisting failure of one pony motor is assumed, and this decreases the primary coolant flow available after the pump coastdown (i.e., after about $10 \mathrm{~s}$ ). The assumed sticking open of a letdown valve slowly depressurizes the primary coolant. This depressurization, and the spurious closure of one loop isolation valve after $10 \mathrm{~min}$, maximizes stress on thermal-hydraulic margins during the transition to natural circulation at $30 \mathrm{~min}$.

At $30 \mathrm{~min}$, when station batteries are assumed to be depleted, all power (including dc power) to 


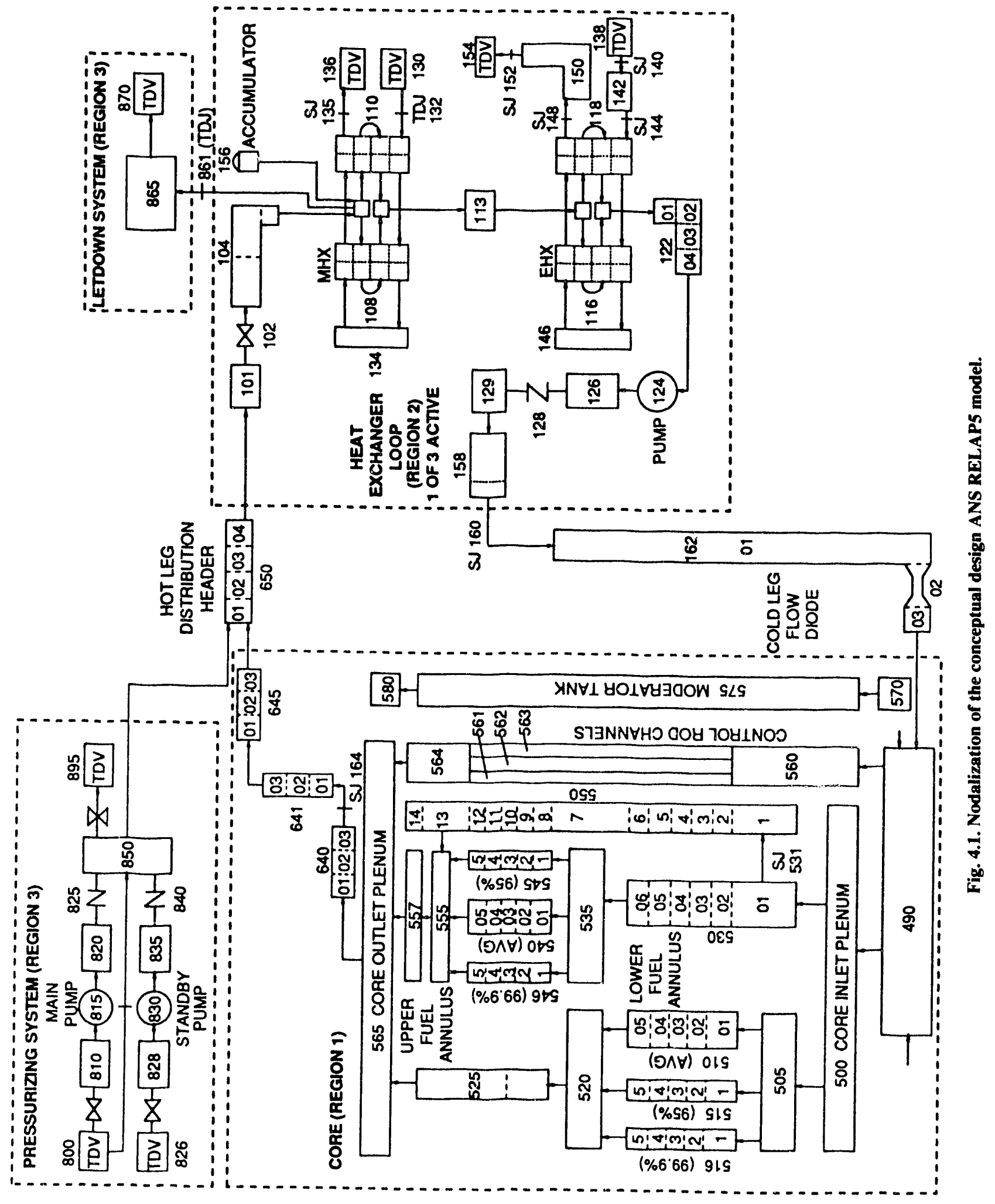

70 Advanced Neutron Source (ANS) Progress Report 
all primary coolant pumps is lost. For this scenario, in order to prevent reaching the thermal limits early in the transient, the flux-to-flow ratio trip was reset from the typical analysis value of 1.2 to a value of 1.105 .

\subsection{Results—station blackout}

When primary coolant pump ac power is lost, the core flow quickly declines, causing increases in the average fuel and core exit temperatures. The scram insertion stroke begins at $10.57 \mathrm{~s}$, and core power quickly drops to the decay heat rate. Loop pressures begin to equilibrate as the pumps coast down, while overall system pressure declines slowly over the entire duration of the transient $(2510 \mathrm{~s})$ as a result of the open letdown valve and loss of makeup flow.
Primary loop flow rates are shown in Fig. 4.2. At about $30 \mathrm{~s}$ into the transient, the two circulation pumps that have active pony motors reach ponymotor speed while the pump with the failed pony motor stops completely, stagnating the flow in that loop. At $610 \mathrm{~s}$, the isolation valve in one of the still active loops spuriously closes, stopping flow in that loop as well. At $1810 \mathrm{~s}$, both active pony motors coast down as a result of depletion of the station batteries. Shortly after battery depletion, natural circulation is established in the two cooling loops that have an open flow path.

Figure 4.3 compares the minimum flow excursion and critical heat-flux ratios (defined as the calculated limiting heat flux divided by the local surface heat flux) at two critical juncturesat the very beginning and during the transition from pumped to natural circulation. The minima in

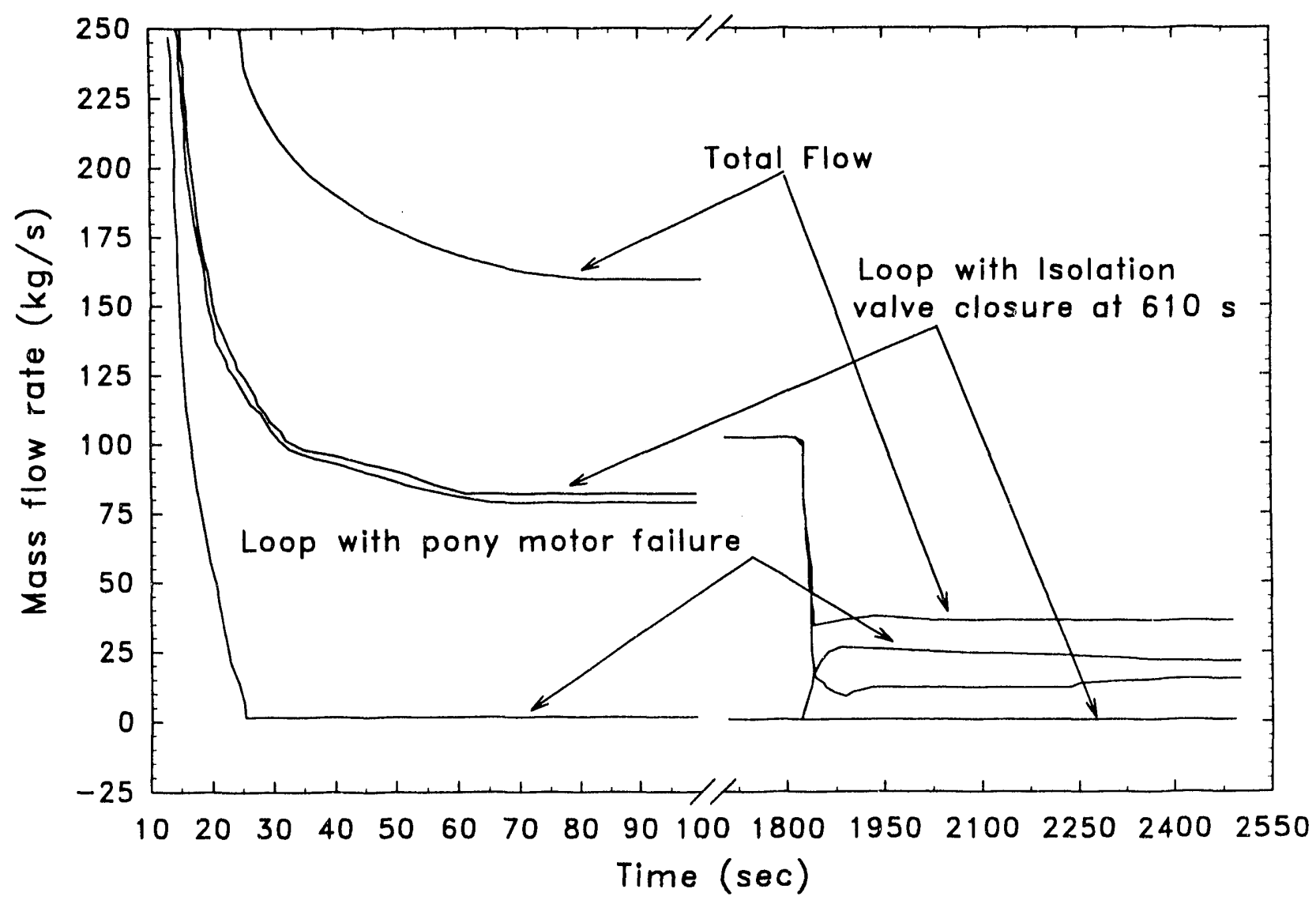

Fig. 4.2. Loop flow rates for the station blackout event. 


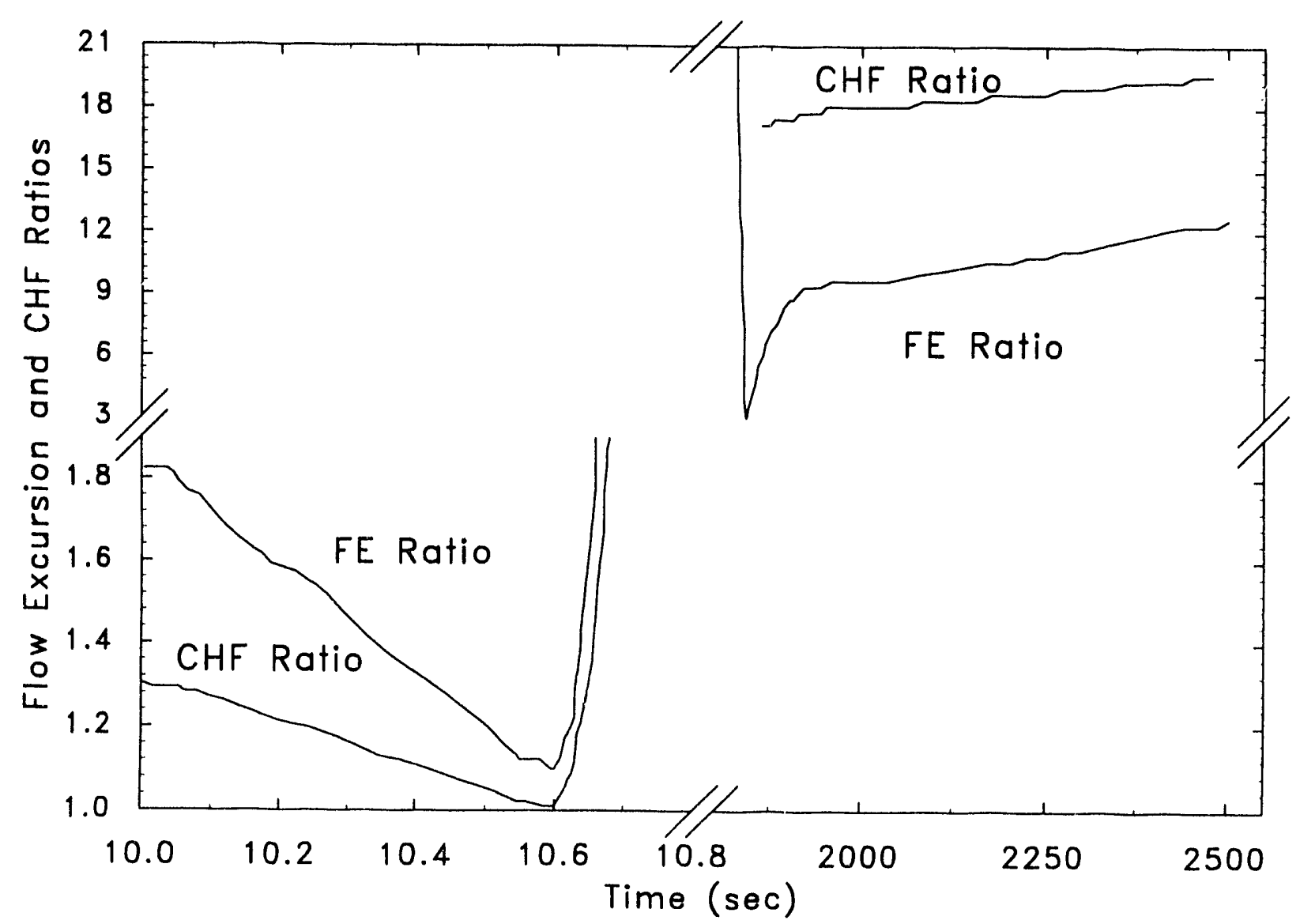

Fig. 4.3. Flow excursion and CHF ratios for the station blackout event.

both of the safety ratios occur after only $570 \mathrm{~ms}-$ before the reactor protection system has a chance to effect a shutdown. The minimum $\mathrm{CHF}$ ratio reaches approximately 1.01 , while the $\mathrm{FE}$ ratio is approximately 1.12. A second minimum in the FE ratio is also noted at approximately $1840 \mathrm{~s}$ as the flow transitions to natural circulation.

In summary, the ANS design is shown to meet the anticipated event acceptance criteria for the station blackout scenario if the reactor flux-toflow scram set point is reduced from the usual analysis input value of 1.2 (based on a nominal scram setting of 1.15 ) to a value of 1.105 (which would be consistent with a nominal scram setting of 1.055). A station blackout scenario, as defined earlier, is initially an anticipated event but becomes an unlikely event when the diesel generators fail to start. This indicates the need for design improvement, because it is desirable to run with a scram set point more than $5.5 \%$ above the normal fuil operating power to avoid too many spurious scrams. Examples of steps that would help include the improvement of core power distribution control (fuel grading) and the addition of an ariticipatory reactor trip that would begin inserting control rods immediately upon loss of off-site power instead of waiting for the flux-toflow ratio to hit the scram set point.

\subsubsection{Selected Pipe Break Events}

To examine methods of accident consequence mitigation, a selected number of break locations 
and mitigá on techniques were chosen for analysis. Primary break transients initiated from three limiting break locations were presented in the ANS CSAR.

Tne locations were chosen to represent the worst-case locations in the primary system piping. They include failure of piping at the core o et, rupture of the outer wall of the CPBT, and failure of the piping at the core inlet. In addition, a sensitivity study examining break-opening time was conducted for breaks at the core inlet. Future calculations will examine regions beyond those limiting break areas.

For the current LOCA calculations, the pressurizing pump is tripped upon break initiation to simulate the loss of ac power at the same time as the LOCA occurs. (The pressurizing pump coasts down to $73 \%$ speed during the first second after trip.) This is done to preclude LOCA from imposing a requirement for fast-starting diesels.

\subsection{Core outlet break with core outlet venturi}

The preferred design approach for the primary piping in the imme liate vicinity of the core outlet is to make it sufficiently thick walled that its rupture would be so improbable $\left[<0.5(10)^{-6} /\right.$ year $]$ as to be excluded from design-basis accident analysis. Nevertheless, a break in this piping was examined to determine if other engineering design features could be incorporated to prevent core failure. I :tial calculations indicated that the hotspot, the hot-channel, and the average channel conditions all exceeded the FE and CHF limits in the lower fuel element for this hypothetical event. It was therefore desired to determine if a venturi device installed at or near the reactor outlet would protect the reactor core from double-ended, instantaneous pipe rupture at any location downstream from the core, between the venturi throat and the circulating pump inlet. The calculations presented in the next section indicate that such a venturi device, would indeed protect the reactor core from the worst possible breaks in the core outlet piping. Vibratory structural loads associated with cavitation phenomena in the venturi have yet to be investigated.

An instantaneous break was assumed to occur in the 610-mm-diam piping at the core outlet. To protect the core from this break scenario, a venturi (234 $\mathrm{mm}$ at the throat region) was placed at the core exit. The venturi was designed so that the fluid in the throat would reach saturation conditions if the core exit pressure at nominal flow and temperature were to decrease by $1 \mathrm{MPa}$, or more, below normal. This rnitigates the initial pressure wave and quickly chokes the exit flow, slowing the core depressurization rate.

\subsection{Results-core outlet break with venturi}

Results showing the core pressure response to the core exit break (with the venturi in place) are presented in Fig. 4.4. The break is initiated at $10 \mathrm{~s}$. The initial pressure wave reaches the core exit approximately $18 \mathrm{~ms}$ into the transient and is evidenced as oscillations about the longer-term, system depressurization rate. This causes a minimum in the CHF ratio (1.48) and FE ratio (1.66).

The closest approach to CHF occurs in the lower element at the fourth axial position, instead of at the fifth axial (exit) position, because the heat flux is relatively low at the exit. The L7 fuel loading has a flat relative power density profile at the entrance but decreases rapidly over the last half of the lower fuel element length. The closest approach to FE occurs at the fifth axial position.

The behavior of the venturi is presented in Fig. 4.5. Pressure vs time histories at the venturi inlet, exit, and throat are shown. As the pressure wave moves from the break (located downstream of the venturi) toward the core inlet, the lowpressure throat region saturates, attenuating the resulting wave, which continues to move toward the core exit.

For this accident scenario, the $95 \%$ probability level hot spot did not exceed either the CHF o: FE limit, thereby meeting the criterion for unliksty events. The very severe, double ended $610-\mathrm{mm}$ 


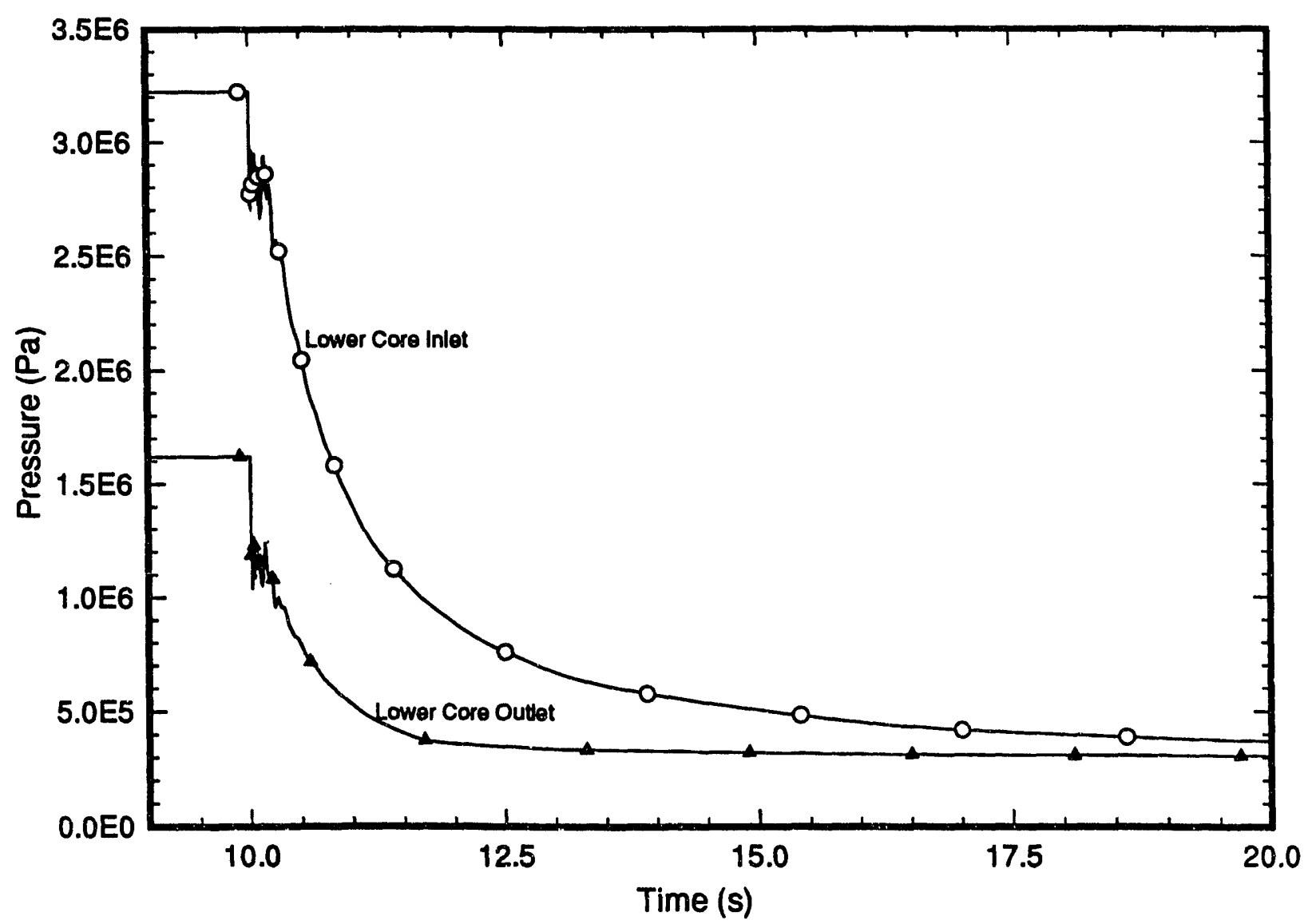

Fig. 4.4. Pressure response for a core outlet break with venturi in place.

break postulated for this scenario would be either unlikely or extremely unlikely.

\subsection{Core inlet break with increased brea opening time}

Recognizing the physical impossibility of an instantaneous, double-ended, guillotine break in the stainless steel portion of the piping system, parametric analyses were performed to examine the impact of using a finite opening time for an inlet break in one of the three normally operating piping legs (356-mm diam) leading to the core inlet. The treak, in this case, was still assumed to be double-ended, but the transition from intact pipe to broken, double-ended configuration is assumed to occur over a finite, although short, period of time: that is how a large break might actually occur during an earthquake when a worst case, preexisting flaw penetrates the full thickness of the pipe wall, grows longer with each seismic stress cycle, and then gives way entirely.

\subsection{Results-core inlet break with increased opening time}

Results showing the core pressure response to a double-ended guillotine break in one of the pipes leading to the core inlet are shown in Fig. 4.6 for a 1.1-s break opening time. The pressure response is much smoother than the nonphysical instantaneous breaks examined, because the high- 


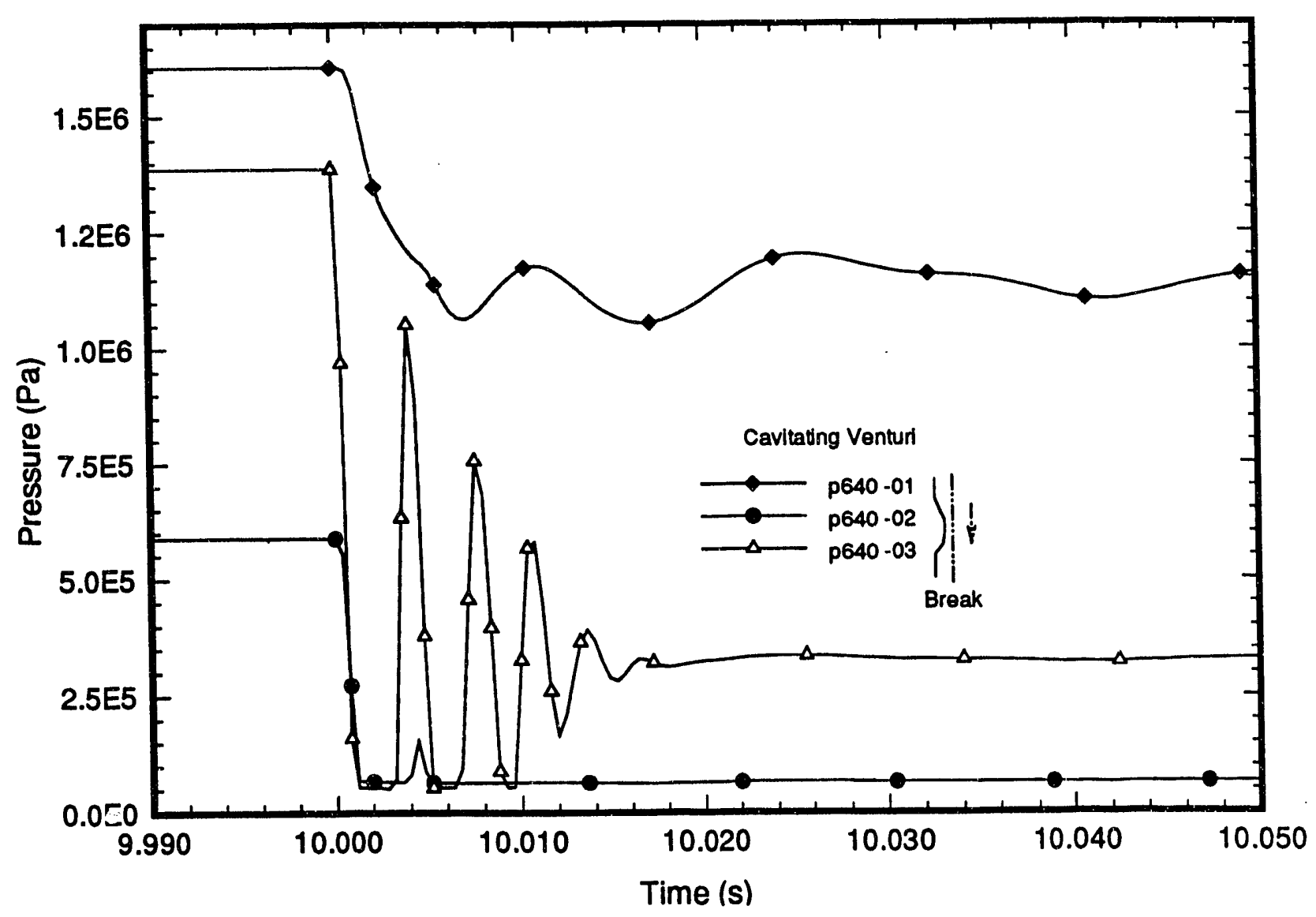

Fig. 4.5. Pressure response of the cavitating venturi-hot leg break (short time scale).

frequency pressure waves computed in an instantaneous break are eliminated by the slower opening times. The pressures stabilize within about 1 to $1.25 \mathrm{~s}$ after the break opening (the break occurs at $10 \mathrm{~s}$ ).

The core power remains constant over the first $400 \mathrm{~ms}$ until the reactor trips on low exit pressure and then drops to decay heat levels. The thermal limit ratios for CHF and FE are presented in Fig. 4.7 for both the $1.1 \mathrm{~s}$ break opening time and a 1 -s opening time. The minima in both the $\mathrm{CHF}$ and $\mathrm{FE}$ ratios occur at $\sim 460 \mathrm{~ms}$ into the transient as the core depressurization, the pump coastdown, and the core power all influence the calculated thermal limits. The FE ratio shows a more pronounced effect to the change in opening time because it is more sensitive to decreases in exit pressure. For the 1100 -ms break time, the 95\% probability-level hot spot did not exceed either the CHF or FE limits, thus meeting the criterion for unlikely events; however, the response for a break time of $1000 \mathrm{~ms}$ did not meet the criterion.

\subsubsection{RELAP Verification and Validation}

The verification and validation of the computer programs used for accident analysis are a continuing and long-term goal. Significant RELAP5 verification and validation efforts began this year and will continue for the next several years. 


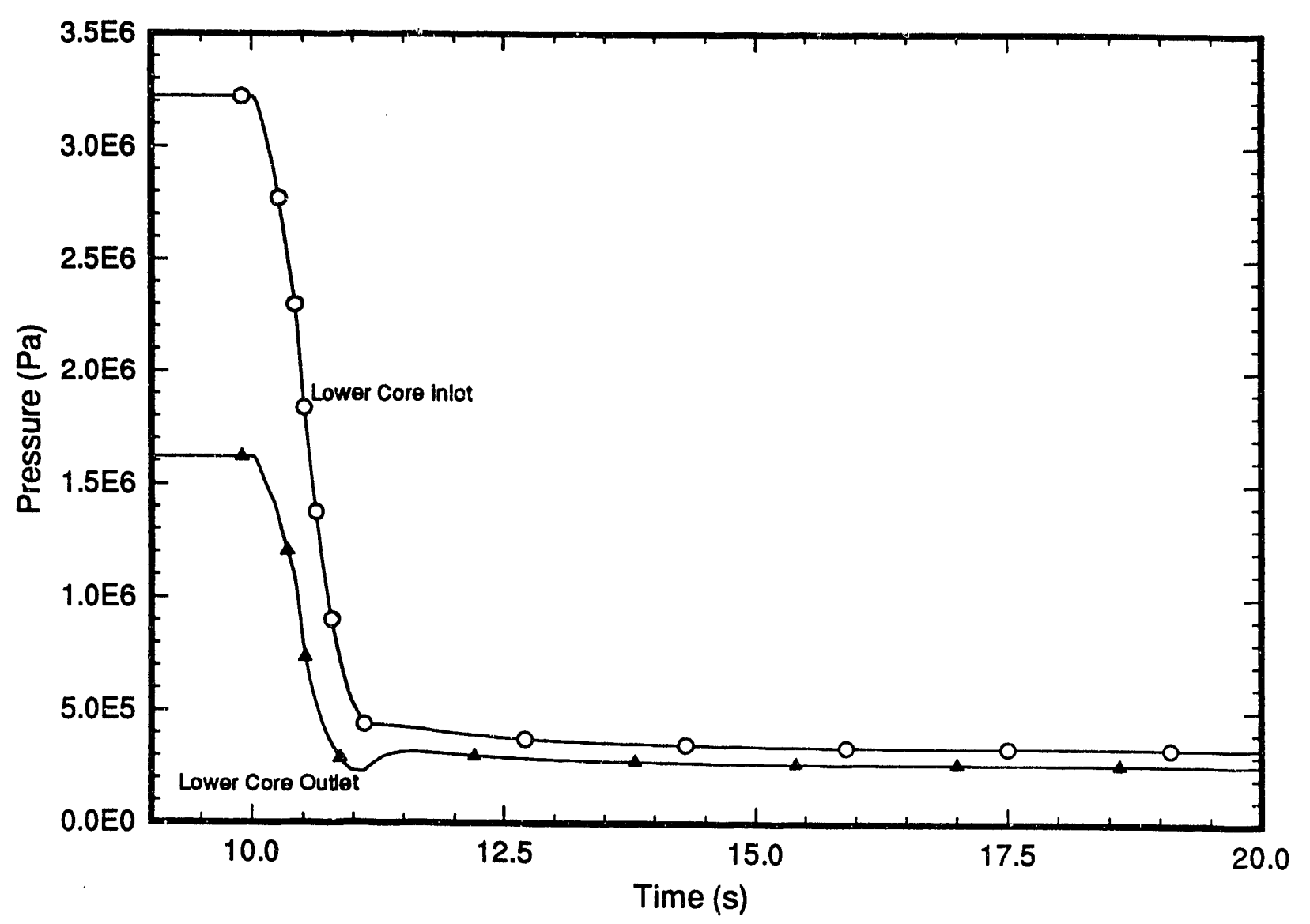

Fig. 4.6. Core inlet and outlet pressure response-increased break opening time (1100 $\mathrm{ms})$.

\subsubsection{RELAP and ANS Dynamic Model Comparison}

An initial comparison between the RELAP5 results and those of the ANS dynamic model was completed during this reporting period. Both steadystate and transients were examined. The steady-state comparison was made by examining thermalhydraulic parameters around the ANS primary loop. These parameters included velocities, local pressures, local bulk coolant temperatures, fuel surface temperatures, and local heat transfer coefficients. The additional detail incorporated in the RELAP model (such as valve and fitting losses) accounted for some minor discrepancies; however, overall comparison of these key parameters indicated that both models agreed quite well when a common set of input parameters was used.
After establishing a common steady-state condition between the two models, a small pipe break transient was compared. A 51-mm-diam break into the light water pool from the CPBT outlet was chosen for the initial comparison, indicating similarity between the two models in both shape and magnitude of the key parameters such as break flow, hot-leg mass flows, CPBT inlet and outlet pressures, and hot-spot surface temperature. However, discrepancies were observed in the accumulator injection flow because (1) the RELAP model used at the time allowed no backflow into the accumulator and (2) RELAP accounts for the finite time required for the pressure wave to propagate from the break to the accumulators, while the dynamic model assumes that it propagates instantaneously. 


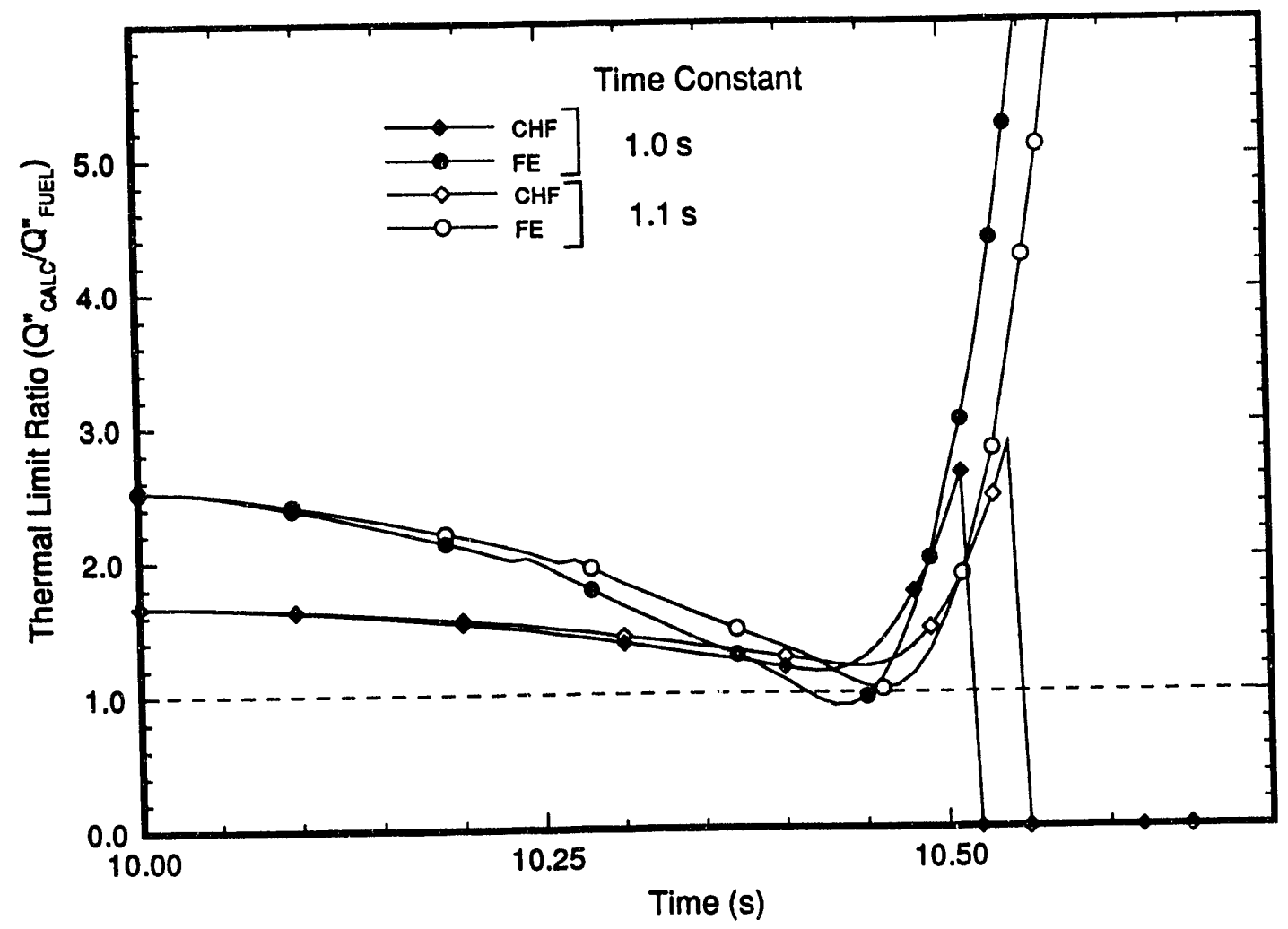

Fig. 4.7. CHF and FE ratios-increased break opening time.

\subsubsection{Phenomena Identification and Ranking}

The final three phenomena identification and ranking (PIR) meetings were completed this fiscal year. The objective of this committee [composed of L. Y. Cheng (BNL); R. Dimmena (Savannah River Laboratory); P. Griffith (MIT); A. E. Ruggles (ORNL, chair); and G. Wilson (INEL)] was to evaluate and rank the important thermal-hydraulic phenomena and system components for ANS reactor (ANSR) safety analysis. Results of these meetings are still being compiled and will be reported in the future.

\subsubsection{Fuel Assembly Inlet Flow Blockage}

The fuel assembly of the ANSR is cooled by 684 narrow, essentially rectangular channels arranged in parallel. Any disruption of the cooling flow by solid matter lodged against the inlet of the fuel assembly cooling channels will perturb the normal heat removal. Calculations have been performed to identify, at least approximately, the smallest size of inlet blockages that might result in damage to the fuel assembly. This information will be used to aid in the design of the fuel element inlet flow geometry. Operating procedures for reactor start-up and administrative controls for the refueling process will also be affected by these results.

Two types of calculations have been performed-simplified hand calculations of the gross effect of core inlet blockage on the total flow through a coolant channel and detailed computational fluid dynamics (CFD) calculations on a computer. These simplified hand calculations have shown that the total mass flow through the channel is not much affected until the blockage covers roughly $50 \%$ of the inlet; this insensitivity to inlet area occurs because the viscous losses in the channel are normally many times larger than the dynamic head. 
To investigate the local perturbation of the thermal-hy ulic conditions in the wake region downstream of a blockage, a CFD model of a narrow channel blockage experiment ${ }^{38}$ has been constructed using the FLUENT code ${ }^{39} \mathrm{~A}$ benchmark was run using this FLUENT model to predict data taken downstream of the inlet blockage. The results show that the FLUENT CFD model under-predicts the length of the flow recovery region downstream of the blockage, a nonconservative result. However, the character of the recirculation region downstream of the blockage was predicted by the model, and refinements in the turbulence modeling may lead to improved performance in the future.

An experiment is also currently under construction to establish the spatial variation in the heat transfer coefficient downstream of coolingchannel inlet blockage. The experiment will use a single channel of typical span and operate at hydraulic conditions typical of the ANSR core. Data from this experiment will be used to validate the CFD code used for safety analysis of flow blockage.

\subsection{SEVERE ACCIDENT ANALYSIS}

Past activities in the area of severe accident analysis included scoping studies on hydrogen explosion loadings, fuel-coolant-interaction (FCI), debris-recriticality safety analyses, preliminary CONTAIN and MELCOR code evaluations for containment pressurization during postulated severe accidents, core melt progression and fission product release, molten-core-concrete-interactions, and the investigation of severe accident mitigation features. The results of these studies have been reported in previous ANS Project annual progress reports. ${ }^{9,12-15}$ Several follow-on efforts have been made to assist in resolving issues highlighted from these studies. For example, a task team has been organized at the national level jointly to resolve FCI and other severe accidcnt issues for $\mathrm{U}-\mathrm{Al}$ fueled reactors in general. The task team consists of participants from other DOE laboratories with U. Al-fueled research, test, or production reactors.
Several meetings have taken place, and plans are being formulated for the definition and development of appropriate analyses. We have supplemented this by initiating experimental efforts investigating the triggerability and energy conversion of silicide fuel/water explosions for best-estimate FCI analysis.

A containment design team has been formed at ORNL and a workshop organized wherein participants from various external organizations provided valuable suggestions for improvements. In addition, cooperative efforts that were initiated with Japan Atomic Energy Research Institute (JAERI) researchers in the general areas of safety research for U-Al-fueled reactors (specifically those using silicide fuel) were further developed and strengthened.

During this reporting period, containment response evaluations that include radionuclide transport were performed for several hypothetical severe accidents using the MELCOR code,${ }^{40}$ and companion off-site consequence evaluations were performed using the MACCS code. ${ }^{41}$ These analyses were reported in the $A N S$ Environmental Report (ER), ${ }^{42}$ in the CSAR, ${ }^{3}$ and in other reports, ${ }^{43,44}$ and actually comprised the bulk of the work effort for the year. During the current reporting period, scoping studies were also conducted on core-debris recriticality and on recriticality-induced severe accidents during refueling. In addition, plans were made for experiments in JAERI's Nuclear Safety Research Reactor (NSRR). Experiments for evaluating ANS fuel performance during explosive $\mathrm{FCI}$ events are also under way.

The results of these activities are summarized in the following.

\subsubsection{Severe Accident Calculations for the Environmental Report and the Conceptual Safety Analysis Report}

During FY 1992, work was conducted towards evaluating ANS containment performance during a variety of hypothetical severe accident scenarios coupled with either intact or failed 
containment configurations. Work for the ER was completed first and is essentially a subset of the overall work done for the CSAR; hence, only the latter is highlighted in this section.

The study conducted for the CSAR goes far beyond the design-basis accidents and the 10-CFR-100-prescribed ${ }^{45}$ fission product releases typically found in SARs in that the issue of containment failure coincident with severe fuel damage accident is addressed. The calculations of this section postulate that a severe core damage event involving melting of the reactor fuel has occurred. An event tree is developed showing the several basically different paths along which the accident might progress, and the paths that represent the greatest possibility for release of radioactivity are selected for detailed calculations. This resulted in the selection of ten sequences involving different combinations of assumed severe accident phenomena and containment failure modes. One of the ten sequences reported in this section adopts the radionuclide source term and containment performance assumptions ${ }^{45}$ prescribed by 10 CFR 100 for evaluation of site suitability. This sequence was chosen to demonstrate that the predicted consequences for this event are very small compared with the 10 CFR 100 exposure guidelines, thereby demonstrating that the ANS design-basis containment capabilities go beyond minimum requirements of the regulations.

Figure 4.8 illustrates the sequence of events between severe accident initiation and various states of debris cooling. Independent factors, such as core irradiation time and core power level at the time of the accident, determine the path followed for a given severe accident although all calculations were done with worst-case input (e.g., end-of-cycle fission product inventory). Six end states are shown in Fig. 4.8. Three of the end states (1, 3, and 4) involve cooled debris under a large quantity of water. For conservatism, no credit was taken for these favorable end states in the CSAR. Two of the end states ( 2 and 5) involve debris that is dispersed in a significant but limited quantity of water $\left(100 \mathrm{~m}^{3}\right)$. End state 2 provided the beginning state for the containment response calculations of the Scenario 1 events (viz., steaming-pool events), whereas end states 5 and 6 provided initializing points for the Scenario 2 events [core-concrete interaction (CCI) events in which molten core debris comes into contact with and degrades concrete]. End state 5 involves a $\mathrm{CCI}$ event in the presence of an overlying pool of water. The water may either accompany relocated core debris, or be available via strategic flooding if such a capability were incorporated in the design. For end state 6, the debris is not flooded because the assumption was made that melt freezing prevents primary coolant heavy water from accompanying core debris into the subpile room. For Scenario 1 source term evaluations, $50 \%$ of the iodine inventory and $100 \%$ of the noble gases are sourced into the high-bay volume (i.e., control volume CV 240 in Fig. 4.9), along with the associated decay energy, and the remaining radionuclides are evenly distributed in the reactor pool water (control volume CV 202). No credit is taken for the presence of the reactor coolant system boundary piping and reflector vessel. For Scenario 2 source term evaluations, the entire core inventory of fission products and fuel-plate structural materials is relocated down into the subpile room. This is a conservative assumption because at least some of the volatile fission products (noble gases and halogens) would have been released prior to ablation of the primary coolant system boundary and subsequent relocation to the subpile room. With $100 \%$ of the core debris and its fission products initialized in the subpile room, we parition the fission products as follows: the volatile fistus products, representing about $50 \%$ ot total core decay heat load, enter the atmospinire of the subpile room, and the nonvolatiles :-main on the subpile room floor where they cause thermal degradation of the concrete. ${ }^{46}$ This is reasonable because at the ablation temperatise of even limestone commonsand concrete $(-350 \mathrm{~K})$, most of the volatile fission prostion couting about $50 \%$ of the debris decty mite: will escape the silicide fuel debris into the wopile room atmosphere. ${ }^{47,48}$ In the interests of armservatism and also because a calculational method for predicting core melt 


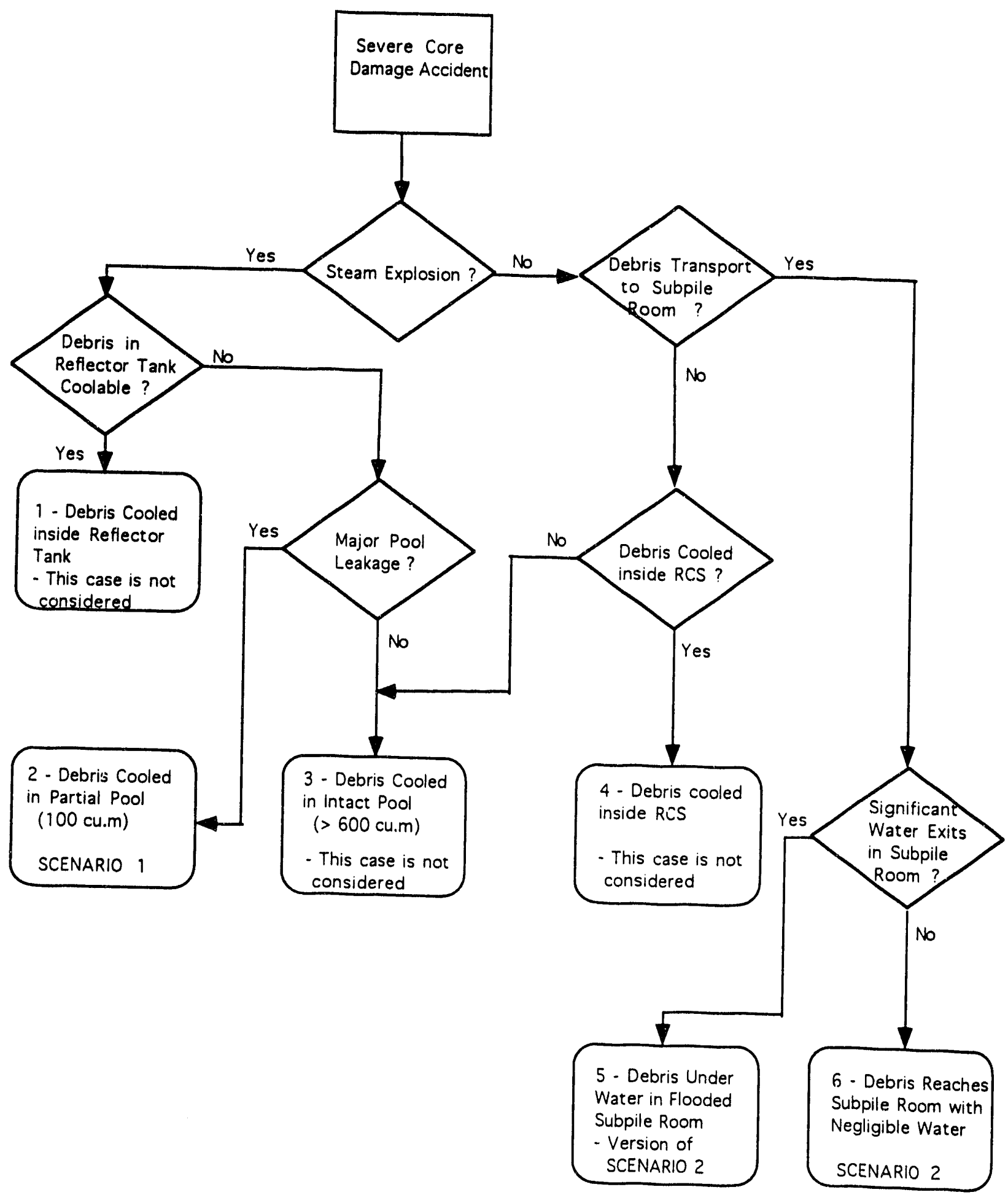

Fig. 4.8. Partial core melt progression event tree for ANS CSAR studies. 


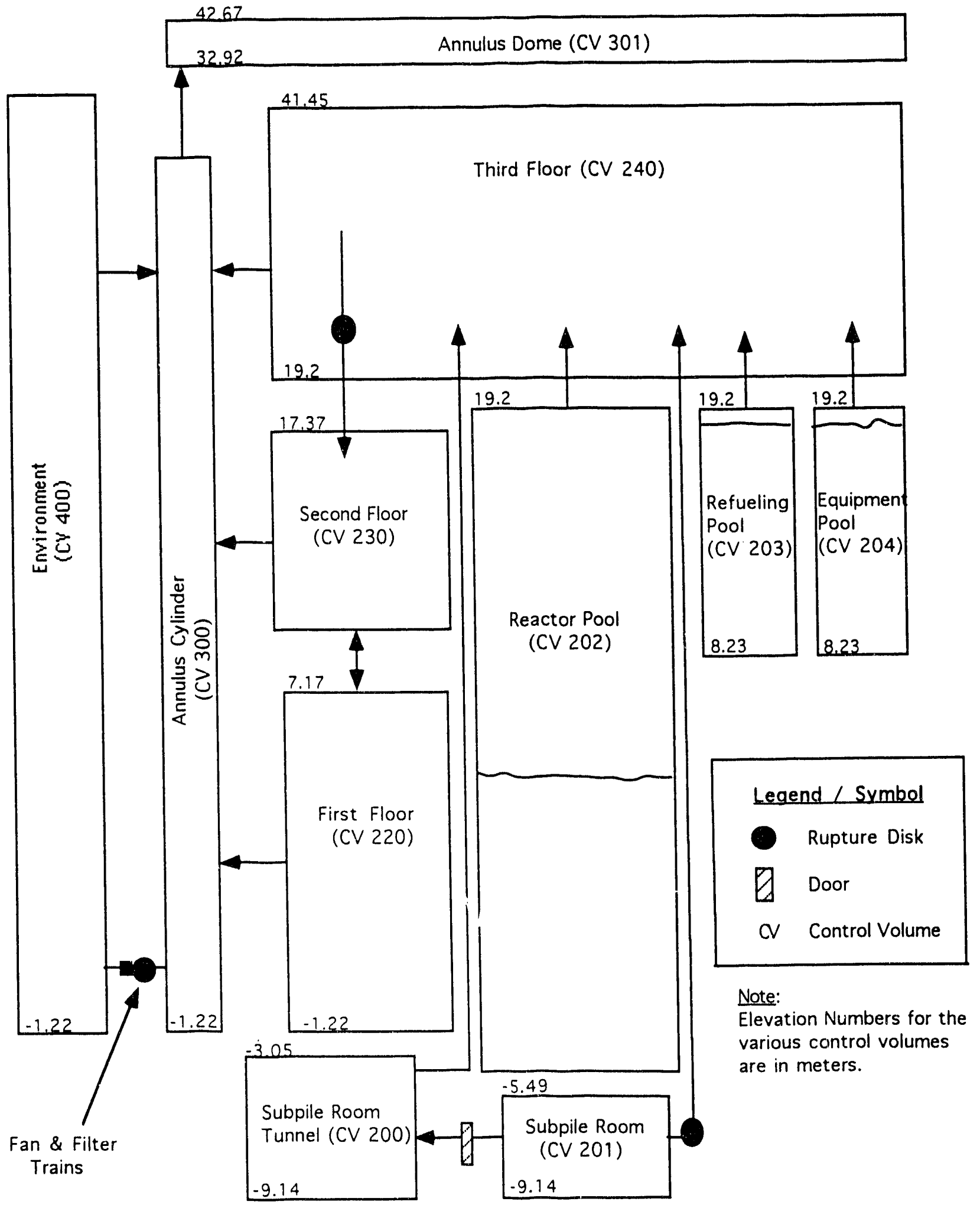

Fig. 4.9. ANS containment (MELCOR) representation for ANS CSAR. 
progression has not been developed, no credit is taken for the various aspects of the core melt progression and associated timing of such events leading up to this stage.

The two basic scenarios of Fig. 4.8 are combined with several different containment failure modes to comprise the cases analyzed for the CSAR. The containment failure configurations range from an intact primary and secondary containment (i.e., successful containment isolation and operation of the secondary containment filtration system) to failure of both the primary and the secondary containment. Containment failure configurations are modeled via specification of flow paths between various volumes. Each failure path was modeled to have a diameter of $0.5 \mathrm{~m}$, representing possible pathways created by missiles, failure of penetrations, or failure of ventilation duct isolation valves to close.

The principal computational tools employed for the ANS CSAR work were the MELCOR ${ }^{40}$ and MACCS $^{41}$ code systems. ORIGEN ${ }^{8}$ was used to evaluate fission product inventory buildup and decay. To remain conservative, EOC inventory of fission products was used for source term calculations. The general purpose severe accident analysis code MELCOR was used to evaluate containment response during severe accidents and to predict the transport of fission product nuclides and their release from the containment. Although general in nature, MELCOR does not have the capability to model specific core melt progression phenomena associated with the ANS aluminumclad silicide fuel. Hence, the three scenarios are modeled without taking into account salient aspects of core melt progression. The MELCOR containment representation developed for the current study is shown in Fig. 4.9. Significant additional coding was done to define or control various aspects of the simulation such as opening and closing of valves; specification of pump characteristics; specification of heat structure boundary conditions; and controlling plot, edit, and restart frequencies. All the major components of the ANS containment have been represented, along with associated flow paths. The model consists of 11 control volumes, 15 flow paths, and 21 heat structures (representing structural components such as walls, ceilings, shells, and miscellaneous materials) of various shapes.

The different cases were analyzed for their effect on the ANS containment and for deriving the source terms that describe escape of fission products from containment. The results are documented in detail elsewhere. ${ }^{3,42-44}$ Not surprisingly, it was found that steaming-pool cases lead to greater containment pressurization.

However, in each case the final pressure is much lower than the ANS design differential pressure of $69 \mathrm{kPa}$ (10 psig). The ANS primary containment atmosphere is divided into zones by rupture disks between the high-bay volume and the experiment/ beam rooms and between the subpile room and the high-bay volume. The rupture disks provide extra time for experimenters or operators inside the primary containment to evacuate in the event of a severe accident. The rupture disks burst only if a pressure difference of $13.8 \mathrm{kPa}(2 \mathrm{psi})$ is exceeded. The $13.8 \mathrm{kPa}$ pressure difference between highbay volume and experiment/beam rooms is exceeded only for those cases with intact primary containment boundary. For Scenario 2 events, it was determined that $\mathrm{CCI}$ occurrence in the subpile room can lead to very high structural temperatures and rapid pressurization of the subpile room. Overall, it was found that Scenario 2 events would lead to earlier releases of radionuclides than the steaming-pool events. However, regardless of scenario, negligible radionuclide release occurs if the containment remains intact. When the primary containment is breached but the secondary containment remains intact, the release levels are considerably lower than if both the primary and secondary containments were breached. This clearly attests to the benefits of having a dual containment configuration for the ANS. Overall, it is clear that significant radionuclide releases will occur if primary containment failure occurs. The likelihood of failure of the secondary containment in conjunction with failure of the primary containment is dependent on thermal-hydraulic conditions prevalent there, coupled with response

\section{Advanced Neutron Source (ANS) Progress Report}


of electrical penetration seals. These are areas that will receive additional scrutiny during the next year.

Off-site consequences were calculated using the MACCS code for each of the severe accident cases. The ORNL site-specific population distribution and meteorology data were utilized. The MACCS code does Gaussian plume radiation exposure calculations with weather conditions treated as a probabilistic variable; the estimated radiation exposures are organized in terms of frequency distributions. This is good because weather phenomena actually seem to be random and because the off-site consequence calculations will be interfaced with the probabilistic source term estimates of the PRA (Level II PRA planned for FY 1995). Space does not suffice to repeat the copious output data provided for each sequence by MACCS, but the results have been reported elsewhere. ${ }^{3,44}$ To summarize, note that radiation exposures resulting from the cases with intact primary containment are small and well within 10 CFR 100 guidelines, even if viewed at the pessimistic end of the meteorological conditions spectrum.

\subsubsection{Core Debris Recriticality}

The study of recriticality represents an important phase of any hypothetical severe accident that has progressed to the point of coredebris relocation outside of the control rod region. This section provides a synopsis of work conducted in this area during FY 1992. The KENO5-SCALE code system $^{49}$ was adapted for the IBM RISC/6000 platform. Detailed benchmarking studies were conducted. Quality assurance checks were implemented and documented. The resulting capability allows for the generation of temperature dependent, 39-group, shielded cross-sectional data for each problem under analysis. Thereafter, a matrix of several calculations was conducted for the ANS. As documented in the ANS FY 1991 progress report, ${ }^{9}$ lumped configurations would not lead to a prompt criticality in the ANS cooling circuit. Therefore, focus was placed on dispersed configurations. A detailed test matrix of calculations was set up to evaluate the effects of mixture temperature, aluminum content, void fraction, fuel burnup, burnable poison, dispersion length, and light water contamination. A summary of the test matrix and results of $\mathrm{k}_{\mathrm{eff}}$ calculations are shown in 'Table 4.3, which indicates that light water contamination can significantly increase reactivity insertion. The thermal-hydraulic conditions prevalent in the mixture zone can also have a significant effect, as can be seen from the variation of $k_{\text {eff }}$ with mixture void fraction. These results are being studied to provide insights for developing mitigative measures.

\subsubsection{Refueling Accident Modeling and Analysis}

During FY 1992 work was initiated to evaluate the potential and resulting consequences from a hypothetical criticality accident during refueling. As is evident, such accidents are highly undesirable because they may lead to containment-damaging steam explosion loads and radiation exposure to individuals on-site and offsite. This preliminary scoping study was motivated by the need to gauge its potential for damage and by the need to consider mitigative features early in the design process. Modeling and problem formulation were conducted using concepts of reactor neutronic theory for determining power level escalation, coupled with ORIGEN and MELCOR code simulations for radionuclide buildup and containment transport. Gaussian plume transport modeling was done for determining off-site radiological consequences. Analysis for containment response was conducted under postulated scenarios that included the effects of aluminum ignition and containment failure. Preliminary results indicate that for all cases considered, individuals at the site boundary will not receive doses beyond regulatory limits. 


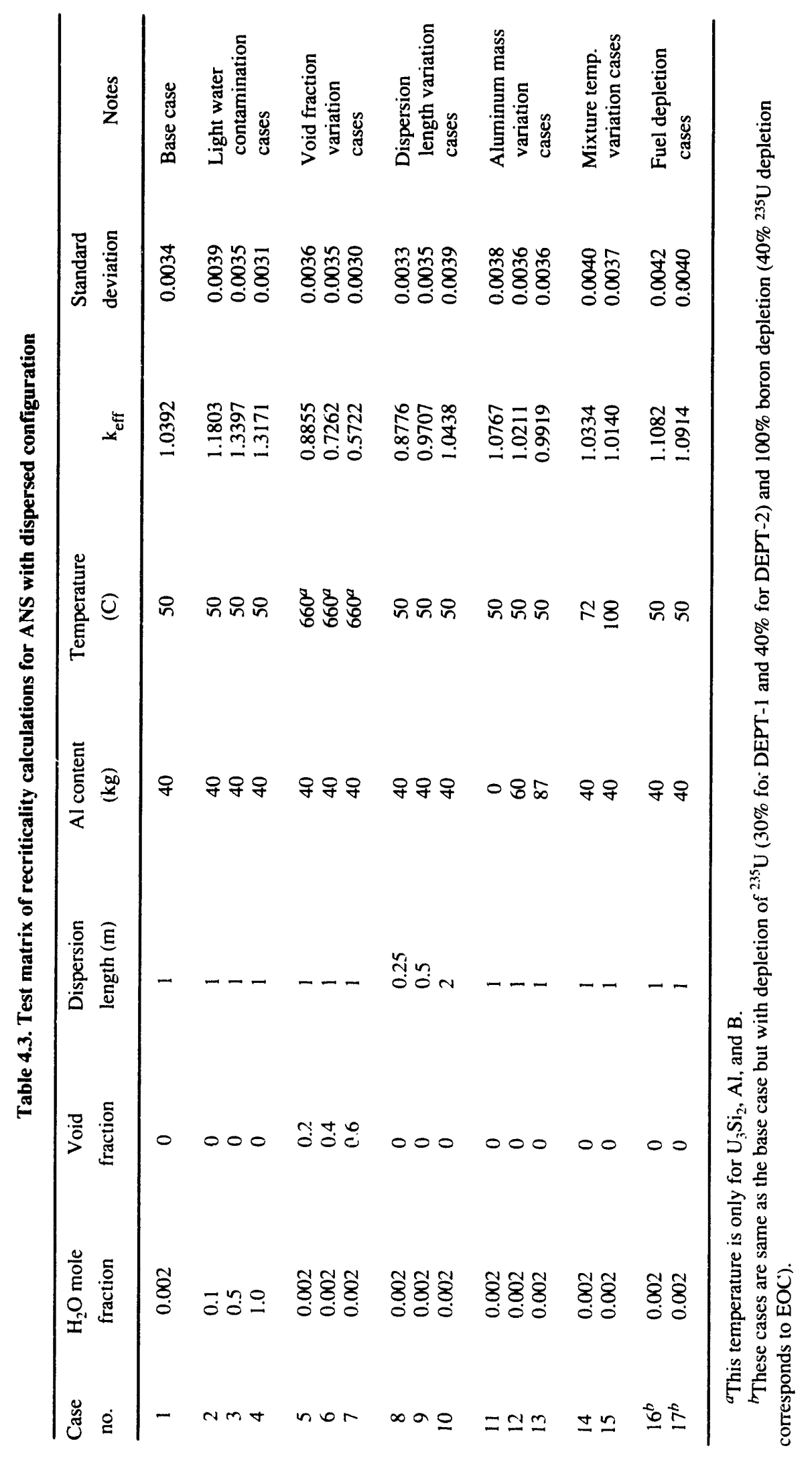

84 Advanced Neutron Source (ANS) Progress Report 


\subsubsection{Core Melt Progression Considerations for the ANS}

The study ${ }^{48}$ of core melt progression and fission product release addresses the most fundamental aspects of severe accident analysis. It pertains to the issues that relate to core heatup, melting, and relocation with concomitant release and transport of the available radionuclide inventory. The core region construction and operation for the ANS are radically different from those of power reactors. Such radical differences make it prudent to conduct a scoping study in order to judge which aspects of the heatup and melting processes require further attention and methodsdevelopment efforts and also to investigate safety concerns that can be addressed by proper system design. The scoping study initiated during FY 1991 was not extended further because of resources being committed towards completion of work for the ER and the CSAR.

\subsubsection{Severe Accident Experimentation}

During FY 1992 work began on steam explosion testing with molten aluminum and fuel interacting with water. Several droplet tests have been conducted with molten drops of aluminum at various temperatures using a variety of trigger pulses. Initial attempts at conducting tests with mixtures of $\mathrm{U}_{3} \mathrm{Si}_{2}-\mathrm{Al}$ have not been successful because the eutectic fuel-aluminum mixture was so viscous that it did not flow out of the crucible. This indicates that during fuel melting accidents in the ANS, the steam explosion potential may be quite low. The problem with melt delivery is currently being rectified. Additional experiments are also to be conducted in a shock-tube apparatus. In this setup, a water column is driven onto a stationary pool of molten $\mathrm{U}_{3} \mathrm{Si}_{2}$-Al mixture with different velocities. Resulting steam explosion energetics will provide guidance for proper modeling and choice of thermal-to-mechanical energy conversion and also for determining the explosivity of the ANS fuel mixture. These data will prove valuable in conducting best-estimate safety analysis for the ANS.
Work was also begun on modeling and analysis of silicide fue! performance data taken in JAERI's NSRR. In those tests, small $\mathrm{U}_{3} \mathrm{Si}_{2}-\mathrm{Al}$ fuel-plate samples representing sections of JAERI's Japanese Material Testing Reactor (JMTR) fuel plates (encapsulated with water) were subjected to rapid bursts of neutrons. The energy deposition levels varied from low to high. At low levels, phenomena such as onset of blistering and structural deformation information were obtained. At the higher levels, enough energy was deposited to cause fuel-plate melting (i.e., of aluminum). However, the JMTR fuel plates retained their structural shapes reasonably well all the way up to melting conditions. Even upon aluminum melting, the plates did not collapse. Material dispersion also did not occur (to cause steam explosions). These data were shared by JAERI researchers with ORNL for joint analyses and modeling, which are now under way.

Currently, miniplates representing sections of the ANS core fuel plates are being fabricated for testing in the NSRR to evaluate the effects of fuel density and fuel-plate geometry on fuel energy deposition performance. It is expected that preliminary testing with these ANS miniplates will be conducted during February 1993. Data obtained will prove valuable in understanding limits to safety of ANS fuel plates, as well as in making important design decisions. It is expected that these data will also prove invaluable in future core melt progression modeling for Level II PRA applications and for further enhancing the safety performance of the ANS.

\subsubsection{Severe Accident Mitigation Studies}

A paper ${ }^{50}$ on the severe accident mitigation features in the ANS was presented at the Fifth International Workshop on Containment Integrity in May 1992. This overall area is to receive considerable attention during FY 1993.

It should be noted that containment failure following any severe accident is considered highly undesirable. Actions are currently being undertaken to minimize risk from severe accidents 
with early containment failure. Efforts under way include (1) the introduction of mitigative features to prevent $\mathrm{CCI}$ occurrence and the introduction of missile shields to prevent containment failure and/ or to allow sufficient time for evacuation and (2) best-estimate evaluation of core melt progression. When these are accounted for, it is expected that the ANS reactor system will be safe both from probabilistic and deterministic standpoints (i.e., negligibly low values of risk and also no fatalities and/or injuries if a severe accident does occur).

86 Advanced Neutron Source (ANS) Progress Report 


\section{PUBLICATIONS FY 1992}

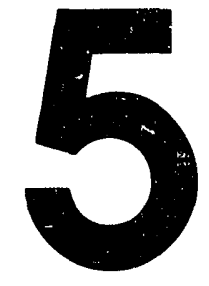

D. J. Alexander, The Effects of Irradiation on the Mechanical Properties of 6061-T651 Aluminum, 16th International Symposium on the Effects of Radiation on Materials, June 1992.

R. G. Alsmiller and R. A. Lillie, "Design Calculations for the ANS Cold Neutron Source II: Heating Rates," Nucl. Instr. \& Methods in Phys. Res., in press (1992).

J. L. Anderson et al., Advanced Neutron Source Reactor Control and Plant Protection Systems Design, 8th Power Plant Dynamics, Control \& Testing Symposium, Knoxville, Tennessee, Department of Nuclear Engineering, the University of Tennessee, May 27-29, 1992.

C. B. Bentley and A. E. Ruggles, "Phase Distribution Measurements in Narrow Rectangular Channels Using Image Processing Techniques," Proceedings of Experimental Techniques in Multiphase Flows, ASME Winter Annual Meeting, Atlanta, December 1-6, 1991.

T. J. Blasing et al., Phase I Environmental Report for the Advanced Neutron Source at Oak Ridge National Laboratory, ORNL/TM-12069, February 1992.

R. S. Booth, Advanced Neutron Source Plant Design Requirements, ORNL/TM-1 1625/R4, May 11, 1992.

N. C. J. Chen, M. W. Wendel, and G. L. Yoder, "Loss-of-Coolant Accident Analysis of the Advanced Neutron Source Reactor," Trans. Am. Nucl. Soc. 64, 672, TANSAO 64 1-754, San Francisco, November 1991.

N. C. J. Chen, G. L. Yoder, and P. T. Williams, Thermal Hydraulic Response of the Advanced Neutron Source Reactor to Piping Breaks Near the Core Region, 8th Power Plant Dynamics, Control \& Testing Symposium, Knoxville, Tennessee, Department of Nuclear Engineering, the University of Tennessee, May 27-29, 1992.

R. K. Davis (Automated Sciences Group, Inc.); R. A. Hopkins (Marrich, Inc.); and W. E. Doll (ORNL); Seismic Refraction Survey of the ANS Preferred Site, ORNL/TM-1 1998, February 1992.

D. K. Felde et al., The Advanced Neutron Source Thermal Hydraulic Test Loop, 8th Power Plant Dynamics, Control \& Testing Symposium, Knoxville, Tennessee, Department of Nuclear Engineering, the University of Tennessee, May 27-29, 1992.

J. B. Hayter, P. B. Thompson, and C. D. West, Status of the Advanced Neutron Source Facility, 8th

Pacific Basin Nuclear Conference, Lung-Tan, Taiwan 32500, Republic of China, April 12-16, 1992. 
J. B. Hayter, "Neutron Optics at the Advanced Neutron Source," SPIE Proceedings Vol. 1738, SPIE's International Symposium on Optical Applied Science and Engineering, San Diego, July 19-24, 1992.

J. B. Hayter, "Reactors and Physics Education," Proceedings 2nd Meeting International Group on Research Reactors (IGORR-II), Saclay, France, May 18-19, 1992.

J. B. Hayter and C. D. West, "Status of the Advanced Neutron Source Project," Neutron News 3, 16 (1992).

J. B. Hayter, The Advanced Neutron Source, American Crystallographic Association Annual Meeting, Symposium on Scattering Instrumentation at Low Momentum Transfers, Pittsburgh, August 12, 1992.

C. R. Hyman, R. P. Taleyarkhan, and S. R. Greene, "Characterization of Debris/Concrete Interaction for Advanced Research Reactor and Commercial BWR Severe Accidents," Trans. Am. Nucl. Soc. 64, 749, TANSAO 64 1-754, San Francisco, November 1991.

S. H. Kim, B. W. Patton, and R. P. Taleyarkhan, "Severe Accident Source Term Evaluation for the Advanced Neutron Sourcc," Trans. Am. Nucl. Soc. 65, 267-269, TANSAO 65 1-580, Boston, June 1992.

J. March-Leuba et ai., Dynamic Simulation as an Aid for the Design of the Advanced Neutron Source Cooling System, 8th Power Plant Dynamics, Control \& Testing Symposium, Knoxville, Tennessee, Department of Nuclear Engineering, the University of Tennessee, May 27-29, 1992.

S. Marland, Analyses of the Reflector Tank, Cold Source, and Beam Tube Cooling for the ANS Reactor, ORNL/M-1607, July 1992.

R. E. Pawel et al., "Cladding Corrosion Studies Under Heat Transfer Conditions for the Advanced Neutron Source," BNL-47763, Proceedings of the TMS Symposium on Radiation Facilities and Defect Studies, San Diego, March 3-4, 1992.

F. J. Peretz, Summary Report of the ANS Reactor Cooling System Workshop, February 15-16, 1990, CONF-9002142, December 1991.

F. J. Peretz, "Innovation in Design-The Advanced Neutron Source," Proceedings WATTec 199219 th Annual Technical Conference and Exhibition, Knoxville, Tennessee, February 18, 1992.

F. J. Peretz et al., Conceptual Design Summary, ORNL/TM-12184, September 1992.

C. C. Queen, ANS Control Rods with Inner Rods Scram Down, Spring Concept, ORNL/M-2233 (drawing), July 1992.

W. K. Sartory, Analysis of Hydraulic Instability of ANS Involute Fuel Plates, ORNL/TM-11580, November 1991.

D. L. Selby, R. M. Harrington, and P. B. Thompson, The Advanced Neutron Source Project Progress Report, FY 1991, ORNL-6696, January 1992.

88 Advanced Neutron Source (ANS) Progress Report 
B. Sigmon, A. C. Heitzman, Jr., and J. Morrissey (Science Applications International Corporation), Oak Ridge Reservation Site Evaluation Report for the Advanced Neutron Source, ORNL/TM-11419, March 1990 (distributed January 1992).

M. Siman-Tov et al., "Thermal-Hydraulic Correlations for the Advanced Neutron Source Reactor Fuel Element Design and Analysis," Proceedings of Symposium on Nuciear Reactor Thermal-Hydraulics-II, ASME Winter Annual Meeting, Atlanta, December 1-6, 1991.

R. P. Taleyarkhan, S. H. Kim, and B. W. Patton, "MACCS Calculations for Advanced Neutron Source Reactor Radiological Risk Evaluations," Trans. Am. Nucl. Soc. 65, 269-270, TANSAO 65 1-580, Boston, .Iune 1992.

R. P. Taleyarkhan, "Analysis and Modeling of Fission Product Release from Heated U-Al Reactor Fuels," Nucl. Safe. 33-1, 6-22, January-March 1992.

K. R. Thoms, "Irradiation Facilities at the Advanced Neutron Source," BNL-47763, Proceedings of the TMS Symposium on Radiation Facilities and Defects Studies, 55-70, San Diego, March 3-4, 1992.

C. D. West, "The Advanced Neutron Source Design-A Status Report," Proceedings 2nd Meeting International Group on Research Reactors (IGORR-II), Saclay, France, May 18-19, 1992.

C. D. West, Irradiation Facilities at the Advanced Neutron Source, International Conference on Irradiation Technology, Saclay, France, May 20-22, 1992.

C. D. West, Advanced Neutron Source Overview and Status Report, 8th Power Plant Dynamics, Control \& Testing Symposium, Knoxville, Tennessee, Department of Nuclear Engineering, the University of Tennessee, May 27-29, 1992.

C. D. West, ed., IGORR News, Issue No. 3, March 1992 (newsletter).

C. D. West, "Recent Activities of the International Group on Research Reactors (IGORR) and of the Advanced Neutron Source (ANS)," Proceedings 3rd Asian Symposium on Research Reactor, Hitachi-shi, Ibaraki-ken, Japan, November 11-14, 1991.

G. T. Yahr, "Protection of Aluminum Components Against Nonductile Fracture in the Advanced Neutron Source," BNL-47763, Proceedings of the TMS Symposium on Radiation Facilities and Defects Studies, San Diego, March 3-4, 1992. 


\section{REFERENCES}

1. R. S. Buoth, Advanced Neutron Source Plant Design Requirements, ORNL/TM-11624/R4, Martin Marietta Energy Systems, Inc., Oak Ridge Natl. Lab., May 11, 1992.

2. M. L. Gildner, ANS Quality Assurance Plan, ORNL/TM-11446/R1, Martin Marietta Energy Systems, Inc., Oak Ridge Natl. Lab., May 1, 1991.

3. R. M. Harrington et al., Conceptual Safety Analysis Report, ORNL/ANS/INT-33, Vols. 1-4, Martin Marietta Energy Systems, Inc., Oak Ridge Natl. Lab., June 1992.

4. U.S. Nuclear Regulatory Commission, Regulatory Guide 1.70, Standard Format and Content of Safety Analysis Reports for Nuclear Power Plants—LWR Edition, Rev. 3, November 1978.

5. U.S. Nuclear Regulatory Commission, Standard Review Plans for the Review of Safety Analysis Reports for Nuclear Power Plants, NUREG-0800 (June 1987).

6. K. Scharmer and H. G. Eckert, FOEHN: The Critical Experiment for the Franco-German High Flux Reactor, ORNL/TR-91/23, translated from the German report KFK 1064 issued by Kernforschungszentrum, December 1971.

7. J. F. Briesmeister, ed., MCNP-A General Monte Carlo Code for Neutron and Photon Transport, LA-7396-M, Rev. 2, Los Alamos National Laboratory, 1986.

8. A. G. Croff, ORIGEN-2-A Revised and Updated Version of the Oak Ridge Isotope Generation and Depletion Code, ORNL-5621, Martin Marietta Energy Systems, Inc., Oak Ridge Natl. Lab., July 1980.

9. D. L. Selby, R. M. Harrington, and P. B. Thompson, Advanced Neutron Source (ANS) Project Progr ess Report, FY 1991, ORNL-6696, Martin Marietta Energy Systems, Inc., Oak Ridge Natl. Lab., January 1992.

10. L. M. Petrie and N. F. Landers, KENO V.a: An Improved Monte Carlo Criticality Program with Supergrouping, ORNL/NUREG/CSD-2, Martin Marietta Energy Systems, Inc., Oak Ridge Nat!. Lab., 1984.

11. D. R. Vondy, T. B. Fowler, and G. W. Cunningham, III, The Bold Venture Computation System for Nuclear Reactor Core Analysis, Version III, CRNL-5711, Martin Marietta Energy Systems, Inc., Oak Ridge Natl. Lab., 1990.

12. D. L. Selby, R. M. Harrington, and F. J. Peretz, ORNL Contributions to the Advanced Neutron Source (ANS) Project for October 1986-March 1987, ORNL/TM-10579, Martin Marietta Energy Systems, Inc., Oak Ridge Natl. Lab., November 1987. 
13. D. L. Selby, R. M. Harrington, and F. J. Peretz, Advanced Neutron Source (ANS) Project Annual Report, April 1987-March 1988, ORNL/TM-10860, Martin Marietta Energy Systerns, Inc., Oak Ridge Natl. Lab., February 1989.

14. D. L. Selby, R. M. Harrington, and F. J. Peretz, Advanced Neutron Source (ANS) Project Progress Report, ORNL-6574, Martin Marietta Energy Systems, Inc., Oa.k Ridge Natl. Lab., April 1990.

15. D. L. Selby, R. M. Harrington, and F. J. Peretz, Advanced Neutron Source (ANS) Project Progress Report, ORNL-6656, Martin Marietta Energy Systems, Inc., Oak Ridge Natl. Lab., February 1991.

16. R. E. Pawel, On the Kinetics of the Aluminum-Water Reaction during Exposure in High-Heat Flux Test Loops. I. A. Computer Program for Oxidation Calculations, ORNL/TM-10602, Martin Marietta Energy Systems, Inc., Oak Ridge Natl. Lab., January 1988.

17. R. E. Pawel and D. W. Yarbrough, Modeling Heat Generation and Flow in the Advanced Neutron Source Test Lonp Specimen, ORNL/TM-10603, Martin Marietta Energy Systems, Inc., Oak Ridge Natl. Lab., January 1988.

18. G. H. Hanson et al., Report of the ANS Aluminum Cladding Corrosion Workshop, Nov. 16-17, 1988, Idaho Falls, Idaho, CONF-881 1203, Martin Marietta Energy Systems, Inc., Oak Ridge Natl. Lab., February 1989.

19. R. E. Pawel et al., The Development of a Preliminary Correlation of Data on Oxide Growth on 6061 Aluminum under ANS Thermal-Hydraulic Conditions, ORNL/TM-11517, Martin Marietta Energy Systemis, Inc., Oak Ridge Natl. Lab., June 1990.

20. B. H. Montgomery, R. E. Pawel, and G. L. Yoder, "The Advanced Neutron Source Test Loop Facility," Trans. Am. Nucl. Soc. 57, 300 (1988).

21. R. E. Pawel et al., "Fuel Cladding Corrosion Studies for the Advanced Neutron Source," Trans. Am. Nucl. Soc. 61, 388 (1990).

22. R. E. Pawel et al., "The Corrosion of 6061 Aluminum under Heat Transfer Conditions in the ANS Corrosion Test Loop," Oxid. Met. 36 (1/2), 175 (1991).

23. G. L. Yoder et al., "The Effect of Aluminum Corrosion on the Thermal-Hydraulic Design of the Advanced Neutron Source Reactor," to be published in J. Nucl. Eng. Design.

24. B. S. Petukhov, "Heat Transfer and Friction in Turbulent Pipe Flow with Variable Physical Properties," Adv. Heat Transfer 6, 504 (1970).

25. J. C. Griess, H. C. Savage, and J. L. English, Effect of Heat Flux on the Corrosion of Aluminum by Water. Part IV. Tests Relative to the Advanced Test Reactor and Correlation with Previous Results, ORNL-3541, Martin Marietta Energy Systems, Inc., Oak Ridge Natl. Lab., February 1964.

26. P. B. Thompson, Project Management Plan, ORNL/ANS/INT-35, Martin Marietta Energy Systems, Inc., Oak Ridge Natl. Lab., June 1992.

92 Advanced Neutron Source (ANS) Progress Report 
27. M. L. Gildner, ANS Procedures Manual, ORNL/ANS/INT-14/Rev. 1, Martin Marietta Energy Systems, Inc., Oak Ridge Natl. Lab., April 15, 1992.

28. R. L. Johnson et al., Cost and Schedule Document, ORNL/ANS/INT-34/S3, Vols. 1-8, Martin Marietta Energy Systems, Inc., Oak Ridge Natl. Lab., J!ne 1992.

29. R. S. Booth, Systems Engineering Management Plan, ORNL/ANS/INT-36/S1, Martin Marietta Energy Systems, Inc., Oak Ridge Natl. Lab., June 1992.

30. F. J. Peretz et al., Integrating System Design Descriptions, ORNL/ANS/INT-26, S21-S25, R0, Martin Marietta Energy Systems, Inc., Oak Ridge Natl. Lab., June 1992.

31. F. J. Peretz et al., System Design Descriptions, ORNL/ANS/INT-26, S31-S36, S41-S411, S51S58, S61-S610, R0, Martin Marietta Energy Systems, Inc., Oak Ridge Natl. Lab., June 1992.

32. U.S. Department of Energy, Order 5480.6, Safety and Department of Energy Owned Reactors, September 1986.

33. J. R. Wolfgong, Advanced Neutron Source Containment Reliability Analysis, ORNL/ANS/ INT-30, Martin Marietta Energy Systems, Inc., Oak Ridge Natl. Lab., March 1992.

34. IEEE Guide to the Collection and Presentation of Electrical, Electronic, Sensing Component, and Mechanical Hardware Reliability Data for Nuclear Power Generating Stations, ANSI/IEEE Standard 500-1984, The IEEE, Inc., New York, Dec. 13, 1983.

35. S. Kaplan et al., Methodology for Probabilistic Risk Assessment of Nuclear Power Plants, PLG-0209, PLG, Inc., Newport Beach, California, June 1981.

36. R. H. Wilson et al., BWC-An Improved Correlation of CHF for Babcock and Wilcox Fuel Assemblies, AIAA/ASME Joint Fluids, Plasma, Thermophysics, and Heat Transfer Conference, St. Louis, Missouri, June 7-11, 1982.

37. J. Weisman and B. S. Pei, "Prediction of CHF in Flow Boiling at Low Qualities," Int. J. Heat Mass Transfer 26, No. 10, 1463-1477 (1983).

38. E. M. Sparrow and N. Cur, "Mal-distributed Inlet Flow Effects on Turbulent Heat Transfer and Pressure Drop in a Flat Rectangular Duct," J. Heat Transfer 105, 527-535 (1983).

39. J. E. Meyer, S. M. Kwak, and T. D. Shubert, Narrow Channel Turbulence Modeling Project, MITNE-299, March 1992.

40. R. M. Summers et al., "MELCOR 1.8.0: A Computer Code for Nuclear Reactor Severe Accident Source Terms and Risk Assessment Analyses," NUREG/CR-5531, January 1991.

41. D. Chanin et al., "MELCOR Accident Consequence Code System-MACCS Version 1.5," NUREG/ CR-4691 (1990). 
42. T. J. Blasing et al., Phase I Environmental Report for the Advanced Neutron Source at Oak Ridge National Laboratory, ORNL/TM-12069, Martin Marietta Energy Systems, Inc., Oak Ridge Natl. Lab., February 1992.

43. S. H. Kim and R. P. Taleyarkhan, "Severe Accident Source Term Evaluation for the Advanced Neutron Source," Proceedings of the 1992 Annual American Nuclear Society Conference, Boston, June 1992.

44. R. P. Taleyarkhan and S. H. Kim, "MACCS Calculations for the Advanced Neutron Source Reactor Radiological Risk Evaluations," Proceedings of the 1992 Annual American Nuclear Society Conference, Boston, June 1992.

45. J. J. DiNunno et al., Calculation of Distance Factors for Power and Test Reactor Sites, Atomic Energy Commission Technical Information Document TID-14844, March 1963.

46. C. R. Hyman and R. P. Taleyarkhan, Characterization of Core Debris/Concrete Interactions for the Advanced Neutron Source, ORNL/TM-1 1761, Martin Marietta Energy Systems, Inc., Oak Ridge Natl. Lab., February 1992.

47. R. P. Taleyarkhan, "Analysis \& Modeling of Fission Product Release from Heated U-Al Reactors Fuels," Nucl. Safe. 33-1, 6-22, January-March 1992.

48. R. P. Taleyarkhan, Core Melt Progression and Fission Product Release Considerations for the Advanced Neutron Source Reactor at ORNL, ORNL/TM-12022, Martin Marietta Energy Systems, Inc., Oak Ridge Natl. Lab., to be published.

49. L. M. Petrie and N. F. Landers, "KENO5A-An Improved Monte Carlo Criticality Program with Supergrouping," Vol. 2, Section F11, SCALE: A Modular Code System for Performing Standardized Computer Analyses for Licensing Evaluation, NUREG/CR-0200 Rev. 2, ORNL/NUREG/CSD-2/R2, December 1984.

50. R. P. Taleyarkhan, and S. H. Kim, "Severe Accident Risk Minimization Studies for the Advanced Neutron Source Reactor Plant at ORNL," Proceedings of the Fifth International Workshop on Containment Integrity, Washington, May 1992.

94 Advanced Neutron Source (ANS) Progress Report 


\section{INTERNAL DISTRIBUTION}

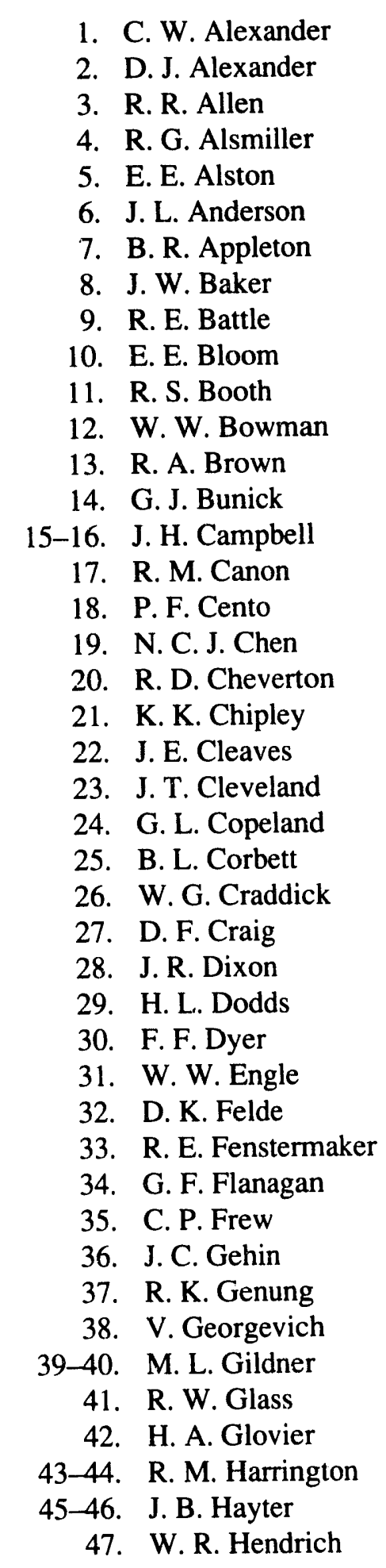

\author{
48. S. E. Holliman \\ 49. L. L. Horton \\ 50. M. Z. Ibn-Khayat \\ 51. D. T. Ingersoll \\ 52. R. L. Johnson \\ 53. J. E. Jones, Jr. \\ 54. M. Kaminaga \\ 55. M. J. Kania \\ 56. H. T. Kerr \\ 57. S. H. Kim \\ 58. W. E. Kohn \\ 59. R. A. Lillie \\ 60. P. S. Litherland \\ 61. A. T. Lucas \\ 62. J. A. March-Leuba \\ 63-64. B. S. Maxon \\ 65. G. T. Mays \\ 66. L. N. McCold \\ 67. M. T. McFee \\ 68. S. V. McGrath \\ 69. T. J. McManamy \\ 70. G. R. McNutt \\ 71. J. T. Mihalczo \\ 72-73. B. H. Montgomery \\ 74. R. M. Moon \\ 75. D. G. Morris \\ 76. M. D. Muhlheim \\ 77. J. A. Murray \\ 78. R. K. Nanstad \\ 79. T. F. Orlin \\ 80. F. S. Patton \\ 81. R. E. Pawel \\ 82. H. R. Payne \\ 83-84. F. J. Peretz \\ 85. C. C. Queen \\ 86. S. Raman \\ 87. C. T. Ramsey \\ 88. J. S. Rayside \\ 89. J. P. Renier \\ 90. J. B. Richard \\ 91. J. B. Roberto \\ 92. T. L. Ryan \\ 93. W. K. Sartory
}




$\begin{aligned} \text { 94-95. } & \text { D. L. Selby } \\ 96 . & \text { H. B. Shapira } \\ 97 . & \text { W. D. Shults } \\ \text { 98. } & \text { M. Siman-Tov } \\ \text { 99. } & \text { G. M. Slaughter } \\ \text { 100. } & \text { B. R. Smith } \\ \text { 101. } & \text { J. O. Stiegler } \\ \text { 102. } & \text { W. F. Swinson } \\ \text { 103. } & \text { R. P. Taleyarkhan } \\ \text { 104. } & \text { D. W. Theisen } \\ \text { 105-106. } & \text { P. B. Thompson } \\ \text { 107. } & \text { K. R. Thoms } \\ \text { 108. } & \text { S. R. Tompkins } \\ \text { 109. } & \text { D. B. Trauger } \\ \text { 110. } & \text { A. W. Trivelpiece }\end{aligned}$

111. B. D. Warnick

112-113. C. D. West

114. J. L. Westbrook

115. B. A. Worley

116. A. L. Wright

117. G. T. Yahr

118. G. L. Yoder

119. A. Zucker

120. ORNL Patent Office

121. Central Research Library

122. Document Reference Section

123. Y-12 Technical Library

124-125. Laboratory Records Department

126. Laboratory Records (RC)

\section{EXTERNAL DISTRIBUTION}

127. R. Avery, Argonne National Laboratory, 9700 S. Cass Avenue, Argonne, IL 60439

128. R. Awan, Division of Energy Research Reactors, Office of Nuclear Energy, Department of Energy, NE-473, Washington, DC 20585

129. P. Ageron, Institut Laue Langevin, 156X 38042, Grenoble Cedex, France

130. J. Ahlf, Joint Research Center, Institute for Advanced Materials, 1755 ZG Petten, P.O. Box 2, The Netherlands

131. P. Armbruster, Institut Laue Langevin, 156X 38042, Grenoble Cedex, France

132. T. Asaoka, Deputy Director General, Tokai Research Establishment, Japan Atomic Energy Research Institute, Tokai-mura, Naka-gun, Ibaraki-ken, Tokyo 319-11, Japan

133. J. Axe, Brookhaven National Laboratory, Building 510A, Upton, NY 11973

134. A. Axmann, Hahn-Meitner Institute Berlin, N3, Glienicker Str. 100, D-1000 Berlin 39, Germany

135. F. Bates, Department of Chemical Engineering and Material Science, University of Minnesota, 151 Amundson Hall, 421 Washington Avenue, SE, Minneapolis, MN 55455

136. G. S. Bauer, Paul Scherrer Institute, $\mathrm{CH}-5234$ Villigen, Switzerland

137. J. M. Baugnet, Nuclear Services Program, S.C.K./C.E.N., Boeretang 200, B2400 Mol, Belgium

138. M. Bieth, High Flux Reactor Division, Institute for Advanced Materials, J.R.C. Petten, P.O. Box 2, 755 ZG Petten, The Netherlands

139. R. C. Birtcher, Argonne National Laboratory, 9700 S. Cass Avenue, Argonne, IL 60439

140. K. Böning, Fakultät für Physik E21, Technische Universität München, D-8046 Garching, Germany

141. P. Breant, CEN Saclay, SPS ORPHEE, 91191 Gif-sur-Yvette Cedex, France

142. R. Burns, Gilbert/Commonwealth, Inc., GH2-3597, P.O. Box 1498, Reading, PA 19603-1498

143. H. A. Capote, Burns \& Roe, 800 Kinderkamack Road, Oradell, NJ 07649

144. G. K. Carlough, DRS Hundley Kling Gmitter, Architects-Planners, One Gateway Center, Pittsburgh, PA 15222 
145. K. N. Clausen, RISO National Laboratory, Physics Department Postbox 49, DK-4000 Roskilde, Denmark

146. R. S. Denning, Sr. Research Leader for Nuclear Safety, Battelle Memorial Institute, 505 King Avenue, Columbus, $\mathrm{OH} 43201$

147. C. Desandre, Technicatome, Centre d'Etudes Nucleaires de Saclay, BP17, 92291 Gif-surYvette Cedex, France

148. R. A. Edlund, U.S. Department of Energy, Oak Ridge Field Office, FEDC, MS-8218, P.O. Box 2009, Oak Ridge, TN 37831-8218

149. W. C. Etter, Project Manager, Stone \& Webster Engineering Corporation, 702 S. Illinois Ave., Suite B-104, Oak Ridge, TN 37831

150. Y. Fanjas, MTR Fuel Technical and Project Manager, CERCA, BP 1114, 26104 Romans Cedex, France

151. B. Farnoux, CEN Saclay, Laboratoire Leon Brillouin, 91191 Gif-sur-Yvette Cedex, France

152. C. D. Fletcher, Idaho National Engineering Laboratory, P.O. Box 1625, Idaho Falls, ID 83415

153. R. R. Fullwood, Building 130, Brookhaven National Laboratory, Upton, NY 11973

154. W. R. Gambill, Route 5, Box 220, Clinton, TN 37716

155. W. Glaser, Fakultät für Physik, Technische Universität München, D-8046 Garching, Germany

156. H. N. Goldstein, Gilbert/Commonwealth, Inc., P.O. Box 1498, Reading, PA 19603-1498

157. B. Gupta, AECL Technologies, 1155 Metcalfe Street, 8th Floor, Montreal, Quebec, H3B 2V6 Canada

158. O. K. Harling, Massachusetts Institute of Technology, 77 Massachusetts Avenue, Cambridge, MA 02139

159. J. R. Harries, Embassy' of Australia, 1601 Massachusetts Avenue, NW, Washington, DC 20036

160. D. Henderson, University of Wisconsin - Madison, Nuclear Engineering and Engineering Physics Department, 1500 Johnson Drive, Madison, WI 53706

161. A. F. Henry, Professor, Department of Nuclear Engineering, Massachusetts Institute of Technology, 77 Massachusetts Avenue, Cambridge, MA 02139

162. G. L. Hofman, Argonne National Laboratory, 9700 S. Cass Avenue, Argonne, IL 60439

163. D. Y. Hsia, P.O. Box 3, Lung-tan, Taoyuan, Taiwan, ROC

164. R. A. Hunter, Director, Office of Facilities, Fuel Cycle/Test Programs, Department of Energy, NE-47, Washington, DC 20585

165. L. C. Ianniello, Acting Associate Director, Office of Basic Energy Sciences, Office of Energy Research, U.S. Department of Energy, ER-10, Washington, DC 20585

166. M. Iizumi, Japan Atomic Energy Research Institute, Tokai Research Establishment, Tokaimura, Naka-gun, Ibaraki-ken 319-11, Tokyo, Japan

167. S. N. Jahshan, Idaho National Engineering Laboratory, P.O. Box 1625, Idaho Falls, ID 83415

168. A. Jostsons, Director, Advanced Materials Program, Australian Nuclear Science \& Technology Organization, New Illawarra Road, Lucas Heights, NSW, Australia

169. K. Kanda, Research Reactor Institute, Kyoto University, Kumatori-cho, Sennan-gun, Osaka 590-04, Japan

170. T. L. Kerlin, University of Tennessee, College of Engineering, 315 Pasqua Engineering Building, Knoxville, TN 37996-2300

171. J. D. Kling, DRS/Hundley Kling Gmitter, Architects/Planners, One Gateway Center, Pittsburgh, PA 15222 
172. E. Koonen, BR2 Department, CEN/ SCK, Boeretang 200, B-2400 MOL, Belgium

173. W. Krull, GKSS, Postfach 1160, D-2054 Geesthacht, Germany

174. N. Kunitomi, Osaka University, 1-1 Yamadaoka, Fuita-Shi, Osaka 565, Japan

175. K. S. Kwok, Massachusetts Institute of Technology, Nuclear Reactor Laboratory, 138 Albany Street, Cambridge, MA 02139

176. R. T. Lahey, Jr., Department of Nuclear Engineering and Engineering Physics, Jonsson Engineering Center, Rensselaer Polytechnic Institute, Troy, NY 12180-3590

177. J. A. Lake, Manager, Nuclear Engineering and Reactor Design, Idaho National Engineering Laboratory, P.O. Box 1625, Idaho Falls, ID 83415

178. D. Lancaster, Georgia Institute of Technology, Atlanta, GA 30332

179. A. G. Lee, Atomic Energy of Canada, Ltd., Whiteshell Nuclear Research Establishment, Pinawa, Manitoba, ROE 1L0, Canada

180. L. LeSage, Argonne National Laboratory, 9700 S. Cass Avenue, Argonne, IL 60439

181. R. F. Lidstone, Atomic Energy of Canada, Ltd., Whiteshell Nuclear Research Establishment, Pinawa, Manitoba, ROE 1L0, Canada

182. W'. F. Manning, ANS Project, U.S. Department of Energy, Oak Ridge Field Office, FEDC, MS-8218, P.O. Box 2009, Oak Ridge, TN 37831-8218

183. S. Matsuura, Japan Atomic Energy Research Institute, Tokai Research Establishment, Tokaimura, Naka-gun, Ibaraki-ken 319-11, Tokyo, Japan

184. J. C. McKibben, Research Reactor Facility, University of Missouri-Columbia, Research Park, Columbia, MO 65211

185. G. McCormick, Babcock \& Wilcox, Inc., P.O. Box 785, Lynchburgh, VA 24505-0785

186. W. E. Meek, Project Manager, Gilbert/Commonwealth, Inc., P.O. Box 1498, Reading, PA 19603-1498

187. A. I. Miller, Manager Chemical Engineering, AECL Research, Chalk River Laboratory, Ontario, K0J 1J0, Canada

188. R. Miller, Lucas Heights Research Laboratories, New Illawarra Road, Lucas Heights, NSW, Australia

189. H. Nakata, Project Engineering Division, Department of JMTR Project, Japan Atomic Energy Research Institute, Oarai Ibaraki-ken, Tokyo, Japan

190. C. H. Oh, Idaho National Engineering Laboratory, P.O. Box 1625, Idaho Falls, ID 83415

191. J. Oliver, Office of Facilities, Fuel Cycle/Test Programs, Department of Energy, NE-473, Washington, DC 20585

192. W. T. Oosterhuis, Materials Science Division, Office of Basic Energy Sciences, Office of Energy Research, U.S. Department of Energy, ER-132, Washington, DC 20585

193. S. L. Ostrow, Ebasco Services, Inc., 2 World Trade Center, 89th Floor, New York, NY 10048

194. Y. V. Petrov, Sanct-Petersburg Nuclear Physics Institute, Russian Academy of Science, 188350 Gatchina, Sanct-Petersburg District, Federal Republic of Russia

195. H. J. Prask, National Institute of Standards \& Technology, A-106 Reactor, Gaithersburg, MD 20899

196. H. E. Preble, Babcock \& Wilcox, Inc., P.O. Box 785, Lynchburg, VA 24505-0785

197. T. J. Raney, Ebasco Services, Inc., 2 World Trade Center, 89th Floor, New York, NY 10048

198. J. Rest, Argonne National Laboratory, 9700 S. Cass Avenue, Argonne, IL 60439

199. H. Reutler, Siemens, Friedrich-Ebert-Strasse, D-5060 Bergish-Gladbach 1, Germany

200. H.-J. Roegler, Siemens, Friedrich-Ebert-Strasse, D-5060 Bergish-Gladbach 1, Germany

201. M. Rowe, National Institute of Standards and Technology, Washington, DC 20234

202. J. J. Rush, National Institute of Standards and Technology, Bldg. 235, Rm. E151, Gaithersburg, MD 20899 
203. J. M. Ryskamp, Idaho National Engineering Laboratory, D.O. Box 1625, Idaho Falls, ID 83415

204. T. Shibata, Japan Atomic Energy Research Institute, Kinki University, Kowakae, HigashiOsaka, Osaka 577, Japan

205. P. J. Shipper, Gilbert/Commonwealth, Inc., P.O. Box 1498, Reading, PA 19603-1498

206. E. Shirai, Department of Research Reactor Operations, Japan Atomic Energy Research Institute, Tokai-mura, Naka-gun, Ibaraki-ken 319-11, Tokyo, Japan

207. C. Shuping, Director of Reactor Engineering Department, Institute of Atomic Energy, P.O. Box 275, Beijing PRC

208. J. B. Slater, Atomic Energy of Canada, Ltd., Research Company, Chalk River Nuclear Laboratories, Chalk River, Ontario, K0J 1J0, Canada

209. J. L. Snelgrove, ANS Fuels Development Task Leader, Argonne National Laboratory, 9700

S. Cass Avenue, Argonne, IL 60439

210. E. Steichele, Physik-Department, der Technische Universität München, D 8046 Garching München, Germany

211. A. Steryl, University of 'Rhode Island, Physics Dept., Kingston, RI 02881

212. P. T. Talarico, Gilbert/Commonwealth, Inc., P.O. Box 1498, Reading, PA 19603-1498

213. T. G. Theofanous, Theofanous \& Company, Inc., 857 Sea Ranch Drive, Santa Barbara, CA 93109

214. I. L. Thomas, Director, Materials Science Div sior, Office of Energy Research, U.S. Department of Energy, ER-13, Washington, $2 \cdots 7585$

215. V. Tschinkel, Landers \& Parsons, 310 W. College Ave., Tallahasse, FL 32301

216. M. Utsuro, Research Reactor Institute, Kyoto University, Kumatori-cho, Sennan-gun, Osaka 590-04, Japan

217. J. Verdier, Centre d'Etudes Nucleaires, SBT, 85X, 38041 Grenoble Cedex, France

218. S. F. Wang, P.O. Box 3, Lung-tan, Taoyuan, Taiwan, ROC

219. J. M. Warren, Gilbert/Commonwealth, Inc., 1055 Commerce Park Drive, Suite 200, Oak Ridge, TN 37830

220. C. A. Wemple, Idaho National Engineering Laboratory, P.O. Box 1625, Idaho Falls, ID 83415

221. R. F. Wichman, Atomic Energy of Canada Ltd., Research Company, Chalk River Nuclear Laboratories, Chalk River, Ontario, K0J 1J0, Canada

222. T. C. Wiencek, Argonne National Laboratory, 9700 S. Cass Avenue, Argonne, IL 60439

223. D. K. Wilfert, ANS Project, U.S. Department of Energy, Oak Ridge Field Office, FEDC, MS8218, P.O. Box 2009, Oak Ridge, TN 37831-8218

224. R. Wilson, Department of Physics, Harvard University, Cambridge, MA 02138

225. P. W. Winkler, Air Products and Chemicals, Inc., 7201 Hamilton Boulevard, Allentown, PA 18195-1501

226. H. G. Wood, III, Associate Professor, Department of Mechanical and Aerospace Engineering, Thornton Hall, University of Virginia, Charlottesville, VA 22901

227. Y. H. Yang, P.O. Box 3, Lung-tan, Taoyuan, Taiwan, ROC

228. Office of Assistant Manager for Energy Research and Development, U.S. Department of Energy, Oak Ridge Field Office, P.O. Box 2001, Oak Ridge, TN 37831-2001

229. Office of Honors and Awards, P. King, P.O. Box 2008, Building 2518, MS-6324, Oak Ridge, TN 37831-6324

230-241. Office of Scientific and Technical Information, P.O. Box 62, Oak Ridge, TN 37831 

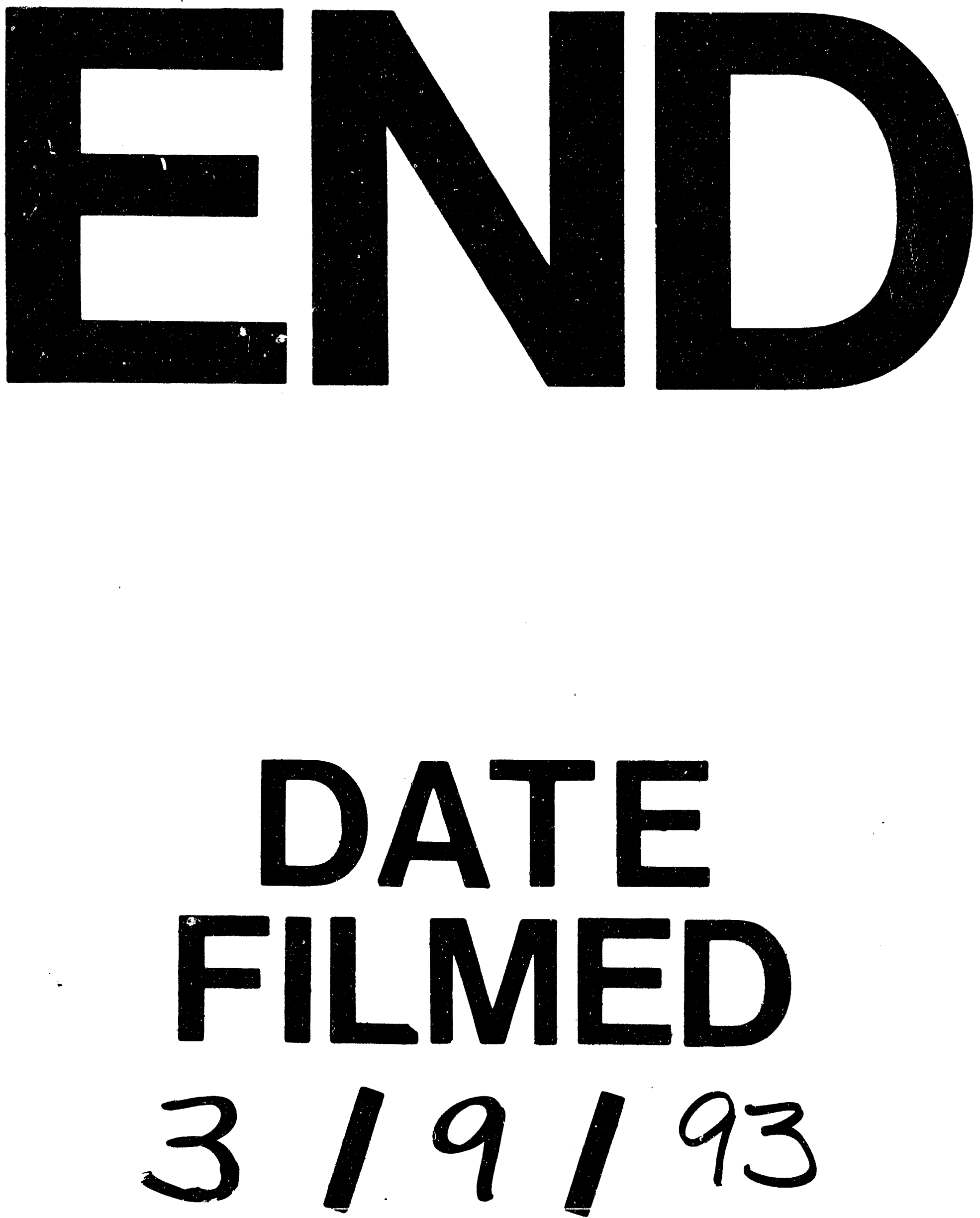
